\title{
Alpha-glucosidase inhibitors for people with impaired glucose tolerance or impaired fasting blood glucose (Review)
}

\author{
Van de Laar FA, Lucassen PLBJ, Akkermans RP, Van de Lisdonk EH, De Grauw WJC
}

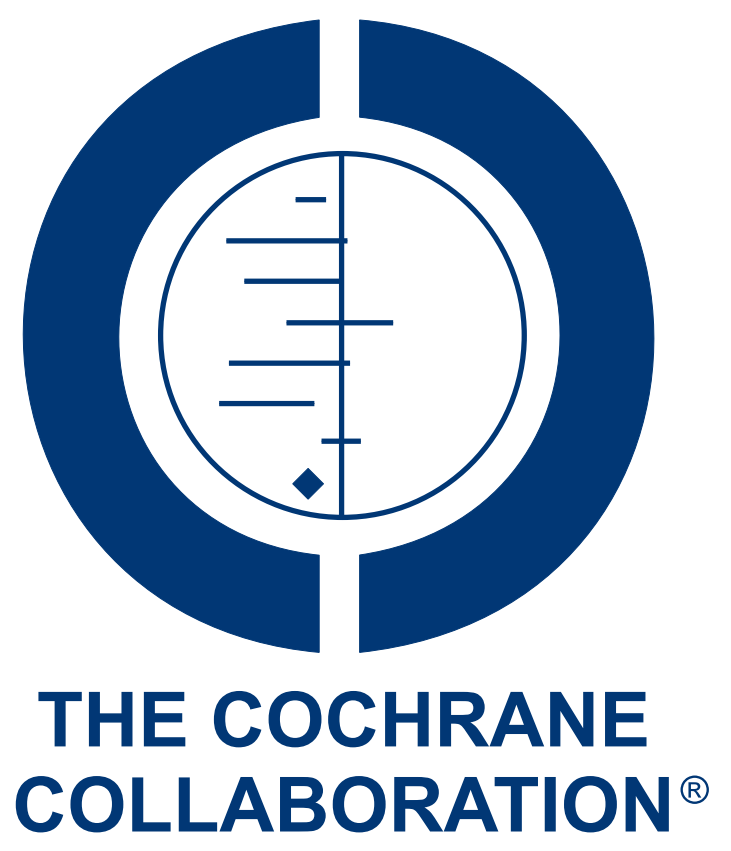

This is a reprint of a Cochrane review, prepared and maintained by The Cochrane Collaboration and published in The Cochrane Library 2009, Issue 1

http://www.thecochranelibrary.com

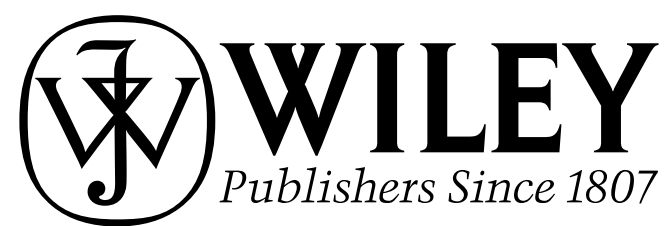

Alpha-glucosidase inhibitors for people with impaired glucose tolerance or impaired fasting blood glucose (Review)

Copyright (C) 2009 The Cochrane Collaboration. Published by John Wiley \& Sons, Ltd. 
TABLE OF CONTENTS

HEADER . . . . . . . . . . . . . . . . . . . . . . . . . . . . . . . . 1

ABSTRACT .. . . . . . . . . . . . . . . . . . . . . . . . . . . . . . . . . . . . . . . . . . . . . . . . .

PLAIN LANGUAGE SUMMARY . . . . . . . . . . . . . . . . . . . . . . . . . . . . . . . . . . . $\quad$. 2

BACKGROUND . . . . . . . . . . . . . . . . . . . . . . . . . . . . . . . . . . . . . 2

OBJECTIVES . . . . . . . . . . . . . . . . . . . . . . . . . . . . . . . . . . . . . 3

METHODS . . . . . . . . . . . . . . . . . . . . . . . . . . . . . . . . . . . . . .

RESUlTS . . . . . . . . . . . . . . . . . . . . . . . . . . . . . . . . . . . . . . . 47

Figure 1. . . . . . . . . . . . . . . . . . . . . . . . . . . . . . . . . . . . . . 8

DISCUSSION . . . . . . . . . . . . . . . . . . . . . . . . . . . . . . . . . . . . . . . . . . .

AUTHORS' CONCLUSIONS . . . . . . . . . . . . . . . . . . . . . . . . . . . . . . . . . . 14

ACKNOWLEDGEMENTS . . . . . . . . . . . . . . . . . . . . . . . . . . . . . . . . . . . . . . . . 14

REFERENCES . . . . . . . . . . . . . . . . . . . . . . . . . . . . . . . . . . . . . 15

CHARACTERISTICS OF STUDIES . . . . . . . . . . . . . . . . . . . . . . . . . . . . . . . . . . . . . 18

DATA AND ANALYSES . . . . . . . . . . . . . . . . . . . . . . . . . . . . . . . . . . . . . . . . . . . . . . . . . . . . 26

Analysis 1.1. Comparison 1 Acarbose versus placebo, Outcome 1 Incidence of type 2 diabetes mellitus. . . . . . $\quad 29$

Analysis 1.2. Comparison 1 Acarbose versus placebo, Outcome 2 Occurrence of death (total). . . . . . . . . . . 30

Analysis 1.3. Comparison 1 Acarbose versus placebo, Outcome 3 Occurrence of cardiovascular death. . . . . . . . 30

Analysis 1.4. Comparison 1 Acarbose versus placebo, Outcome 4 Occurrence of cardiovascular disease (any). . . . $\quad 31$

Analysis 1.5. Comparison 1 Acarbose versus placebo, Outcome 5 Occurrence of myocardial infarctions. . . . . . . 31

Analysis 1.6. Comparison 1 Acarbose versus placebo, Outcome 6 Occurrence of angina pectoris. . . . . . . . . . 32

Analysis 1.7. Comparison 1 Acarbose versus placebo, Outcome 7 Occurrence of revascularisation procedures. . . . . 32

Analysis 1.8. Comparison 1 Acarbose versus placebo, Outcome 8 Occurrence of congestive heart failure. . . . . . $\quad 33$

Analysis 1.9. Comparison 1 Acarbose versus placebo, Outcome 9 Occurrence of cerebrovascular events. . . . . . . . 33

Analysis 1.10. Comparison 1 Acarbose versus placebo, Outcome 10 Occurrence of peripheral vascular events. . . . $\quad 34$

Analysis 1.11. Comparison 1 Acarbose versus placebo, Outcome 11 Change in glycated haemoglobin (\%). . . . . $\quad 34$

Analysis 1.12. Comparison 1 Acarbose versus placebo, Outcome 12 Change in fasting blood glucose $(\mathrm{mmol} / \mathrm{l})$. $\quad . \quad 35$

Analysis 1.13. Comparison 1 Acarbose versus placebo, Outcome 13 Change in post-load blood glucose (mmol/l). $\quad . \quad 35$

Analysis 1.14. Comparison 1 Acarbose versus placebo, Outcome 14 Change in total cholesterol (mmol/l). . . . . 36

Analysis 1.15. Comparison 1 Acarbose versus placebo, Outcome 15 Change in HDL-cholesterol (mmol/l). . . . . 36

Analysis 1.16. Comparison 1 Acarbose versus placebo, Outcome 16 Change in LDL-cholesterol (mmol/l). . . . . . 37

Analysis 1.17. Comparison 1 Acarbose versus placebo, Outcome 17 Change in triglycerides (mmol/l). . . . . . . $\quad 37$

Analysis 1.18. Comparison 1 Acarbose versus placebo, Outcome 18 Change in fasting insulin levels (pmol/l). . . . $\quad 38$

Analysis 1.19. Comparison 1 Acarbose versus placebo, Outcome 19 Change in post-load insulin levels (pmol/l). . . $\quad 38$

Analysis 1.20. Comparison 1 Acarbose versus placebo, Outcome 20 Change in body weight $(\mathrm{Kg})$. . . . . . . . . . . . 39

Analysis 1.21. Comparison 1 Acarbose versus placebo, Outcome 21 Change in body mass index $(\mathrm{Kg} / \mathrm{m} 2)$. . . . . $\quad 39$

Analysis 1.22. Comparison 1 Acarbose versus placebo, Outcome 22 Change in diastolic blood pressure (mmHg). $\quad . \quad 40$

Analysis 1.23. Comparison 1 Acarbose versus placebo, Outcome 23 Change in systolic blood pressure (mmHg). . . $\quad 40$

Analysis 1.24. Comparison 1 Acarbose versus placebo, Outcome 24 Occurrence of side effects (total). . . . . . . . . 41

Analysis 1.25. Comparison 1 Acarbose versus placebo, Outcome 25 Occurrence of gastro-intestinal side-effects. $\quad . \quad$. 41

Analysis 2.1. Comparison 2 Acarbose versus metformin, Outcome 1 Incidence of type 2 diabetes mellitus. . . . . 42

Analysis 2.2. Comparison 2 Acarbose versus metformin, Outcome 2 Change in fasting blood glucose (mmol/l). $\quad$. $\quad 42$

Analysis 2.3. Comparison 2 Acarbose versus metformin, Outcome 3 Change in post-load blood glucose (mmol/l). $\quad . \quad 43$

Analysis 2.4. Comparison 2 Acarbose versus metformin, Outcome 4 Change in total cholesterol (mmol/l). . . . . $\quad 43$

Analysis 2.5. Comparison 2 Acarbose versus metformin, Outcome 5 Change in triglycerides $(\mathrm{mmol} / \mathrm{l})$. . . . . . . $\quad 44$

Analysis 2.6. Comparison 2 Acarbose versus metformin, Outcome 6 Change in body mass index $(\mathrm{Kg} / \mathrm{m} 2)$. . . . . . $\quad 44$

Analysis 2.7. Comparison 2 Acarbose versus metformin, Outcome 7 Change in diastolic blood pressure $(\mathrm{mmHg}) . \quad$. $\quad 45$

Analysis 2.8. Comparison 2 Acarbose versus metformin, Outcome 8 Change in systolic blood pressure (mmHg). . . 45

Analysis 3.1. Comparison 3 Acarbose versus diet and exercise, Outcome 1 Incidence of type 2 diabetes mellitus. . . 46

Analysis 3.2. Comparison 3 Acarbose versus diet and exercise, Outcome 2 Change in fasting blood glucose (mmol/l). 46

Analysis 3.3. Comparison 3 Acarbose versus diet and exercise, Outcome 3 Change in post-load blood glucose (mmol/l). 47

Analysis 3.4. Comparison 3 Acarbose versus diet and exercise, Outcome 4 Change in total cholesterol (mmol/l). $\quad$. $\quad 47$

Alpha-glucosidase inhibitors for people with impaired glucose tolerance or impaired fasting blood glucose (Review)

Copyright @ 2009 The Cochrane Collaboration. Published by John Wiley \& Sons, Ltd. 
Analysis 3.5. Comparison 3 Acarbose versus diet and exercise, Outcome 5 Change in triglycerides (mmol/l). . . .

Analysis 3.6. Comparison 3 Acarbose versus diet and exercise, Outcome 6 Change in body mass index $(\mathrm{Kg} / \mathrm{m} 2)$. . .

Analysis 3.7. Comparison 3 Acarbose versus diet and exercise, Outcome 7 Change in diastolic blood pressure ( $\mathrm{mmHg}$ ).

Analysis 3.8. Comparison 3 Acarbose versus diet and exercise, Outcome 8 Change in systolic blood pressure $(\mathrm{mmHg})$.

Analysis 4.1. Comparison 4 Acarbose versus no treatment, Outcome 1 Incidence of type 2 diabetes mellitus. . . .

Analysis 4.2. Comparison 4 Acarbose versus no treatment, Outcome 2 Change in fasting blood glucose (mmol/l).

Analysis 4.3. Comparison 4 Acarbose versus no treatment, Outcome 3 Change in post-load blood glucose (mmol/l).

APPENDICES . . . . . . . . . . . . . . . . . . . . . . . . . . . . . . . . . . . . . . . 55

WHAT'S NEW . . . . . . . . . . . . . . . . . . . . . . . . . . . . . . . . . . . . . . . . . . . .

HISTORY . . . . . . . . . . . . . . . . . . . . . . . . . . . . . . . . . . . . . . . 64

CONTRIBUTIONS OF AUTHORS . . . . . . . . . . . . . . . . . . . . . . . . . . . . . . . . . . . . . . 64

DECLARATIONS OF INTEREST . . . . . . . . . . . . . . . . . . . . . . . . . . . . . . . . . . . 64

SOURCES OF SUPPORT . . . . . . . . . . . . . . . . . . . . . . . . . . . . . . . . . . . . . . . . . . . 64

INDEX TERMS . . . . . . . . . . . . . . . . . . . . . . . . . . . . . . . . . . . . 65 


\section{Alpha-glucosidase inhibitors for people with impaired glucose tolerance or impaired fasting blood glucose}

Floris A Van de Laar ${ }^{1}$, Peter LBJ Lucassen ${ }^{2}$, Reinier P Akkermans ${ }^{3}$, Eloy H Van de Lisdonk ${ }^{4}$, Wim JC De Grauw ${ }^{3}$

${ }^{1}$ Department of General Practice, 117 HAG, Radboud University Nijmegen Medical Centre, Nijmegen, Netherlands. ${ }^{2}$ Department of General Practice and Family Medicine, Radboud University Medical Centre, Nijmegen, Netherlands. ${ }^{3}$ Department of General Practice, 117 HAG, Radboud University Nijmegen Medical Centre, Nijmegen, Netherlands. ${ }^{4}$ Department of General Practice and Family Medicine, Radboud University Medical Centre, Nijmegen, Netherlands

Contact address: Floris A Van de Laar, Department of General Practice, 117 HAG, Radboud University Nijmegen Medical Centre, P.O. Box 9101, Nijmegen, 6500 HB, Netherlands. f.vandelaar@cochraneprimarycare.org. f.vandelaar@hag.umcn.nl.

Editorial group: Cochrane Metabolic and Endocrine Disorders Group.

Publication status and date: Edited (no change to conclusions), published in Issue 1, 2009.

Review content assessed as up-to-date: 27 February 2006.

Citation: Van de Laar FA, Lucassen PLBJ, Akkermans RP, Van de Lisdonk EH, De Grauw WJC. Alpha-glucosidase inhibitors for people with impaired glucose tolerance or impaired fasting blood glucose. Cochrane Database of Systematic Reviews 2006, Issue 4. Art. No.: CD005061. DOI: 10.1002/14651858.CD005061.pub2.

Copyright (c) 2009 The Cochrane Collaboration. Published by John Wiley \& Sons, Ltd.

\section{A B S T R A C T}

\section{Background}

Alpha-glucosidase inhibitors (AGIs) reduce blood glucose levels and may thus prevent type 2 diabetes and cardiovascular disease in patients with impaired glucose tolerance (IGT). These possible effects, and the effects on quality of life, plasma lipids and body weight, have never been investigated in a systematic literature review and meta-analysis.

Objectives

To assess the effects of alpha-glucosidase inhibitors in patients IGT or impaired fasting blood glucose (IFBG), or both.

Search methods

We searched The Cochrane Library, PUBMED, EMBASE, Web of Science, LILACS, databases of ongoing trials, reference lists of relevant reviews, and we contacted experts and manufacturers.

\section{Selection criteria}

Randomised controlled trials of at least one-year duration in patients with IGT or IFBG, or both, comparing AGI monotherapy with any other intervention.

Data collection and analysis

Two reviewers read all abstracts, assessed quality and extracted data independently. Discrepancies were resolved by consensus or by the judgement of a third reviewer.

\section{Main results}

We included five trials (2360 participants), all investigating acarbose, that included patients with IGT or patients 'at increased risk for diabetes' $(\mathrm{n}=1)$. Study duration was one, three $(\mathrm{n}=2)$, five and six years. One study was at low risk of bias and four studies at high risk of bias. Except for the outcome incidence of type 2 diabetes in acarbose versus no treatment (two studies), meta-analyses were 
not possible. Data from the study at low risk of bias suggests that acarbose decreases the occurrence of type 2 diabetes $(\mathrm{NNT}=10)$, cardiovascular events (NNT $=50$, based on 47 events, study not initially powered for this outcome), post-load blood glucose ( -0.6 $\mathrm{mmol} / \mathrm{L}, 95 \% \mathrm{CI}-1.0$ to -0.3$)$ and body mass index $\left(0.3 \mathrm{~kg} / \mathrm{m}^{2}, 95 \%\right.$ CI -0.1 to -0.5$)$. No statistically significant effects were observed on mortality, other morbidity, glycated haemoglobin, fasting blood glucose, lipids and blood pressure. The effects on the incidence of type 2 diabetes were confirmed in two studies at high risk of bias (OR $0.2,95 \%$ CI 0.1 to 0.6 ). Adverse effects were mostly of gastrointestinal origin (OR 3.5, 95\% CI 2.7 to 4.4 ).

\section{Authors' conclusions}

There is evidence that acarbose reduces the incidence of type 2 diabetes in patients with IGT. However, it is unclear whether this should be seen as prevention, delay or masking of diabetes. Acarbose may prevent the occurrence of cardiovascular events, but this finding needs to be confirmed in more studies.

\section{PLAIN LANGUAGESUMMARY}

\section{Alpha-glucosidase inhibitors for people with impaired glucose tolerance or impaired fasting blood glucose}

Alpha-glucosidase inhibitors (acarbose, miglitol, voglibose) are drugs that delay the breakdown of carbohydrates in the gut, and consequently slow down the absorption of sugars. Patients with type 2 diabetes may use it therapeutically. People with a raised blood glucose level (without being a diabetes patient) may use this drug in order to prevent developing type 2 diabetes and diabetes related morbidity such as cardiovascular diseases. To find evidence for these assumptions, we searched the medical literature for randomised controlled trials of at least one-year duration, investigating alpha-glucosidase inhibitors for patients with impaired glucose tolerance (IGT) or impaired fasting blood glucose (IFBG). Patients with IGT or IFBG have raised blood glucose levels, but do not meet the criteria for having type 1 or type 2 diabetes.

In our review we included five studies, representing 2360 participants, investigating acarbose. Of these studies, one was of high quality, and two did not show exact data, as the results were not available in full publication. The study of high quality yielded that if 10 people with IGT would take acarbose for three years, one case of diabetes would not occur. This finding was confirmed in studies of lower quality. The relevance of this finding is questionable because we found only small effects on blood glucose levels, and the mechanism behind this finding remains unclear: does acarbose really prevent diabetes does it delay the occurrence or mask type 2 diabetes? With respect to the effect on the occurrence of cardiovascular diseases, a dubious preventive effect of acarbose on the occurrence of myocardial infarctions was found. However, definitive conclusion could not be drawn and this latter finding should be confirmed in other studies. We found no statistically significant effects on the occurrence of death, other complications related to IGT, or quality of life. Side effects were mostly of gastro-intestinal origin (flatulence, diarrhoea).

The low number of studies, the poor quality of four of the included studies, and the missing data of two included studies limited this review. First, the missing data of two included studies need to be made available for a future update of this review. Next, the results of the two ongoing studies should be implemented in the review. If, after that, the evidence remains inconclusive, new trials should be initiated in order to investigate the true value of alpha-glucosidase inhibitors for patients with impaired glucose tolerance or impaired fasting blood glucose.

\section{B A C K G R O U N D}

\section{Description of the condition}

Impaired glucose tolerance (IGT) and impaired fasting blood glucose (IFBG) are generally recognised as an expression of abnormal glucose homeostasis that is not severe enough to meet the crite- ria for type 2 diabetes mellitus. The term IGT was introduced in 1979. In the past IGT has been called a 'pre-state' of diabetes or 'prediabetes' (NDDG 1979). The term IFBG (sometimes referred to as impaired fasting glycaemia) has been introduced much later (ADA 1997). IGT and IFBG represent different pathophysiological mechanisms: IGT is seen as a characteristic of peripheral in- 
sulin resistance and IFBG is seen as an expression of raised hepatic glucose output and a defect in early insulin secretion. On the other hand, there are many similarities, as both IGT and IFBG are associated with an increased risk of diabetes and the development of (diabetes related) complications such as cardiovascular disease (Unwin 2002). Currently, the criteria for IGT and IFBG are as follows (plasma venous glucose concentrations):

- IGT - fasting blood glucose less than $7.0 \mathrm{mmol} / \mathrm{L}$ and twohour post-load blood glucose 7.8 to $11.0 \mathrm{mmol} / \mathrm{L}$;

- IFBG - fasting blood glucose 6.1 to $6.9 \mathrm{mmol} / \mathrm{L}$ (two-hour post-load blood glucose less than $7.8 \mathrm{mmol} / \mathrm{L}$, if measured) (ADA 1999; WHO 1999). In 2003, the ADA recommended to change these criteria to 5.6 to $6.9 \mathrm{mmol} / \mathrm{L}$ (ADA 2003)

IGT and IFBG cause no symptoms and the condition should be seen as a risk factor more than a disease itself. It is closely related to other risk factors of type 2 diabetes such as obesity and overweight, unfavourable dietary habits and a shortage of exercise. People with IGT or IFBG are at increased risk of developing type 2 diabetes and cardiovascular disease (even before the onset of diabetes). Thus, the question arises whether an intervention in patients with IGT or IFBG could prevent the development of type 2 diabetes and cardiovascular complications. Life-style interventions consisting of exercise or diet, or both, showed that the incidence of diabetes might be reduced (relative risk reduction) in up to 58\% of cases (Pan 1997; Tuomilehto 2001; Knowler 2002). In addition, pharmacological interventions have been investigated in patients with IGT. Especially drugs that claim to intervene with insulin resistance seem appropriate: biguanides (metformin: decreases hepatic glucose output and increases insulin action) (Knowler 2002), thiazolidinediones (rosiglitazone, pioglitazone: increase insulin sensitivity by increasing glucose utilization in muscle and liver) (Buchanan 2002) and alpha-glucosidase inhibitors (see further).

\section{Description of the intervention}

Alpha-glucosidase inhibitors (AGIs) are reversible inhibitors of alpha-glucosidase, an enzyme present in the brush border of the small intestine. Currently, three AGIs exist: acarbose, miglitol and voglibose. Emiglitate, a fourth AGI, is currently not available on the market. AGIs delay absorption of complex carbohydrates and thus inhibit postprandial glucose peaks and consequently lower postprandial insulin levels. In the treatment of type 2 diabetes, AGIs have been proven to have beneficial effects on glycaemic control and post-load insulin levels but there is no evidence for a reduction of mortality or morbidity (Van de Laar 2005).

Potential side-effects are of special importance in the use of medication in persons with IGT or IFBG for two reasons. First, IGT and IFBG are asymptomatic, so people will, in contrast to potential side-effects, not notice any direct benefits from the medication. Second, because of the chronic and long-lasting character of
IGT and IFBG, medication will have to be used for a long period of time. Therefore, long-term safety is very important. AGIs cause unfavourable dose-dependent side-effects, mostly flatulence and other gastro-intestinal side-effects, when compared to placebo or sulphonylurea. But there is no evidence for long-term detrimental effects of AGIs (Van de Laar 2005).

\section{Why it is important to do this review}

More recently, AGIs have been put into a new light as a result of a study on the efficacy of acarbose in patients with IGT (Chiasson 2002; Chiasson 2003). This study showed that acarbose could prevent or delay the development of IGT into type 2 diabetes. Moreover, it showed a reduced risk of cardiovascular disease and hypertension in the acarbose treated group. However, the conclusions of this study are heavily debated (Chiasson 2004; Kaiser 2004; Sawicki 2004). We have found no systematic review that focuses exclusively on the efficacy of AGIs for patients with IGT or IFBG.

\section{O B J E C T I VES}

To assess the effects of alpha-glucosidase inhibitors for people with impaired glucose tolerance or impaired fasting blood glucose.

\section{METHODS}

\section{Criteria for considering studies for this review}

\section{Types of studies}

We included randomised controlled trials with a minimum duration of one year. Because the common adverse effects of AGIs make true blinding difficult, both blinded and non-blinded studies were included. Studies published in any language and all identified trials, published or unpublished, were investigated.

\section{Types of participants}

Patients referred to as having a prediabetic state, that is IGT or IFBG, or both, existing or newly diagnosed. Changes in diagnostic criteria, both for IGT or IFBG, or both, or diabetes mellitus type 2 (ADA 1997; ADA 1999; NDDG 1979; Unwin 2002; WHO 1980; WHO 1985; WHO 1999) may have produced variability in the clinical characteristics of the patients included as well as in the results obtained. We planned to explore these differences in a sensitivity analysis. 


\section{Types of interventions}

Monotherapy with AGIs (acarbose, miglitol or voglibose) compared with:

- placebo;

- a non-pharmacological intervention (for example: diet therapy, exercise);

- biguanides (for example, metformin);

- thiazolidinediones (for example, pioglitazone);

- sulphonylurea (for example, glibenclamide);

- meglitinide (for example, nateglinide);

- any other pharmacological intervention.

\section{Types of outcome measures}

\section{Primary outcomes}

- incidence of type 2 diabetes mellitus: diagnosed with criteria prevailing at the time of the diagnosis (ADA 1997; ADA 1999; NDDG 1979; WHO 1980; WHO 1985; WHO 1998);

- morbidity related to impaired glucose metabolism, the metabolic syndrome or type 2 diabetes: vascular complications (angina pectoris, myocardial infarction, stroke, peripheral vascular disease, amputation), neuropathy, retinopathy, nephropathy, erectile dysfunction, and hyperosmolar nonketotic dysregulation;

- mortality: total mortality, mortality related to impaired glucose metabolism, the metabolic syndrome or type 2 diabetes (death from myocardial infarction, stroke, renal disease, or sudden death, death from hyperosmolar nonketotic coma);

\section{Secondary outcomes}

- glycaemic control: glycated haemoglobin levels, fasting and post-load blood glucose levels;

- plasma lipids (triglycerides, total-, high-density lipoprotein (HDL)- and low-density lipoprotein (LDL)-cholesterol);

- blood pressure: diastolic and systolic blood pressure;

- fasting and post-load insulin and C-peptide levels;

- body weight (or body mass index);

- adverse effects (for example diarrhoea, stomachache, flatulence);

- quality of life, assessed with a validated instrument;

- costs.

Specific patient covariates, effect modifiers, confounders

- Compliance.

\section{Timing of outcome assessment (length of intervention)}

We assessed a possible influence of treatment duration in a sensitivity analysis.

\section{Search methods for identification of studies}

\section{Electronic searches}

We used the following sources for the identification of trials:

- The Cochrane Library (2006, Issue 1);

- PUBMED (http://www.ncbi.nlm.nih.gov/entrez/ query.fcgi) (contains MEDLINE and a number of additional life science journals, 1966 to February 2006);

- EMBASE (1974 to October 2005);

- LILACS (www.bireme.br/bvs/I/ibd.htm) from 1986 to March 2006;

- Web of Science (contains: Science Citation Index Expanded 1945 to February 2006; Social Sciences Citation Index 1956 to February 2006; Arts \& Humanities Citation Index 1975 to February 2006).

We also searched databases of ongoing trials (latest access March 2006):Current Controlled Trials (http://www.controlledtrials.com - with links to other databases of ongoing trials); $\mathrm{UKNa}$ tional Research Register (http://www.update-software.com/National/nrr-frame.html); USA - CenterWatch Clinical Trials Listing Service (http://www.CenterWatch.com/); USA - National Institutes of Health (http://clinicalstudies.info.nih.gov/); Dutch Trial Register (Nederlands Trial Register) (http://www.trialregister.nl/). The described search strategy (see Appendix 1) was used for PUBMED. For use with EMBASE and Web of Science the strategy was slightly adapted because these databases have different interfaces. The necessary changes in the search string were done in such a way that the search became more sensitive (that is yields a higher number of 'hits'). In The Cochrane Library, LILACS and the databases of ongoing trials we searched with the various text words for the AGIs and their brand names.

We combined three different search strategies (specified in Appendix 1):

- for alpha-glucosidase inhibitors we used a strategy used for a recent systematic review on AGIs (Van de Laar 2005);

- controlled trials we used a sensitive validated search strategy (Robinson 2002);

- for IGT and IFBG we developed a search strategy combining keywords (MeSH headings) and text words. We extensively tested it by running the search and subsequently investigated whether known key-studies were not included, we then adjusted the model until we didn't find any relevant study that was not found by the search string. 


\section{Searching other resources}

Authors of relevant identified studies and other experts were contacted by mail in order to obtain additional references, unpublished trials, and ongoing trials or to obtain missing data not reported in the original trials. Similarly, manufacturers and patent holders (Bayer AG, Sanofi-Synthelabo, Pfizer, Takeda) were contacted in order to retrieve information on AGIs trials, published and unpublished.

We searched reference lists of relevant trials and AGI reviews and selected possible references that were already in our own files.

\section{Data collection and analysis}

\section{Selection of studies}

Two reviewers (FVDL and PL) independently checked the titles, abstract sections and keywords of every record retrieved. Full articles were retrieved for further assessment when the information given suggested that the study:

- included patients with IGT or IFBG;

- compared AGIs with placebo or any other control;

- assessed one or more relevant predefined clinical outcomes;

- used random allocation to the comparison groups.

In case of any doubt regarding these criteria from the information given by the title and abstract, the full article was retrieved for clarification. Interrater agreement for study selection was assessed using the kappa statistic (Cohen 1960). A third party (EVDL) resolved differences in opinions between the two reviewers. If resolving disagreement was not possible, the article was added to those 'awaiting assessment' and the authors were contacted for clarification. If no clarification was provided, we planned to consult the review group editorial base.

\section{Data extraction and management}

Two reviewers extracted data on intervention and outcomes independently, using a pre-tested data extraction form that was adapted from a standard form provided by the review group. The data extraction form included the following items:

- General information: author, type of publication (including the existence of duplicate or multiple publications), year of publication, language, country where the study was conducted, setting (general practice, hospital or outpatient/rural, city, developed/developing world/single or multi-centre), the stated aim of the study published, sponsor(s), ethics approval;

- Study characteristics: parallel or cross-over, type of control groups (placebo, other medication etc.), existence of run-in or wash-out period, or both, description of possible carry-over effect (for cross-over studies), method, type and quality of randomisation, method and quality of allocation concealment, method and quality of blinding, information about handling of drop-outs, withdrawals and losses to follow-up, numbers of and reasons for drop-out, method and quality of blinding of outcome assessment (if applicable), method and quality of blinding of analyses, existence of possible sub-groups, method of assessment of compliance;

- Participants: description of diagnostic criteria for IGT or IFBG, or both, and diabetes mellitus type 2, inclusion and exclusion criteria;

- Interventions: specification of possible life-style cointervention, the nature, dose and regimen of AGI(s) and control interventions, duration of intervention and follow-up;

- Baseline characteristics and measurements: numbers of patients, sex, age, ethnicity, socio-economic status and duration of diabetes, other risk factors for type 2 diabetes or macrovascular disease (familiar disposition, history of gestational diabetes, exercise, smoking) existence of significant differences at baseline, baseline glycated haemoglobin, fasting and post-load blood glucose, plasma lipids (triglycerides, total-, HDL- and LDL-cholesterol), height, weight and body mass index (BMI), fasting and post-load insulin and C-peptide (standard deviations if applicable), specifications (including reference ranges) of all laboratory measurements, type of post-load test, time between fasting and post-load measurements, centralisation of laboratory measurements, assessment of health-status, definitions of health outcomes (for example myocardial infarction, heart failure, renal failure);

- Outcomes: total and disease specific deaths and morbidity, quality of life (including method of assessment), mean changes (standard deviation, SD) of the following values: glycated haemoglobin, fasting and post-load blood glucose, lipids, fasting and post-load insulin / C-peptide, body weight, BMI, occurrence of adverse events (total and gastro-intestinal), compliance, costs.

Differences in data extraction were resolved by consensus, referring back to the original article. If necessary, information was sought from the authors of the original studies. If necessary, we also planned to extract data from graphical figures: two reviewers (FVDL and PL) would calculate the data independently and if both outcomes were not similar, a third reviewer (EVDL) would recalculate the data. A statistician checked all extracted data for errors, after transfer to the database.

\section{Assessment of risk of bias in included studies}

The two reviewers (FVDL and PL) assessed each trial independently. Possible disagreement was resolved with consensus, or with consultation of a third reviewer (EVDL) in case of disagreement. We assessed the following quality items: 


\section{Minimisation of selection bias}

- randomisation procedure: the randomisation procedure was scored 'adequate' if the resulting sequences were unpredictable (for example computer generated schemes, tables of random numbers, coin tossing).

- allocation concealment: allocation concealment was scored 'adequate' if participating patients and investigators could not foresee the assignment (for example by central randomisation remote from trial site, sequentially numbered and sealed radioopaque envelopes).

\section{Minimisation of performance bias}

- method of blinding: blinding was scored 'adequate' if the two (or more) drugs / pills were similar in size, colour and shape or when a double-dummy method was applied. Because of the sometimes-obvious adverse effects of AGIs, true blinding is difficult. For trials that reported blinding of patients for medications, we also investigate whether blinding was checked (for example by asking patient and investigator afterwards about the medication they suspected to have been supplied with).

\section{Minimisation of attrition bias}

- handling of drop-outs: handling of drop-outs was considered 'adequate' when studies reported a complete description of all patients failing to participate until the end of the trial and if the data were analysed on intention-to-treat (ITT) basis, that means with all randomised patients included.

- quantity of dropouts: overall dropout rate less than $15 \%$ was considered 'adequate'.

- selective dropout: a difference in dropout rates between the main treatment groups less than 10\% was considered 'adequate'.

\section{Minimisation of detection bias}

- method of blinding outcome-assessment: outcome assessment was considered 'adequate' if the outcome assessors were completely blind for the intervention. This item was considered less relevant for studies with laboratory data or death as main outcomes.

- method of blinding of analysis: this was considered 'adequate' if the outcome assessors (investigators, statisticians) were completely blind for the intervention up to the point that all analyses were completed. Blinding of analyses is to date not a common practice in the conduct of randomised trials. Therefore we only planned to explore possible influences of blinded analyses in a sensitivity analysis and we did not plan to use this item for the overall quality assessment.

Following these criteria, studies were broadly subdivided into the following three categories using an adapted version of the Cochrane Handbook for Systematic Reviews of Interventions criteria:
A - All quality criteria met (1. adequate randomisation and allocation concealment, 2 . adequate blinding, 3. adequate ITT analysis or both drop-out rate less than $15 \%$ or selective drop-out less than $10 \%$, or both 4 . adequate blinding outcome-assessment): low risk of bias.

B - One or more quality criteria only partially met (1. inadequate randomisation or inadequate allocation concealment, 2 . mentioning of blinding but exact method unclear, 3. inadequate/unclear ITT analysis but drop-out less than $15 \%$ or selective drop-out less than $10 \%, 4$. mention of blinding outcome-assessment but exact method unclear): moderate risk of bias.

$\mathrm{C}$ - One or more quality criteria not met (1. inadequate randomisation and allocation concealment, 2 . inadequate or no blinding, 3. inadequate ITT and drop-out rate equal to or greater than 15\% and selective drop-out equal to or greater than $10 \%, 4$. inadequate blinding outcome-assessment): high risk of bias.

We explored the influence of individual quality criteria in a sensitivity analysis (see under 'sensitivity analyses'). The two reviewers discussed all quality items. In cases of disagreement, a third reviewer was planned to be consulted (EVDL).

\section{Data synthesis}

The table of comparison was divided in all possible comparisons first (for example acarbose versus placebo), then sub-divided into all possible outcomes (for example death, glycated haemoglobin, adverse events) and finally, within the outcome sub-groups were made for the different dosages. Outcomes were calculated per subgroup and for all sub-groups together.

Dichotomous data were expressed as relative risks (RR). We calculated the risk difference $(\mathrm{RD})$ and we converted the $\mathrm{RD}$ into the number needed to treat (NNT) or the number needed to harm (NNH) taking into account the time of follow-up.

Continuous data were expressed as weighted mean differences (WMD) and an overall WMD was calculated. We used the differences from baseline to endpoint as the actual measure of effect of all continuous variables. The standard deviations of these differences are essential for the data to be included in the metaanalysis. If the standard deviation (SD) of the difference were not reported, we first asked the authors to provide these data. If the SDs were not provided we estimated the SD of the difference with the following formula:

$\mathrm{SD}_{\text {paireddifference }}=\sqrt{ }\left[\left(\mathrm{SD}_{1}\right)^{2}+\left(\mathrm{SD}_{2}\right)^{2}-2 \times \mathrm{r} \times \mathrm{SD}_{1} \times \mathrm{SD}_{2}\right]$. $\mathrm{SD}_{\text {paireddifference }}=$ standard deviation of the difference (pre- $/$ post-treatment)

$\mathrm{SD}_{1}=$ Standard deviation of the pre-treatment value, $\mathrm{SD}_{2}=$ Standard deviation of the post-treatment value, $r=$ correlation coefficient. We used a conservative correlation coefficient of 0.4 .

Overall results were calculated based on the random effects model. Heterogeneity was statistically tested by using the $\mathrm{Z}$ score and the $\chi^{2}$ - statistic with significance set at $\mathrm{P}<0.10$. Quantification of 
the effect of heterogeneity was assessed by means of $\mathrm{I}^{2}$, ranging from $0 \%$ to $100 \%$ including its $95 \%$ confidence interval (Higgins 2002). $\mathrm{I}^{2}$ demonstrates the percentage of total variation across studies due to heterogeneity and was used to judge the consistency of evidence. Possible sources of heterogeneity were (planned to be) assessed by subgroup, sensitivity and meta-regression analyses as described below.

The analyses were done with Review Manager (RevMan 4.2).

\section{Subgroup analysis and investigation of heterogeneity}

We planned to investigate main outcome measures by subgroup analyses in order to explore differences in effect as follows:

- glycated haemoglobin level at baseline (subdivided into groups, based on data);

- age (subdivided into groups, based on data);

- gender (subdivided into groups, based on data);

- body mass index (BMI) (subdivided into groups, based on data);

- different kinds of life-style co-interventions used (that is dietary advice, exercise, help with smoking cessation, combined interventions);

- duration of intervention (subdivided into groups, based on data);

- use of an individually titrated versus fixed dose of AGI;

- use of a step-up dose versus administering the full dose immediately.

\section{Sensitivity analysis}

We planned to perform sensitivity analyses for a number of factors by comparing the results of the meta-analysis for studies with and without certain characteristics. Data from a minimum of five studies had to be available for both groups to be considered.

The following factors were planned to be investigated:

- comparing published and unpublished studies;

- comparing studies with and without (or with unknown) quality characteristics: adequate randomisation, adequate allocation concealment, adequate method of blinding, adequate ITT analyses, adequate blinding of outcome-assessment (if applicable), adequate method of blinding of analyses. Further, comparing studies with an overall drop-out rate of more than or equal to $15 \%$ and less than $15 \%$, differences in drop-out rates less than $10 \%$ and more than or equal to $10 \%$ between the main treatment groups. In addition, the overall score for quality based on the Cochrane criteria was used (studies with score A and B compared to studies with C);
- repeating the analyses excluding trials using the following filters: diagnostic criteria (patients with IGT or IFBG, or both), language of publication, source of funding (industry versus other or no sponsoring) or country;

- repeating the analyses using different measures of effect size (relative risk, risk difference) and different statistical models (fixed and random effects models);

- repeating the analyses excluding large studies or studies with a long duration (based on data) to establish how much they dominate the results;

- repeating the analyses excluding studies in which other risk factors for the development of type 2 diabetes or macrovascular disease were not equally distributed between treatment groups.

\section{Meta-regression analyses}

We planned to use meta-regression analyses (in SAS proc MIXED, version 8.0) to explore the influence of characteristics of study population and study design on the outcomes. We planned to examine all dependent variables for which sufficient studies are available; the minimal number of studies would need to be 10 to gain sufficient power. The independent variables were similar to the pre-defined sub-groups. The weight of each trial would be equal to the inverse sum of the within trial variance and the residual between trial variance, in order to perform a random effects analysis.

\section{Assessment of small study bias}

Small study bias was planned to be tested by using the funnel plot or other corrective analytical methods depending on the number of clinical trials included in the systematic review (Begg 1994; Egger 1997; Hedges 1992).

\section{RE S U L T S}

\section{Description of studies}

See: Characteristics of included studies; Characteristics of excluded studies; Characteristics of ongoing studies.

\section{Results of the search}

Trials identified (see Figure 1) 
Figure I. Study flow-diagram.

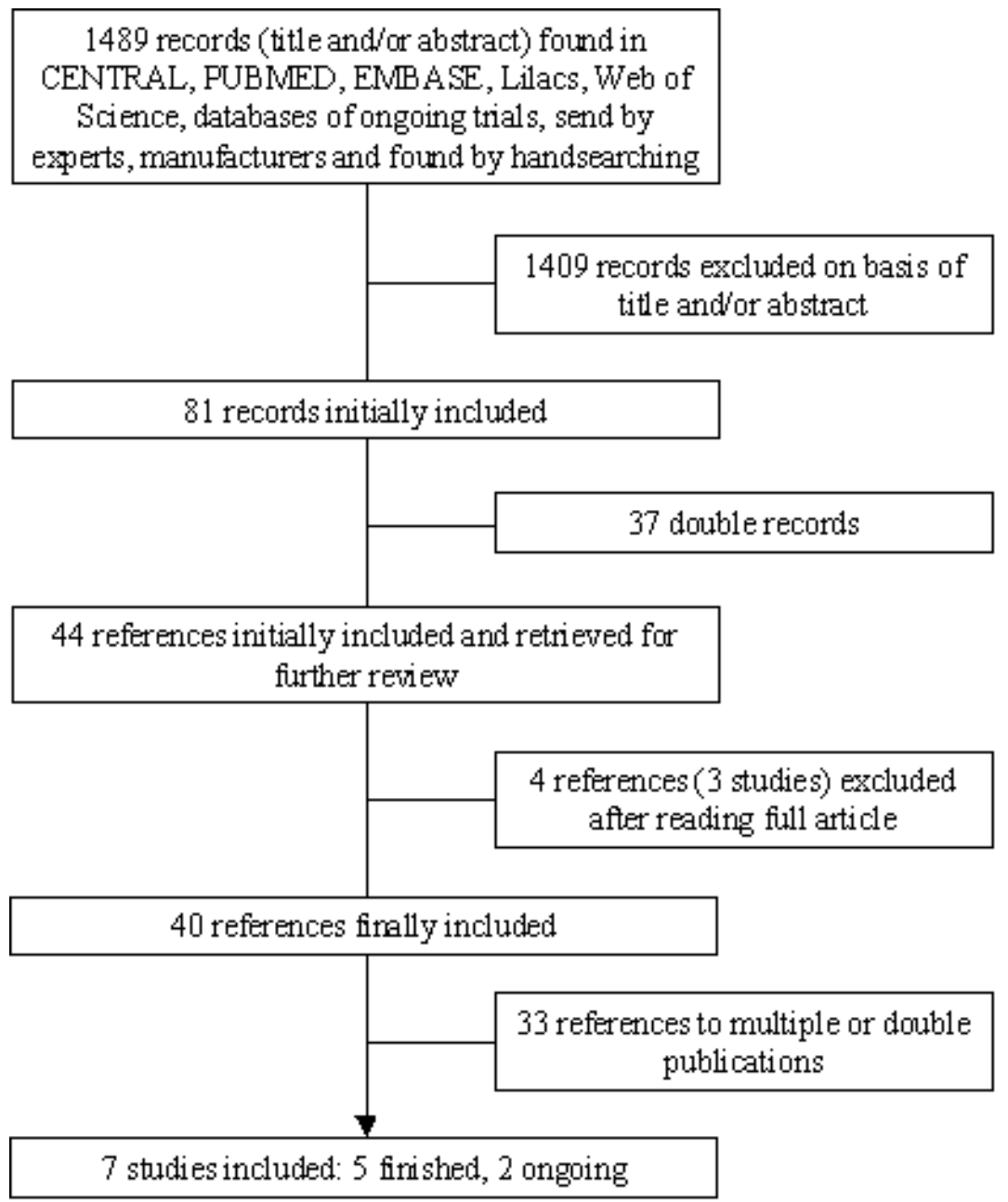

PUBMED: 224 records were retrieved and assessed on basis of title or abstract, or both (until 22 March 2006), 13 records were initially included for further reading and 12 were included in the final review.

EMBASE: 551 records were retrieved and assessed on basis of title or abstract, or both (until 21 October 2005), 20 records were initially included for further reading and 19 were included in the final review.

The Cochrane Library: 432 records were retrieved and assessed on basis of title or abstract, or both (Issue 1, 2006), 10 records were initially included for further reading. All of those records remained included in the final review.

Web of Science: 117 records were retrieved and assessed on basis of title or abstract, or both (until 7 February 2006); eight records were initially included for further reading. All of those records remained included in the final review.

LILACS: 95 records were retrieved and assessed on basis of title or abstract, or both (until 7 February 2006). None of these references were initially included.

Experts: We obtained two references by corresponding with experts or authors. One of those references was deemed interesting and could be included in the final review (EDIT).

Manufacturers: Bayer is the developer of acarbose and miglitol and Takeda the developer of voglibose. Sanofi-Synthelabo is patent holder of miglitol. Bayer send us four references, four were initially included and three were finally included in the review. Takeda and Sanofi did not reply to our letters.

Handsearching (checking references of existing reviews, browsing on the Internet, posters on congress etc.): Twenty-one references found by handsearching seemed possibly interesting based on title or abstract, or both. Nineteen references were finally included. 
Databases for ongoing trials: we retrieved 43 records, four of which were initially included (last search March 22nd 2006). Thus far, we did not receive any (un)published data that gave cause to exclude those studies for the review. Two of those studies were finished by the time of retrieval (DAISI; EDIT) and two other studies were started in 2005 and will be completed in 2009 (ABC-Study) and 2013 (Tamita 2006) (see Characteristics of ongoing studiese Characteristics of ongoing studies).

\section{Interrater agreement}

Interrater kappa for agreement on inclusion, calculated on basis of the first 1210 titles or abstracts, or both, read by the two reviewers (FVDL and PL) was 0.77 (95\% CI 0.65 to 0.90$)$. All differences in opinion were resolved by consensus.

\section{Included studies}

Five studies with 2360 participants, described in 36 articles, abstracts or web sites were finally included in the review. Details are given in Characteristics of included studies.

\section{Missing data}

We contacted all authors for data clarification and missing data. This was successful for one study (STOP-NIDDM). The corresponding author of the DAISI study sent us the full statistical report with the restriction that we were not allowed to use the data before their manuscript was accepted for publication. The authors of the EDIT study promised us to sent more details once their manuscript was in the galley-proof stage. For the other two studies the authors did not reply to our letters and mails (Fang 2004; Wang 2000).

\section{Publication type}

Three studies were (predominantly) published as journal articles (Fang 2004; STOP-NIDDM; Wang 2000). For the STOPNIDDM study we also considered correspondence and debate articles as a result of the main publications. The other two studies were published on a web site or as abstracts, or both (DAISI; EDIT).

\section{Participants}

Three studies included patients with IGT according to the WHO criteria of 1985 (DAISI; Fang 2004; Wang 2000). One study included participants with IGT according to the WHO criteria of 1999 in addition to a fasting blood glucose equal or greater than $5.6 \mathrm{mmol} / \mathrm{L}$ and less than $7.8 \mathrm{mmol} / \mathrm{L}$ (STOP-NIDDM) and one study included participants at increased risk for type 2 diabetes' with a fasting BG 5.5 to $7.7 \mathrm{mmol} / \mathrm{L}$ (EDIT). In the STOPNIDDM study patients were (mainly) recruited through screening of high-risk patients and followed as outpatients in study-centres.
In the EDIT study the patients were 'self-referred' but the exact setting was unclear. Setting and recruitment for the other studies remained unclear, thus far.

\section{Trial design}

All studies had a parallel design. One study had a double-blind $2 \times 2$ factorial design (EDIT). Two studies were blinded (DAISI; STOP-NIDDM) and two studies were not blinded (Fang 2004; Wang 2000).

All studies investigated acarbose as the alpha-glucosidase inhibitor and compared it to placebo (DAISI; EDIT; STOP-NIDDM), metformin (EDIT; Fang 2004), diet and exercise (Fang 2004) or treatment, or both (Fang 2004; Wang 2000). Thus far, we found no completed studies with miglitol or voglibose.

Study duration was six years (EDIT), five years (Fang 2004), three years (DAISI; STOP-NIDDM) and one year (Wang 2000). In one study the treatment duration was followed by a three months washout period (placebo given for both groups, STOP-NIDDM), In all other cases treatment duration was similar to the follow-up duration.

\section{Outcome measures}

All studies reported occurrence of type 2 diabetes as a primary outcome. Data on cardiovascular morbidity and mortality was available for the STOP-NIDDM study only. For two studies additional data for glycaemic control, lipids, blood pressure and body weight were available (Fang 2004; STOP-NIDDM). The DAISI and EDIT study reported, that they investigated a number of additional outcomes (for example plasma glucose, lipids) but these data were not accessible for us thus far.

\section{Excluded studies}

Three studies were initially included but excluded after reading the full article. Two studies turned out to be not randomised ( Mangiagli 2004; Yang 2001) and one study included patients with type 2 diabetes (EDIP).

\section{Risk of bias in included studies}

With respect to selection bias only one study had both an adequate randomisation and allocation concealment (STOP-NIDDM). The risk of attrition bias was low in three studies. However, no study had adequate intention-to-treat analysis. Blinding (performance bias) was adequate in one study (STOP-NIDDM) and for two studies information was lacking about precise methods of blinding (DAISI; EDIT). In one study outcomes were adequately assessed in a blinded fashion (STOP-NIDDM) (see Table 1).

The overall quality was roughly assessed on a three-point scale according to the Cochrane Handbook for Systematic Reviews of Interventions: one study scored A (low risk of bias) and four studies scored C (high risk of bias). 


\section{Effects of interventions}

With one exception, we were unable to perform meta-analyses in this review because for none of the comparisons data were available from more than one study.

\section{Acarbose versus placebo (see appendix 2 and data and analyses section)}

Three studies compared acarbose with placebo (DAISI; EDIT; STOP-NIDDM). However, only for one study sufficient data were available to allow statistical comparison (STOP-NIDDM). For the other two studies most of the data are not yet available (DAISI; EDIT).

\section{Mortality, incidence of type 2 diabetes and cardiovascular disease}

No significant effects on total mortality and mortality due to cardiovascular causes were found (STOP-NIDDM). Data for the other two studies were missing (DAISI; EDIT).

Acarbose reduced the incidence of (conversion to) type 2 diabetes in the acarbose group: RR 0.78 (95\% CI 0.68 to 0.90 ), Risk difference (RD) 0.09 (95\% CI 0.04 to 0.14 ), Number Needed to Treat $(\mathrm{NNT})=10($ STOP-NIDDM $)$. The NNT indicates that 10 patients have to be treated for three years with acarbose in order to prevent one case of type 2 diabetes. Also, in the EDIT-study it was reported that the use of acarbose had a preventive effect on the incidence of type 2 diabetes: RR $0.66(\mathrm{P}=0.046)$.

In the STOP-NIDDM study a decreasing effect for acarbose on the incidence of cardiovascular disease as a combined endpoint (myocardial infarction, angina, revascularization procedures, cardiovascular death, congestive heart failure, cerebrovascular events and peripheral vascular disease) was found: RR 0.47 (95\% CI 0.26 to 0.86 ). Also, a decreasing effect on myocardial infarctions (RR 0.08 (95\% CI 0.01 to 0.64$)$ was found. The RDs were 0.02 (95\% CI 0.01 to 0.04 ; NNT $=50)$ and $0.02(95 \%$ CI 0.01 to 0.03 ; NNT $=50)$ respectively. No significant differences in the incidence of angina pectoris, revascularization procedures, congestive heart failure, cerebrovascular events or peripheral vascular events were found. In total, 47 events took place in the whole study population and the study was not initially powered for this outcome. Thus far, we found no data on cardiovascular morbidity from the EDIT and DAISI studies.

\section{Glycaemic control}

Acarbose decreased post-load glucose by $0.61 \mathrm{mmol} / \mathrm{L}$ (95\% CI 0.27 to 0.95 ). No significant effects on glycated haemoglobin and fasting blood glucose were observed (STOP-NIDDM). In the EDIT study acarbose decreased fasting blood glucose by 0.1 $\mathrm{mmol} / \mathrm{L}(\mathrm{P}=0.0043)$ and post-load blood glucose by $0.4 \mathrm{mmol} /$ $\mathrm{L}(\mathrm{P}=0.0075)$.

\section{Plasma lipids}

No significant effects on lipids were found (STOP-NIDDM) or no data were available (DAISI; EDIT).

\section{Blood pressure}

In our analysis, we found no significant effects on diastolic and systolic blood pressure (Comparison 1, outcomes $41 \& 42$ ). However, in one study the authors reported a beneficial effect on the incidence of new cases of hypertension (which was not an outcome in our review) (STOP-NIDDM). In the acarbose and placebo groups 78 and 115 patients developed hypertension respectively (hazard ratio $0.66,95 \%$ CI 0.49 to 0.89$)$. Hypertension was defined as a blood pressure greater than $140 / 90 \mathrm{~mm} \mathrm{Hg}$ on two visits or if the family physician added antihypertensive medication. It is remarkable that at baseline almost half of all patients were already diagnosed with hypertension (acarbose 357/682, placebo 345/686), but these participants were kept in the analysis for the development of hypertension. No data on blood pressure was available for the other studies with the comparison acarbose-placebo (DAISI; EDIT).

\section{Fasting and post-load insulin and C-peptide}

No significant effects on fasting and post-load insulin levels were found (STOP-NIDDM) or no data were available (DAISI; EDIT).

\section{Body weight}

Acarbose decreased body weight by $1.2 \mathrm{~kg}$ (95\% CI 0.5 to 1.8 ) and BMI by $0.3 \mathrm{~kg} / \mathrm{m}^{2}$ (95\% CI 0.1 to 0.5 ). For the other studies (DAISI; EDIT), no data were available.

\section{Adverse events}

Acarbose caused more gastro-intestinal side effects compared to placebo: RR 1.40 (95\% CI 1.31 to 1.50$)$ and RD 0.24 (95\% CI 0.20 to 0.29 ; Number Needed to Harm $(\mathrm{NNH})=4)$. For the other studies, no data were available.

\section{Quality of life}

We found no data for 'quality of life', although it was stated for the EDIT study that this outcome would be measured.

\section{Costs and compliance}

Resource consumption data were not systematically collected in the STOP-NIDDM study. A cost-effectiveness study was published in which the likely consumption of healthcare resources were estimated and used for analyses. 
It was reported that compliance was assessed by pill counting but we found no outcome data in the published articles. We failed to ask for those data in our correspondence with the authors.

\section{Adjustment for high discontinuation rate in the acarbose arm of the STOP-NIDDM study (see appendix 3)}

One of the main criticisms on the STOP-NIDDM study was that the discontinuation rate in the acarbose group was higher than in the placebo group (acarbose 31\% versus placebo 19\%). Despite the fact that discontinuing patients remained in the ITT analyses, it was suggested that those patients were not followed-up regularly every three months and thus possible occurrence of diabetes or a cardiovascular event was less likely to be discovered (Sawicki 2004).

In order to investigate the possible influence of differences in the frequency of follow-up, we re-analysed the data with the following adjustments: first we requested for the mean number of study visits for both treatment groups. Next, we divided the number of visits of the placebo group by the number of visits in the acarbose group. We used this outcome as correction factor for the number of events in the acarbose group (occurrence of cardiovascular morbidity and type 2 diabetes)

The authors of the STOP-NIDDM study reported that the mean numbers of study visit in the acarbose $(\mathrm{n}=682)$ and in the placebo group $(\mathrm{n}=686)$ were $13.3(\mathrm{SD}=5.4)$ and $14.6(\mathrm{SD}=4.3)$ respectively. The calculated correction factor was: $14.6 / 13.3=1.1$. The outcomes before and after this correction factor are listed in Appendix 3. The effects sizes (Odds Ratios) of the outcomes for incidence of type 2 diabetes and occurrence of any cardiovascular disease became smaller after the correction but remained statistically significant. The (statistically significant) effects size for myocardial infarctions did not change (due to the fact that there was only one case in the acarbose group). The other outcomes remained statistically not significant after correction.

\section{Acarbose versus metformin (see appendix 4 and data and analyses section)}

One study investigated both agents in a $2 \times 2$ factorial design ( EDIT). From this study no data on the comparison acarbose versus metformin is available thus far.

Another study directly compared acarbose with metformin (Fang 2004). Acarbose showed a decreasing effect on post-load blood glucose compared to metformin: $1.40 \mathrm{mmol} / \mathrm{L}$ (95\% CI 0.55 to 2.25). Metformin showed a statistically significant decreasing effect on total cholesterol $(0.90 \mathrm{mmol} / \mathrm{L}, 95 \%$ CI 0.19 to 1.61$)$ and diastolic blood pressure (6 mmHg, 95\% CI 2.81 to 9.19) compared to acarbose. No significant effects for acarbose or metformin were found for the effect on incidence of type 2 diabetes, fasting blood glucose, triglycerides, BMI or systolic blood pressure. Data for cardiovascular events, quality of life, insulin or C-peptide levels, costs, compliance or adverse events were not found.

\section{Acarbose versus diet and exercise (see appendix 5 and data and analyses section)}

One study investigated the comparison acarbose versus diet and exercise (Fang 2004). In this study a beneficial effect of acarbose compared to diet and exercise was found on the incidence of type 2 diabetes: RR 0.40 (95\% CI 0.17 to 0.96), Risk difference (RD) $0.20(95 \%$ CI 0.02 to 0.38 , NNT $=5)$.

Further, acarbose significantly reduced fasting blood glucose ($1.37 \mathrm{mmol} / \mathrm{L}, 95 \% \mathrm{CI}-0.50$ to -2.24$)$ and post-load blood glucose (-2.79 $\mathrm{mmol} / \mathrm{L}, 95 \% \mathrm{CI}-1.79$ to -3.79$)$. Effects on total cholesterol, triglycerides, body weight and BMI were not statistically significant. Data for cardiovascular events, quality of life, insulin or C-peptide levels, costs, adverse events or compliance were not found.

\section{Acarbose versus no treatment (see appendix 6 and data and analyses section)}

Two studies compared acarbose with no treatment (Fang 2004; Wang 2000).

\section{Mortality, incidence of type 2 diabetes and cardiovascular disease}

The combined results of the two studies indicated that acarbose reduced the incidence of type 2 diabetes: RR 0.31 (95\% CI 0.14 to 0.69), Risk difference (RD) 0.17 ( $95 \%$ CI -0.09 to 0.43 , NS). We found no data for effects on mortality or cardiovascular morbidity.

\section{Glycaemic control}

One study reported data for the effects on fasting and post-load blood glucose. Compared to patients who were given no treatment, acarbose significantly reduced fasting blood glucose $(-1.39 \mathrm{mmol} /$ L, $95 \%$ CI -0.54 to -2.24$)$ and post-load blood glucose ( -4.53 $\mathrm{mmol} / \mathrm{L}, 95 \% \mathrm{CI}-3.54$ to -5.52 ) (Fang 2004).

\section{Plasma lipids}

One study reported data for the effects on total cholesterol and triglycerides. Compared to patients who were given no treatment, acarbose significantly reduced total cholesterol $(-1.00 \mathrm{mmol} / \mathrm{L}$, 95\% CI -0.194 to -1.81 ) (Fang 2004).

\section{Blood pressure}

One study reported data for the effects of acarbose on diastolic and systolic blood pressure: no significant effects were found (Fang 2004). 


\section{Fasting and post-load insulin and C-peptide}

No data were found for insulin or C-peptide levels.

\section{Body weight}

Data were available from one study: compared to patients with no treatment acarbose showed a non-significant effect on BMI (-1.1 $\mathrm{kg} / \mathrm{m}^{2}, 95 \%$ CI -2.2 to $0, \mathrm{P}=0.05$ ) (Fang 2004).

\section{Adverse events}

One study reported data on adverse effects (Wang 2000). Two patients in the acarbose group and no patients who received no treatment reported adverse effects. The difference was not statistically significant.

\section{Quality of life}

We found no data for effects on quality of life.

\section{Costs, compliance}

No data were found for these outcomes.

\section{Sensitivity analyses, sub-group analyses, meta- regression analyses, small study bias}

Due to the low number of included studies no further analyses could be performed.

\section{Heterogeneity}

Because not more than a maximum of two studies could be included per (statistical) comparison, formal testing of heterogeneity was not performed.

The studies were reasonably homogeneous with respect to a number of important items:

- all trials used acarbose as the alpha-glucosidase inhibitor (all with a dosage of $50 \mathrm{mg}$ TID, except for the STOP-NIDDM study in which a dosage of $100 \mathrm{mg}$ TID was given);

- all trials focused on patients with IGT (instead IFBG), except for the EDIT study which included patients 'at risk' for developing diabetes (with a fasting blood glucose 5.5 to 7.7 $\mathrm{mmol} / \mathrm{L}$ );

- in all trials the number of included females and males were almost similar, ranging from $47 \%$ females (Fang 2004) to $51 \%$ females (STOP-NIDDM);

- all trials included patients with a similar age, ranging from a mean of 49.1 years (Fang 2004) to 63.5 years (Wang 2000).

The following items could cause possible heterogeneity:

- two studies were performed in an Asian population (Fang 2004; Wang 2000). The effects of alpha-glucosidase inhibitors may be different from European or American populations (the other trials) due to differences in amount and type of carbohydrate in the regular diet;

- the mean BMI ranged from a normal BMI (Wang 2000) to overweight (Fang 2004; EDIT) or obesity (STOP-NIDDM). It was unknown for the DAISI study;

- baseline glycated haemoglobin was below $6.0 \%$ in two studies (EDIT; STOP-NIDDM), but unknown for the other studies;

- in two trials, all participants received additional advice on diet and life-style (STOP-NIDDM; Wang 2000) but for the other trials this information was missing.

\section{DISCUSSION}

\section{Summary of main results}

In this systematic review we found evidence from one large study of high quality (STOP-NIDDM) that acarbose compared to placebo reduces the incidence of type 2 diabetes and myocardial infarctions in patients with impaired glucose tolerance. These findings could not be confirmed nor refuted by two other (but highly similar) studies because most data were not available thus far (DAISI; EDIT). Two smaller studies of low quality comparing acarbose with no treatment or exercise, confirmed the capacity of acarbose to reduce the incidence of type 2 diabetes. Effects on cardiovascular morbidity could not be confirmed in other comparisons. Moreover it should be noted that the effects on cardiovascular morbidity in the STOP-NIDDM study were based on a limited number of events and the study was not initially powered for this outcome. Compared to placebo, acarbose induces more gastrointestinal side-effects $(\mathrm{NNH}=4)$.

\section{Decrease in incidence of type $\mathbf{2}$ diabetes mellitus}

We found evidence from several studies that acarbose reduces the incidence of type 2 diabetes (Fang 2004; STOP-NIDDM; Wang 2000). A firm effect on the incidence of type 2 diabetes is not surprising. After all, acarbose has a clear effect on glycaemic control in patients with type 2 diabetes (Van de Laar 2005). Such a drug will have large effects on the 'incidence' of diabetes for people who are at the border of fulfilling the criteria for type 2 diabetes. So, the question is whether acarbose prevents, delays or even masks type 2 diabetes. The authors of the STOP-NIDDM study are undecided, as they sometimes speak of 'prevention' (in the title) and sometimes of 'delay' (in the summary) (Chiasson 2002). Critics of the STOPNIDDM study suggested that acarbose masks type 2 diabetes since $15,4 \%$ of the patients on acarbose compared to $10,6 \%$ (placebo) converted to diabetes during a three months wash-out phase ( Kaiser 2004). 
To assess the value of acarbose with respect to the effects on the development of type 2 diabetes, it is probably more straightforward to look at the effects on glycaemic control. After all, IGT refers to an intermediate state between normal glucose homeostasis and type 2 diabetes. In the STOP-NIDDM study these effects are disappointing: no significant effect on glycated haemoglobin and fasting blood glucose, and a small effect on post-load blood glucose $(-0.61 \mathrm{mmol} / \mathrm{L}, 95 \% \mathrm{CI}-0.95$ to -0.27$)$ were found. Those effects are smaller than obtained in a Cochrane review on alphaglucosidase inhibitors for patients with type 2 diabetes (Van de Laar 2005). This may be explained by the fact that in the before mentioned review it was found that the effects on glycaemic control were less strong with lower baseline values of glycaemia and longer study duration. Further, most trials in the Cochrane review studied post-load glucose with a full meal tolerance test, and not an oral glucose tolerance test (OGTT) as has been done in the STOP-NIDDM study. Acarbose has no direct effects on an OGTT as alpha-glucosidase inhibitors only delay the breakdown of complex polysaccharides (and not monosaccharide such as glucose). In this light, the decreasing effect of acarbose on a 2 hours OGTT is positive because it indicates a beneficial effect of insulin resistance.

Another argument in the question whether an effect of acarbose on the incidence of type 2 diabetes is relevant or important, is the desirability of a drug intervention in people at high risk for type 2 diabetes. It is well recognized that the increase in the number of patients with type 2 diabetes is in life-style factors such as a shortage of exercise and an unhealthy diet. Focussing on drugs as the solution of the problem may distract people from the issues that are truly important: eat less and exercise more.

Finally the question arises whether true (primary) prevention of type 2 diabetes with a single drug is possible at all. Type 2 diabetes is a very complex disease in which many pathophysiological mechanisms are involved (for example insulin sensitivity, blood pressure regulation). Only when one predominant mechanism would be identified, primary prevention by a drug targeting this mechanism would be feasible. Currently, it seems not likely that this will be the case for type 2 diabetes in the near future. In the mean while, drug interventions for IGT or IFBG should be regarded as secondary or tertiary prevention.

\section{Decrease in incidence of cardiovascular disease}

The observed beneficial effects on the occurrence of cardiovascular morbidity (STOP-NIDDM) are very interesting. However, these results should be interpreted with great prudence. This is underlined by the authors who sensibly stated that because effects on cardiovascular morbidity were secondary objectives and the number of events relatively small, they should be seen as hypothesis generating (Chiasson 2004).

Critics mentioned the skewed discontinuation rate as another explanation for the observed effects, other than an effect of acar- bose (Sawicki 2004). Because more patients in the acarbose group stopped taking their medication (mostly due to side-effects), the patients in the acarbose group were not followed-up as regular as the patients in the placebo group and could have had therefore less chance to be 'detected' in case a cardiovascular event had taken place. We re-analysed the data accounting for differences in followup rate and found that the odds ratios for the occurrence of any cardiovascular event became less strong, but remained statistically significant.

Another explanation could be in the existence of (unknown) confounding factors. Clues for differences in treatment groups were reported in the cost-effectiveness sub-study of the STOP-NIDDM trial (Quilici 2005). Baseline risk profiles were determined with a formula for the identification of high risk for type 2 diabetes (Stern 2002) or cardiovascular risk (Anderson 1991). Based on these risk scores, it was stated that '... more placebo patients than acarbosetreated patients were represented in the high-risk subgroups...'. So, patients in the placebo group could have had a higher a-priori risk than patients on acarbose.

We conclude that the observed effects of acarbose on cardiovascular disease may be due to a treatment effect or to (unknown) confounding factors, or both. The results from the ongoing studies are needed to confirm or refute the observed effects in the STOP-NIDDM study (ABC-Study; Tamita 2006).

\section{Effects on incidence of hypertension}

We could not confirm the beneficial effects on hypertension observed in the STOP-NIDDM study, in which hypertension was studied as a clinical outcome (blood pressure greater than 140/ $90 \mathrm{mmHg}$ on two or more occasions). Instead we studied the differences in diastolic and systolic blood pressure. These outcomes yielded no statistically significant effects of acarbose compared to placebo (STOP-NIDDM), and a detrimental effect of acarbose compared to metformin in one study of low quality and a low number of participants $-6 \mathrm{~mm} \mathrm{Hg}$ (95\% CI 3 to 9) (Fang 2004).

\section{Potential biases in the review process}

One of the main strengths of this review is the rigourness and completeness of the search. It is remarkable that only one trial (STOP-NIDDM) was listed in the database that is mostly used by clinicians all over the world (PUBMED), and that the other studies were retrieved from less well-known databases (EMBASE or The Cochrane Library), in databases of ongoing trials or by handsearching. Second, the a priori decision to include randomised trials only with a duration of at least one year ensured a 'minimum level' of quality. Third, we assessed many different outcomes in the review which enables the readers to judge by themselves what matters most for their own particular question. Finally, we think that the tables and figures and the extensive provision of all out- 
come data and information related to quality and heterogeneity, makes the review transparent.

It is clear that the main limitations are the missing data, especially from the EDIT and DAISI studies. The authors have kindly promised their help once their manuscripts are accepted for publication, but it is remarkable that these important studies have not been accepted for publication to date (May 2006). This points to a possible time lag bias: a kind of reporting bias in which studies may be published rapidly or delayed depending on the nature and direction of the results. Of course we will use upcoming data from these studies, and from the studies that are still going on in future updates of our review. Another limitation is the external validity of the results. Only for one study the recruitment of the participants was clearly described. It is important to know how selection took place in order to be able to generalize the results to other clinical settings. For example, were the participants volunteers recruited with an newspaper advertisement (and thus highly motivated), or were they recruited from the files of general practitioners (and maybe less motivated). Further, we only found studies with acarbose as the AGI. The question whether the results may be extrapolated to miglitol or voglibose depends on the existence of a possible group effect for AGIs. The answer to this question is not known, although in the Cochrane review on AGIs for type 2 diabetes comparable results for acarbose and miglitol were obtained for most outcomes (Van de Laar 2005).

\section{Agreements and disagreements with other studies or reviews}

As far as we are aware of, no systematic review has been done with an exclusive focus on alpha-glucosidase inhibitors for people with IGT of IFBG. Nevertheless, alpha-glucosidase inhibitors have been studied as part of a recent systematic review on all kind of drug therapy to delay or prevent type 2 diabetes (Padwal 2005). In that review two studies on acarbose were included: the STOP-NIDDM study, and a non-randomised study (Yang 2001) (excluded for the current review). It was concluded that acarbose reduced the incidence of type 2 diabetes compared with placebo but that it could not definitively be recommended for diabetes prevention. Similar conclusions were drawn for metformin, troglitazone and orlistat (a weight reducing agent). Further, inconclusive results for a decrease in the incidence of type 2 diabetes were reported for cholesterol lowering agents (fibrates and statins), an- tihypertensive agents and oestrogens. A systematic review on the efficacy of lifestyle education concluded that lifestyle education was clearly effective for reducing two-hour plasma glucose $(0.84$ $\mathrm{mmol} / \mathrm{L}, 95 \%$ CI 0.39 to 1.29$)$ and the incidence of type 2 diabetes over one year (RR $0.55,95 \%$ CI 0.44 to 0.69 ), and should thus be recommended for patients with patients at high risk for type 2 diabetes (Yamaoka 2005).

\section{A U THORS' CONCLUSIONS}

\section{Implications for practice}

In patients with impaired glucose tolerance the use of acarbose reduces the incidence of type 2 diabetes, but the effects on glycaemic control are limited. Acarbose has a possible effect on cardiovascular morbidity, which has to be confirmed in other studies. Life-style interventions remain the cornerstone of treatment for patients at risk for type 2 diabetes. If physicians and patients feel that an active treatment for impaired glucose tolerance is needed, they should consider this evidence together with evidence for other interventions, especially life-style interventions.

\section{Implications for research}

First, the disclosure of the finished - but unpublished - studies is needed in order to confirm or refute the possible effects on cardiovascular morbidity. If the evidence remains inconclusive after these data have been incorporated in the systematic review, the results from two ongoing long-term intervention studies on the effects of alpha-glucosidase inhibitors for patients with IGT or IFBG may be awaited. Otherwise, new long-term studies with a similar focus could be initiated.

\section{ACKNOWLEDGEMENTS}

We would like to thank the following people: all authors, investigators and manufacturers who were willing to answer our questions and who provided us with additional data.

Bas Aarts for the translation of the articles from Chinese language, and Leon Bax for the translation of abstracts in the Japanese language. 


\section{R E F E R E N C E S}

\section{References to studies included in this review}

\section{DAISI \{published data only\}}

Nijpels G. Dutch Acarbose Intervention Trial (DAISI).

http://www.controlled-trials.com/isrctn/trial///0/ 33274262.html accessed 15th march 20062005.

Nijpels G, Ruige J. Dutch Acarbose Intervention Study in IGT (DAISI). http://www.emgo.nl/research_prog/diabetes/ researchprojects_01.asp (accessed sept 14th 2004) 2004.

\section{EDIT \{published data only\}}

Anonymous. Early Diabetes Intervention Trial (protocol). http://www.dtu.ox.ac.uk/ accessed 15th march 2006. Citroën HA, Tunbridge FKE, Holman RR. Possible prevention of type 2 diabetes with acarbose or metformin over three years. Diabetologia 2000;43(Suppl. 1):A73. Holman RR. Early Diabetes Intervention Trial (EDIT Study). http://www.controlled-trials.com/isrctn/trial///0/ 96631607.html accessed 13 march 20062002.

Holman RR, Blackwell L, Manley SE, Tucker L, Frighi V, Stratton IM. Results from the early diabetes intervention trial. Diabetes 2003;52(Suppl. 1):A16.

Holman RR, Blackwell L, Stratton IM, Manley SE, Tucker L, Frighi V. Six-years results from the Early Diabetes Intervention Trial. Diabetic Medicine 2003;20(Suppl. 2): 15.

Holman RR, North BV, Tunbridge FKE. Early diabetes intervention trial. Diabetologia 1997; Vol. 40, issue Suppl. 1:A17.

* Holman RR, North BV, Tunbridge FKE. Early Diabetes Intervention Trial. Diabetes 1997;46(Suppl 1):157A.

Holman RR, North BV, Tunbridge FKE. Possible prevention of type 2 diabetes with acarbose or metformin. Diabetes YR 2000;49(Suppl. 1):450-P.

Fang 2004 \{published data only\}

* Fang YS, Li TY, Chen SY. Effect of medicine and nonmedicine intervention on the outcomes of patients with impaired glucose tolerance: 5-year follow-up [Chinese]. Zhongguo Linchuang Kangfu (Chinese Journal for Clinical Rehabilitation) 2004;8(30):6562-3.

\section{STOP-NIDDM \{published and unpublished data\}}

Anonymous. STOP-NIDDM (Flash player presentation). www.stop-niddm.com accessed 8 february 2006 www.stopniddm.com accessed 8th february 20062006.

Anonymous. The "STOP NIDDM" program--can diabetes in the aged be prevented? An international long-term study revisited; does Acarbose delay or prevent the manifestations of type II diabetes [STOP NIDDM Programm - Kann man den Altersdiabetes verhindern? Eine internationale Langzeit-Studie untersucht, ob Acarbose die Manifestation des Typ II-Diabetes verzogert oder verhindert]. Deutsche Medizinische Wochenschrift 1997;122(38 Suppl):1-4. Anonymous. The STOP-NIDDM Trial Study TO Prevent non insulin dependent diabetes mellitus (powerpoint presentation). http://www.stop-niddm.com/study/slides/ $\mathrm{htm}$ accessed 1st august 2003.

Bridges CM. Acarbose for patients with hypertension and impaired glucose tolerance. JAMA 2003;290(23):3066-7. Chiasson JL. The potential use of acarbose in the prevention of type 2 diabetes and cardiovascular disease. European Heart Journal Supplements 2000;2(Supplement D):D35. Chiasson JL, Gomis R, Hanefeld M, Josse RG, Karasik A, Laakso M. The STOP-NIDDM Trial: an international study on the efficacy of an alpha-glucosidase inhibitor to prevent type 2 diabetes in a population with impaired glucose tolerance: rationale, design, and preliminary screening data. Study to Prevent Non-Insulin-Dependent Diabetes Mellitus. Diabetes Care 1998;21(10):1720-5.

* Chiasson JL, Josse RG, Gomis R, Hanefeld M, Karasik A, Laakso M. Acarbose for prevention of type 2 diabetes mellitus: the STOP-NIDDM randomised trial. Lancet 2002;359(9323):2072-7.

Chiasson JL, Josse RG, Gomis R, Hanefeld M, Karasik A, Laakso M. Acarbose for the prevention of Type 2 diabetes, hypertension and cardiovascular disease in subjects with impaired glucose tolerance: facts and interpretations concerning the critical analysis of the STOP-NIDDM Trial data. Diabetologia 2004;47(6):969-75.

Chiasson JL, Josse RG, Gomis R, Hanefeld M, Karasik A, Laakso M. Acarbose treatment and the risk of cardiovascular disease and hypertension in patients with impaired glucose tolerance: the STOP-NIDDM trial. JAMA 2003;290(4): 486-96.

Chiasson JL, Josse RG, Hanefeld M, Karasik A, Laakso M. Acarbose can prevent type 2 diabetes and cardiovascular disease in subjects with impaired glucose tolerance: The STOP-NIDDM Trial. Diabetologia 2002;45(Suppl 2): A104.

Delorme S, Chiasson JL. Acarbose in the prevention of cardiovascular disease in subjects with impaired glucose tolerance and type 2 diabetes mellitus. Current Opinion in Pharmacology 2005;5(2):184-9.

Gonzalez-Clemente JM, Ortega-Martinez d, V, GimenezPalop O, Mauricio D. Acarbose for patients with hypertension and impaired glucose tolerance. JAMA 2003; 290(23):3067-9.

Hanefeld M, Chiasson JL, Koehler C, Henkel E, Schaper F, Temelkova-Kurktschiev T. Acarbose slows progression of intima-media thickness of the carotid arteries in subjects with impaired glucose tolerance. Stroke 2004;35(5):1073-8. Kaiser T, Sawicki PT. Acarbose for patients with hypertension and impaired glucose tolerance. JAMA 2003; 290(23):3066-9.

Kaiser T, Sawicki PT. Acarbose for prevention of diabetes, hypertension and cardiovascular events? A critical analysis of the STOP-NIDDM data. Diabetologia 2004;47(3): 
575-80.

Muhlhauser I. Acarbose for type 2 diabetes prevention. Lancet 2002;360(9344):1517.

Quilici S, Chancellor J, Maclaine G, McGuire A, Andersson D, Chiasson JL. Cost-effectiveness of acarbose for the management of impaired glucose tolerance in Sweden. International Journal of Clinical Practice 2005;59(10): 1143-52.

Rosenthal JH. Acarbose for patients with hypertension and impaired glucose tolerance. JAMA 2003;290(23):3066. Sabes R. Cost-effectiveness analysis of acarbose in the treatment of patients with impaired glucose tolerance. Gaceta sanitaria / SESPAS 2004;18(6):431-9.

Sawicki PT, Kaiser T. Response to Chiasson et al.: Acarbose for the prevention of Type 2 diabetes, hypertension and cardiovascular disease in subjects with impaired glucose tolerance: facts and interpretations concerning the critical analysis of the STOP-NIDDM Trial data. Diabetologia 2004;47(6):976-7.

Scheen AJ. Acarbose for type 2 diabetes prevention. Lancet 2002;360(9344):1516.

Temelkova-Kurktschiev TS, Koehler C. Lower progression of carotid intima media thickness under acarbose: the STOP-NIDDM study. Diabetologia 2003;46(Suppl 2): A122-3.

Windler E. Acarbose for prevention of diabetes mellitus. STOP-NIDDM [Acarbose zur Diabetes-mellitusPravention]. Der Internist 2003;44(4):491-3.

Zeymer, U. Effect of acarbose treatment on the risk of silent myocardial infarctions in patients with impaired glucose tolerance: results of the randomised STOP-NIDDM trial electrocardiography substudy. International Journal of Cardiology 2006;107(1):11-20.

Zeymer U. Cardiovascular benefits of acarbose in impaired glucose tolerance and type 2 diabetes. International Journal of Cardiology 2006;107(1):11-20.

Zeymer U, Schwarzmaier-D'assie A, Petzinna D, Chiasson JL. Acarbose reduces silent myocardial infarctions in patients with impaired glucose tolerance. Results of the randomized STOP-NIDDM ECG substudy. Diabetologia 2004;47(Suppl 1):A47.

Wang 2000 \{published data only\}

* Wang H, Xu WH, Wang GY. An evalualion on efficacy of acarbose interfering trentment on IGT [Chinese]. Shanxi Clinical Medicine Journal 2000;9(2):116-7.

\section{References to studies excluded from this review}

\section{EDIP \{published data only\}}

Perry RC, Shankar RR, Fineberg N, McGill J, Baron AD. HbAlc measurement improves the detection of type 2 diabetes in high-risk individuals with nondiagnostic levels of fasting plasma glucose: the Early Diabetes Intervention Program (EDIP). Diabetes Care 2001;24(3):465-71. Shankar RR, Shankar SS, Brizendine E, Shen G, McGill J, Baron AD, Kirkman MS. Acarbose in 'Early' Diabetes - Data from the Early Diabetes Intervention Program (EDIP). Diabetes 2005;54(Suppl 1):A132.
Mangiagli 2004 \{published data only\}

Mangiagli A, Campisi S, De Sanctis V, Nicoletti MC, Cardinale G, Galati MC, Raiola G, Rigano P, Saviano A. Effects of acarbose in patients with beta-thalassaemia major and abnormal glucose homeostasis. Pediatric Endocrinology Reviews 2004;2(Suppl 2):276-8.

Yang 2001 \{published data only\}

* Yang W, Lin L, Qi J, Yu Z, Pei H, He G, Yang Z, Wang F, Li G, Pan X. The preventive effect of Acarbose and Metformin on the progression to diabetes mellitus in the IGT population: a 3-year multicenter prospective study [translated from Chinese, available from Bayer website www.stop-niddm.com, accessed september 13th 2004]. Chinese Journal of Endocrinology and Metabolism 2001;17 (3):131-6.

\section{References to ongoing studies}

\section{ABC-Study \{published data only\}}

Kim J. Alpha-Glucosidase-Inhibitor Blocks Cardiac Events in Patients With Myocardial Infarction and IGT (ABC Study). http://clinicaltrials.gov/show/NCT00212017 accessed 15th march 20062006.

\section{Tamita 2006 \{published data only\}}

Tamita K. Acarbose for Secondary Prevention of Cardiovascular Events in Patients With Coronary Stenting and Abnormal Glucose Tolerance. http://clinicaltrials.gov/ show/NCT00221156 accessed 15th march 2006.

\section{Additional references}

\section{ADA 1997}

American Diabetic Association. Report of the Expert Committee on the Diagnosis and Classification of Diabetes Mellitus. Diabetes Care 1997;20:1183-97.

ADA 1999

The Expert Committee on the Diagnosis and Classification of Diabetes Mellitus. Report of The Expert Committee on the Diagnosis and Classification of Diabetes Mellitus. Diabetes Care 1999;22 Suppl 1:S5-19.

\section{ADA 2003}

The Expert Committee on the Diagnosis and Classification of Diabetes Mellitus. Follow-up Report on the Diagnosis of Diabetes Mellitus. Diabetes Care 2003;26(11):3160-7.

Anderson 1991

Anderson KM, Odell PM, Wilson PW, Kannel WB. Cardiovascular disease risk profiles. American Heart Journal 1991;121(1 Pt 2):293-8.

\section{Begg 1994}

Begg CB, Mazumbar M. Operating characteristics of a rank correlation test for publication bias. Biometrics 1994;50: 1088-101.

\section{Buchanan 2002}

Buchanan TA, Xiang AH, Peters RK, Kjos SL, Marroquin A, Goico J, et al.Preservation of pancreatic $B$-cell function and prevention of type 2 diabetes by pharmacological treatment of insulin resistance in high-risk Hispanic women. Diabetes 2002;51(9):2796-803 


\section{Chiasson 2002}

Chiasson JL, Josse RG, Gomis R, Hanefeld M, Karasik A, Laakso M. Acarbose for prevention of type 2 diabetes mellitus: the STOP-NIDDM randomised trial. Lancet 2002;359(9323):2072-7.

\section{Chiasson 2003}

Chiasson JL, Josse RG, Gomis R, Hanefeld M, Karasik A, Laakso M. Acarbose treatment and the risk of cardiovascular disease and hypertension in patients with impaired glucose tolerance: the STOP-NIDDM trial. JAMA 2003;290(4): 486-94.

\section{Chiasson 2004}

Chiasson JL, Josse RG, Gomis R, Hanefeld M, Karasik A, Laakso M. Acarbose for the prevention of Type 2 diabetes, hypertension and cardiovascular disease in subjects with impaired glucose tolerance: facts and interpretations concerning the critical analysis of the STOP-NIDDM Trial data. Diabetologia 2004;47(6):969-75.

\section{Cohen 1960}

Cohen J. A coefficient of agreement for nominal scales. Educational and Psychological Measurement 1960;20:37-46.

\section{Egger 1997}

Egger M, Davey SG, Schneider M, Minder C. Bias in metaanalysis detected by a simple, graphical test. BMJ 1997;315 (7109):629-34.

\section{Hedges 1992}

Hedges LV. Modeling publication selection effects in metaanalysis. Statistical Science 1992;7:246-55.

\section{Higgins 2002}

Higgins JP, Thompson SG. Quantifying heterogeneity in a meta-analysis. Statistics in Medicine 2002;21(11):1539-58.

\section{Kaiser 2004}

Kaiser T, Sawicki PT. Acarbose for prevention of diabetes, hypertension and cardiovascular events? A critical analysis of the STOP-NIDDM data. Diabetologia 2004;47(3): 575-80.

\section{Knowler 2002}

Knowler WC, Barrett-Connor E, Fowler SE, Hamman RF, Lachin JM, Walker EA, et al.Reduction in the incidence of type 2 diabetes with lifestyle intervention or metformin. New England Journal of Medicine 2002;346(6):393-403.

\section{NDDG 1979}

National Diabetes Data Group. Classification and diagnosis of diabetes mellitus and other categories of glucose intolerance. Diabetes 1979;28:1039-57.

\section{Padwal 2005}

Padwal R, Majumdar SR, Johnson JA, Varney J, McAlister FA. A systematic review of drug therapy to delay or prevent type 2 diabetes. Diabetes Care 2005;28(3):736-44.

\section{Pan 1997}

Pan XR, Li GW, Hu YH, Wang JX, Yang WY, An ZX, et al.Effects of diet and exercise in preventing NIDDM in people with impaired glucose tolerance. The Da Qing IGT and Diabetes Study. Diabetes Care 1997;20(4):537-44.

\section{Quilici 2005}

Quilici S, Chancellor J, Maclaine G, McGuire A, Andersson D, Chiasson JL. Cost-effectiveness of acarbose for the management of impaired glucose tolerance in Sweden. International Journal of Clinical Practice 2005;59(10): $1143-52$.

\section{Robinson 2002}

Robinson KA, Dickersin K. Development of a highly sensitive search strategy for the retrieval of reports of controlled trials using PubMed. International Journal of Epidemiology 2002;31(1):150-3.

\section{Sawicki 2004}

Sawicki PT, Kaiser T. Response to Chiasson et al.: Acarbose for the prevention of Type 2 diabetes, hypertension and cardiovascular disease in subjects with impaired glucose tolerance: facts and interpretations concerning the critical analysis of the STOP-NIDDM Trial data. Diabetologia 2004;47(6):976-7.

\section{Stern 2002}

Stern MP, Williams K, Haffner SM. Identification of persons at high risk for type 2 diabetes mellitus: do we need the oral glucose tolerance test?. Annals of Internal Medicine 2002;136(8):575-81.

\section{Tuomilehto 2001}

Tuomilehto J, Lindstrom J, Eriksson JG, Valle TT, Hamalainen H, Ilanne-Parikka P, et al.Prevention of type 2 diabetes mellitus by changes in lifestyle among subjects with impaired glucose tolerance. New England Journal of Medicine 2001;344(18):1343-50.

\section{Unwin 2002}

Unwin N, Shaw J, Zimmet P, Alberti KG. Impaired glucose tolerance and impaired fasting glycaemia: the current status on definition and intervention. Diabetic Medicine 2002;19 (9):708-23.

Van de Laar 2005

Van de Laar FA, Lucassen PLBJ, Akkermans RP, Van de Lisdonk EH, Rutten GEHM, Van Weel C. Alphaglucosidase inhibitors for type 2 diabetes mellitus. Cochrane Database of Systematic Reviews 2005, Issue 2. [Art. No.: CD003639. DOI: 10.1002/14651858.CD003639.pub2]

\section{WHO 1980}

World Health Organisation. WHO Technical Report Series 646. Second report. WHO Expert Committee on Diabetes Mellitus 1980.

\section{WHO 1985}

World Health Organisation. Technical Report Series No. 727. Report of a WHO Study Group.. WHO Expert Committee on Diabetes Mellitus 1985.

\section{WHO 1998}

Alberti KM, Zimmet PZ. Definition, diagnosis and classification of diabetes mellitus and its complications. Part I: diagnosis and classification of diabetes mellitus. Provisional report of a WHO consultation. Diabetic Medicine 1998;15:539-53. 
WHO 1999

World Health Organization. Definition, Diagnosis and Classification of Diabetes Mellitus and its Complications. Report of a WHO Consultation. Part 1: Diagnosis and Classification of Diabetes Mellitus. Geneva: World Health Organization, 1999:1-59.

\section{Yamaoka 2005}

Yamaoka K, Tango T. Efficacy of lifestyle education to prevent type 2 diabetes: a meta-analysis of randomized controlled trials. Diabetes Care 2005;28(11):2780-6.

* Indicates the major publication for the study 
CHARACTERISTICS OF STUDIES

Characteristics of included studies [ordered by study ID]

DAISI

\begin{tabular}{|c|c|}
\hline Methods & $\begin{array}{l}\text { DESIGN: parallel study } \\
\text { RANDOMISATION PROCEDURE: unclear } \\
\text { BLINDING: double-blind } \\
\text { DURATION: } 3 \text { years (treatment and follow-up) }\end{array}$ \\
\hline Participants & $\begin{array}{l}\text { COUNTRY: Netherlands } \\
\text { SETTING: unclear } \\
\text { RECRUITMENT: unclear } \\
\text { DIAGNOSTIC CRITERIA: 2-hour post-load BG > } 8.6 \mathrm{mmol} / \mathrm{L} \text { and }<11.1 \mathrm{mmol} / \mathrm{L} \text { after } 2 \text { OGTTs } \\
\text { (WHO 1985) } \\
\text { NUMBER: AGI: included 61, completed 27, ITT 60, PP 32; CONTROL included 60, completed 33, } \\
\text { ITT 58, PP } 39 \\
\text { SEX: 'sex ratio nearly 1:1' } \\
\text { AGE (YEARS (MEDIAN)): AGI 61; CONTROL } 56 \\
\text { BMI (KG/M2 (MEAN)): ND } \\
\text { GLYCATED HAEMOGLOBIN: ND }\end{array}$ \\
\hline
\end{tabular}

Interventions $\quad$ Dietary advice: unclear

AGI: acarbose, week $150 \mathrm{mg}$ OD; week $250 \mathrm{mg}$ BID; week 3 - endpoint $30 \mathrm{mg}$ TID

CONTROL: placebo, dosing schedule not described

Outcomes
1. Mortality: unclear
2. Complications related to hyperglycaemia: incidence of type 2 diabetes and 'conversion to' normal
3. Quality of Life: unclear
4. Glycaemic control: fasting venous glucose
5. Lipids: Total- \& HDL-cholesterol, triglycerides
6. Insulin levels: B-cell function and insulin sensitivity
7. Weight: unclear
8. Blood pressure: unclear
9. Adverse effects: unclear
10. Costs: unclear

Risk of bias

\begin{tabular}{l|ll}
\hline Item & Authors' judgement & Description \\
\hline Allocation concealment? & Unclear & B - Unclear \\
\hline
\end{tabular}




\begin{tabular}{|c|c|}
\hline Methods & $\begin{array}{l}\text { DESIGN: parallel study, } 2 \times 2 \text { factorial design, patients randomised for both acarbose and metformin versus } \\
\text { placebo } \\
\text { RANDOMISATION PROCEDURE: unclear } \\
\text { BLINDING: double-blind } \\
\text { DURATION: } 6 \text { years (treatment and follow-up) }\end{array}$ \\
\hline Participants & $\begin{array}{l}\text { COUNTRY: United Kingdom } \\
\text { SETTING: unclear } \\
\text { RECRUITMENT: unclear, 'self-referred' } \\
\text { DIAGNOSTIC CRITERIA: Patients 'at risk' for developing diabetes, Fasting BG 5.5-7.7 mmol/L } \\
\text { NUMBER: recruited 671, randomised } 631 \\
\text { SEX: } 51 \% \text { Female, } 49 \% \text { Male } \\
\text { AGE (YEARS (MEAN (SD)): randomised patients 52,1 }(10,0) \\
\text { BMI (KG/M2 (MEAN (SD))): randomised patients } 28,6(4,5) \\
\text { GLYCATED HAEMOGLOBIN (\% (MEAN (SD))): all randomised patients } 5.9(0.5)\end{array}$ \\
\hline Interventions & $\begin{array}{l}\text { Dietary advice: unclear } \\
\text { 2X2 Factorial design, four possible treatments: } \\
\text { AGI: acarbose } 50 \mathrm{mg} \text { TID + placebo TID } \\
\text { CONTROL1: placebo TID + placebo TID } \\
\text { CONTROL2: metformin } 500 \mathrm{mg} \text { TID + placebo TID } \\
\text { CONTROL3: metformin } 500 \mathrm{mg} \text { TID + acarbose } 50 \mathrm{mg} \text { TID }\end{array}$ \\
\hline
\end{tabular}

1. Mortality: unclear
2. Complications related to hyperglycemia: progression to type 2 diabetes
3. Quality of Life: yes
4. Glycaemic control: fasting BG
5. Lipids: 'lipid profiles'
6. Insulin levels: beta-cell function and insulin sensitivity
7. Weight: body weight
8. Blood pressure: unclear
9. Adverese effects: unclear
10. Costs: unclear

Because we planned to investigate AGI monotherapy, we will not consider the outcomes for the combination group (acarbose + metformin)

Sponsor: funded by an educational grant from Bayer and Merck-Lipha

Author contacted: study currently submitted for publication, the manuscript will be made accessible when the galley proof is available.

Study retrieved: databases of ongoing studies, handsearching, experts

\section{Risk of bias}

\begin{tabular}{l|ll}
\hline Item & Authors' judgement & Description \\
\hline Allocation concealment? & Unclear & B - Unclear \\
\hline
\end{tabular}


Fang 2004

\begin{tabular}{|c|c|c|}
\hline Methods & \multicolumn{2}{|c|}{$\begin{array}{l}\text { DESIGN: parallel } \\
\text { RANDOMISATION PROCEDURE: adequate } \\
\text { BLINDING: no mention of blinding or use of placebo } \\
\text { DURATION: } 5 \text { years (treatment and follow-up) }\end{array}$} \\
\hline Participants & \multicolumn{2}{|c|}{$\begin{array}{l}\text { COUNTRY: China } \\
\text { SETTING: unclear } \\
\text { RECRUITMENT: selected volunteers, details missing } \\
\text { DIAGNOSTIC CRITERIA: IGT according to WHO } 1985 \\
\text { NUMBER: } 549 \text { volunteers screened; } 178 \text { cases of IGT included: AGI 50, CONTROL1 40, CONTROL2 } \\
\text { 48, CONTROL3 40; analysed AGI 45, CONTROL1 35, CONTROL2 44, CONTROL3 } 36 \\
\text { SEX (F/M): AGI 22/28, CONTROL1 18/22, CONTROL2 22/26, CONTROL3 22/18 } \\
\text { AGE (YEARS (MEAN (SD)): analysed patients: AGI } 50 \text { (7), CONTROL1 } 47 \text { (14), CONTROL2 } 50 \\
\text { (7), CONTROL3 } 49 \text { (6) } \\
\text { BMI (KG/M2 (MEAN (SD))): analysed patients: AGI 24.9 (2.1), CONTROL1 } 24.8 \text { (2.5), CONTROL2 } \\
\text { 25.2 (2.8), CONTROL3 25.3 (1.9) } \\
\text { GLYCATED HAEMOGLOBIN: ND }\end{array}$} \\
\hline Interventions & \multicolumn{2}{|c|}{$\begin{array}{l}\text { Dietary advice: unclear } \\
\text { AGI: acarbose } 25-50 \mathrm{mg} \text { TID } \\
\text { CONTROL1: no treatment (common diabetes prevention education) } \\
\text { CONTROL2: flumamine (= metformin) } 125-250 \mathrm{mg} \text { TID } \\
\text { CONTROL3: Diet and exercise: Education and dietary advice and exercise based on personal situation }\end{array}$} \\
\hline Outcomes & \multicolumn{2}{|c|}{$\begin{array}{l}\text { 1. Mortality: ND } \\
\text { 2. Complications related to hyperglycaemia: incidence of type } 2 \text { diabetes } \\
\text { 3. Quality of Life: ND } \\
\text { 4. Glycaemic control: fasting and 2-hours post-prandial blood glucose } \\
\text { 5. Lipids: total cholesterol \& triglycerides } \\
\text { 6. Insulin levels: ND } \\
\text { 7. Weight: BMI } \\
\text { 8. Blood pressure: systolic \& diastolic blood pressure } \\
\text { 9. Adverse effects: ND } \\
\text { 10. Costs: ND }\end{array}$} \\
\hline Notes & \multicolumn{2}{|l|}{$\begin{array}{l}\text { Sponsor: unclear } \\
\text { Author contacted: yes, no reply } \\
\text { Study retrieved: EMBASE }\end{array}$} \\
\hline \multicolumn{3}{|l|}{ Risk of bias } \\
\hline Item & Authors' judgement & Description \\
\hline Allocation concealment? & Unclear & B - Unclear \\
\hline
\end{tabular}




\section{STOP-NIDDM}

\begin{tabular}{|c|c|c|}
\hline Methods & \multicolumn{2}{|c|}{$\begin{array}{l}\text { DESIGN: parallel study } \\
\text { RANDOMISATION PROCEDURE: adequate } \\
\text { BLINDING: double-blind } \\
\text { DURATION: mean } 3.3 \text { years (SD 1.5) treatment period, followed by a three months wash out period }\end{array}$} \\
\hline Participants & \multicolumn{2}{|c|}{$\begin{array}{l}\text { COUNTRIES: Canada, Germany, Austria, Norway, Denmark, Sweden, Finland, Israel, Spain } \\
\text { SETTING: Outpatients } \\
\text { RECRUITMENT: through screening of high-risk populations, and in particular from first degree relative } \\
\text { of patients with type } 2 \text { diabetes } \\
\text { DIAGNOSTIC CRITERIA: IGT (WHO 1999): } 2 \text { hour BG >=7.8 and < } 11.1 \mathrm{mmol} / \mathrm{L} \text { and fasting BC } \\
\text { >=5.6 and <7.8 mmol/L } \\
\text { NUMBER: randomised 1429, analysed } 1368 \text { (AGI 682, CONTROL 686); medication discontinuation } \\
\text { AGI 230/682, CONTROL 130/686 } \\
\text { SEX (F/M): analysed group AGI 353/329, CONTROL } 342 / 344 \\
\text { AGE (YEARS (MEAN (SD)): analysed patients: AGI } 54.3(7.9) \text {, CONTROL } 54.6(7.9) \\
\text { BMI (KG/M2 (MEAN (SD))): analysed patients: AGI } 31.0(4.3) \text {, CONTROL } 30.9(4.2) \\
\text { GLYCATED HAEMOGLOBIN (\% (MEAN (SD))): analysed patients: AGI } 5.24(0.74) \text {, CONTROI } \\
\text { 5.24 (0.78) }\end{array}$} \\
\hline Interventions & \multicolumn{2}{|c|}{$\begin{array}{l}\text { Dietary advice: all patients were instructed to go on a weight-reduction or weight-maintenance diet anc } \\
\text { were encouraged to exercise regularly; these instructions were reinforced at each visit } \\
\text { AGI: acabose, started with } 50 \mathrm{mg} \text { (once daily) and uptitrated to } 100 \mathrm{mg} \text { TID or maximum tolerated dose } \\
\text { Mean daily dose } 194 \mathrm{mg} \text { (SD 87) } \\
\text { CONTROL: placebo, dosage adjusted similar to acarbose, 'mean daily dose' was } 238 \mathrm{mg} \text { (SD missing) }\end{array}$} \\
\hline Outcomes & \multicolumn{2}{|c|}{$\begin{array}{l}\text { 1. Mortality: yes } \\
\text { 2. Complications related to hyperglycaemia: incidence of diabetes \& cardiovascular events } \\
\text { 3. Quality of Life: ND } \\
\text { 4. Glycaemic control: glycated haemoglobin, fasting \& post-load blood glucose } \\
\text { 5. Lipids: Total-, HDL \& LDL-cholesterol, triglycerides } \\
\text { 6. Insulin levels: fasting \& post-load insulin } \\
\text { 7. Weight: body weight, BMI } \\
\text { 8. Blood pressure: Diastolic \& Systolic blood pressure, occurrence of hypertension } \\
\text { 9. Adverse effects: yes } \\
\text { 10. Costs: ND }\end{array}$} \\
\hline Notes & \multicolumn{2}{|c|}{$\begin{array}{l}\text { Sponsor: Bayer, manufacturer of acarbose } \\
\text { Author contacted: additional data sent by author } \\
\text { Study retrieved: PUBMED, CENTRAL, EMBASE, WOS, Handsearch, manufacturer }\end{array}$} \\
\hline \multicolumn{3}{|l|}{ Risk of bias } \\
\hline Item & Authors' judgement & Description \\
\hline Allocation concealment? & Yes & A - Adequate \\
\hline
\end{tabular}




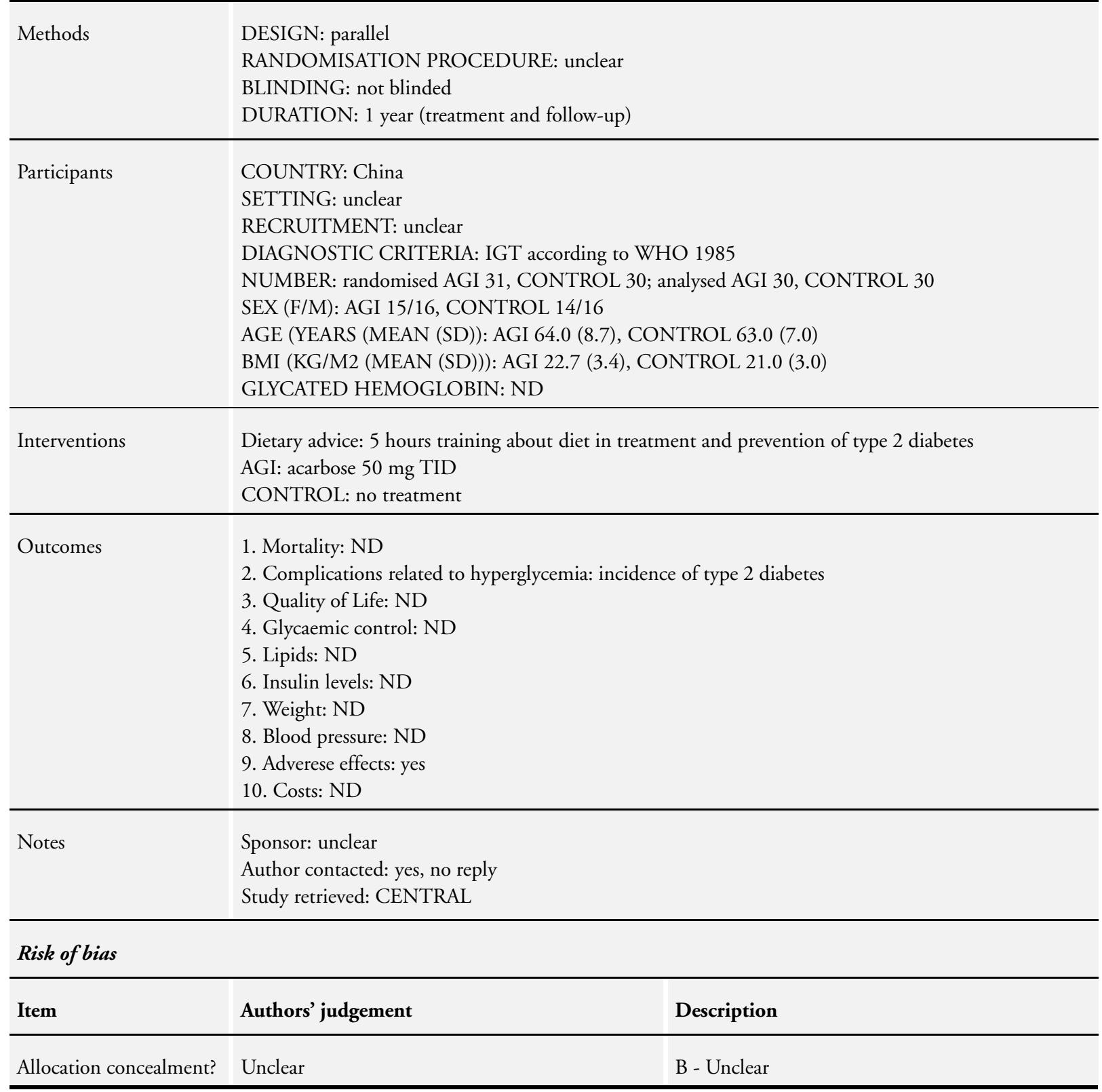

BG = Blood Glucose; BID = Bis In Die (twice daily); BMI = Body Mass Index; IGT = Impaired Glucose Tolerance; ITT = Intention

To Treat Population; ND = No Data; OD = once daily; OGTT = Oral Glucose Tolerance Test; PP = Per Protocol Population; TID

$=$ Ter In Die (three times a day) 
Characteristics of excluded studies [ordered by study ID]

\begin{tabular}{ll}
\hline Study & Reason for exclusion \\
\hline EDIP & All enrolled subjects have type 2 diabetes (as defined by a 2-hours post load plasma glucose $>=11.1 \mathrm{mmol} / \mathrm{L})$ \\
\hline Mangiagli 2004 & Study was not randomised \\
\hline Yang 2001 & $\begin{array}{l}\text { No mention of randomisation in the translated manuscript. Attempts to contact the authors failed (e-mails were } \\
\text { rejected) }\end{array}$ \\
\hline
\end{tabular}

\section{Characteristics of ongoing studies [ordered by study ID]}

\section{ABC-Study}

\begin{tabular}{ll} 
Trial name or title & $\begin{array}{l}\text { Alpha-Glucosidase-Inhibitor Blocks Cardiac Events in Patients With Myocardial Infarction and IGT (ABC } \\
\text { Study) }\end{array}$ \\
\hline Methods & Patients with IGT and old myocardial infarction. \\
\hline Participants & acarbose versus standard diet and exercise treatment \\
\hline Interventions & $\begin{array}{l}\text { Primary outcomes: } 1 \text { cardiovascular mortality; } 2 \text { hospitalisation due to cardiovascular events; Secondary } \\
\text { outcomes: } 1 \text { all cause mortality; } 2 \text { hospitalisation due to coronary artery disease; } 3 \text { progression of IGT to } \\
\text { diabetes; } 4 \text { development or deterioration of either hypertension or hyperlipidaemia; } 5 \text { deterioration of renal } \\
\text { function; } 6 \text { hospitalisation due to cerebrovascular disease; } 7 \text { hospitalisation due to heart failure }\end{array}$ \\
\hline Outcomes & April 2005; last follow-up April 2009 \\
\hline Starting date & $\begin{array}{l}\text { Masafumi Kitakaze MD, PhD } \\
\text { Tel: } 81-6-6833-5012 \text { ext.: } 2225 \text { kitakaze@ } e_{\text {zf6.so-net.ne.jp }}\end{array}$ \\
\hline Contact information & \\
\hline Notes & \\
\hline
\end{tabular}

Tamita 2006

Trial name or title Acarbose and Secondary Prevention After Coronary Stenting

\begin{tabular}{ll}
\hline Methods & \\
\hline Participants & patients with abnormal glucose tolerance and coronary artery disease \\
\hline Interventions & acarbose versus standard lifestyle modification
\end{tabular}


Tamita 2006 (Continued)

Outcomes $\quad$ Primary outcome: cardiovascular event free survival time. Secondary outcomes: 1 conversion of abnormal glucose tolerance to type 2 diabetes; 2 all cause of death; 3 occurrence of every cardiovascular event; 4 occurrence of in-stent restenosis; 5 regression of intimal plus medial complex of the carotid artery; 6 change in fasting, 2-hour blood glucose and insulin level; 7 change in homeostasis model assessment of insulin resistance; 8 change in HbA1c; 9 change in lipid profile

\begin{tabular}{ll}
\hline Starting date & May 2005; last follow-up April 2013 \\
\hline Contact information & $\begin{array}{l}\text { Koichi Tamita MD } \\
\text { Tel: }+81-78-304-4321 \text { k-tamita@kcgh.gr.jp }\end{array}$ \\
\hline Notes & \\
\hline
\end{tabular}


DATA AND ANALYSES

\section{Comparison 1. Acarbose versus placebo}

$\begin{array}{llccc}\text { Outcome or subgroup title } & \begin{array}{l}\text { No. of } \\ \text { studies }\end{array} & \begin{array}{c}\text { No. of } \\ \text { participants }\end{array} & \text { Statistical method } & \text { Effect size }\end{array}$

\begin{tabular}{|c|c|c|c|}
\hline $\begin{array}{l}1 \text { Incidence of type } 2 \text { diabetes } \\
\text { mellitus }\end{array}$ & 1 & Odds Ratio (M-H, Random, 95\% CI) & Totals not selected \\
\hline 1.1 Acarbose 100 mg TID & 1 & Odds Ratio (M-H, Random, 95\% CI) & Not estimable \\
\hline 2 Occurrence of death (total) & 1 & Odds Ratio (M-H, Random, 95\% CI) & Totals not selected \\
\hline 2.1 Acarbose $100 \mathrm{mg}$ TID & 1 & Odds Ratio (M-H, Random, 95\% CI) & Not estimable \\
\hline $\begin{array}{l}3 \text { Occurrence of cardiovascular } \\
\text { death }\end{array}$ & 1 & Odds Ratio (M-H, Random, 95\% CI) & Totals not selected \\
\hline 3.1 Acarbose $100 \mathrm{mg}$ TID & 1 & Odds Ratio (M-H, Random, 95\% CI) & Not estimable \\
\hline $\begin{array}{l}4 \text { Occurrence of cardiovascular } \\
\text { disease (any) }\end{array}$ & 1 & Odds Ratio (M-H, Random, 95\% CI) & Totals not selected \\
\hline 4.1 Acarbose $100 \mathrm{mg}$ TID & 1 & Odds Ratio (M-H, Random, 95\% CI) & Not estimable \\
\hline $\begin{array}{l}5 \text { Occurrence of myocardial } \\
\text { infarctions }\end{array}$ & 1 & Odds Ratio (M-H, Random, 95\% CI) & Totals not selected \\
\hline 5.1 Acarbose $100 \mathrm{mg}$ TID & 1 & Odds Ratio (M-H, Random, 95\% CI) & Not estimable \\
\hline 6 Occurrence of angina pectoris & 1 & Odds Ratio (M-H, Random, 95\% CI) & Totals not selected \\
\hline 6.1 Acarbose $100 \mathrm{mg}$ TID & 1 & Odds Ratio (M-H, Random, 95\% CI) & Not estimable \\
\hline $\begin{array}{l}7 \text { Occurrence of revascularisation } \\
\text { procedures }\end{array}$ & 1 & Odds Ratio (M-H, Random, 95\% CI) & Totals not selected \\
\hline 7.1 Acarbose 100 mg TID & 1 & Odds Ratio (M-H, Random, 95\% CI) & Not estimable \\
\hline $\begin{array}{l}8 \text { Occurrence of congestive heart } \\
\text { failure }\end{array}$ & 1 & Odds Ratio (M-H, Random, 95\% CI) & Totals not selected \\
\hline 8.1 Acarbose $100 \mathrm{mg}$ TID & 1 & Odds Ratio (M-H, Random, 95\% CI) & Not estimable \\
\hline $\begin{array}{l}9 \text { Occurrence of cerebrovascular } \\
\text { events }\end{array}$ & 1 & Odds Ratio (M-H, Random, 95\% CI) & Totals not selected \\
\hline 9.1 Acarbose $100 \mathrm{mg}$ TID & 1 & Odds Ratio (M-H, Random, 95\% CI) & Not estimable \\
\hline $\begin{array}{l}10 \text { Occurrence of peripheral } \\
\text { vascular events }\end{array}$ & 1 & Odds Ratio (M-H, Random, 95\% CI) & Totals not selected \\
\hline 10.1 Acarbose $100 \mathrm{mg}$ TID & 1 & Odds Ratio (M-H, Random, 95\% CI) & Not estimable \\
\hline $\begin{array}{l}11 \text { Change in glycated } \\
\text { haemoglobin (\%) }\end{array}$ & 1 & Mean Difference (IV, Random, 95\% CI) & Totals not selected \\
\hline 11.1 Acarbose $100 \mathrm{mg}$ TID & 1 & Mean Difference (IV, Random, 95\% CI) & Not estimable \\
\hline $\begin{array}{l}12 \text { Change in fasting blood glucose } \\
(\mathrm{mmol} / \mathrm{l})\end{array}$ & 1 & Mean Difference (IV, Random, 95\% CI) & Totals not selected \\
\hline 12.1 Acarbose $100 \mathrm{mg}$ TID & 1 & Mean Difference (IV, Random, 95\% CI) & Not estimable \\
\hline $\begin{array}{l}13 \text { Change in post-load blood } \\
\text { glucose }(\mathrm{mmol} / \mathrm{l})\end{array}$ & 1 & Mean Difference (IV, Random, 95\% CI) & Totals not selected \\
\hline 13.1 Acarbose $100 \mathrm{mg}$ TID & 1 & Mean Difference (IV, Random, 95\% CI) & Not estimable \\
\hline $\begin{array}{l}14 \text { Change in total cholesterol } \\
(\mathrm{mmol} / \mathrm{l})\end{array}$ & 1 & Mean Difference (IV, Random, 95\% CI) & Totals not selected \\
\hline 14.1 Acarbose $100 \mathrm{mg}$ TID & 1 & Mean Difference (IV, Random, 95\% CI) & Not estimable \\
\hline $\begin{array}{l}15 \text { Change in HDL-cholesterol } \\
(\mathrm{mmol} / \mathrm{l})\end{array}$ & 1 & Mean Difference (IV, Random, 95\% CI) & Totals not selected \\
\hline
\end{tabular}

Alpha-glucosidase inhibitors for people with impaired glucose tolerance or impaired fasting blood glucose (Review) 
15.1 Acarbose 100 mg TID

16 Change in LDL-cholesterol $(\mathrm{mmol} / \mathrm{l})$

16.1 Acarbose $100 \mathrm{mg}$ TID 1

17 Change in triglycerides $(\mathrm{mmol} / \mathrm{l})$

17.1 Acarbose $100 \mathrm{mg}$ TID

18 Change in fasting insulin levels (pmol/l)

18.1 Acarbose $100 \mathrm{mg}$ TID 1

19 Change in post-load insulin 1 levels (pmol/l)

19.1 Acarbose $100 \mathrm{mg}$ TID 1

20 Change in body weight $(\mathrm{Kg}) \quad 1$

20.1 Acarbose $100 \mathrm{mg}$ TID 1

21 Change in body mass index 1

$(\mathrm{Kg} / \mathrm{m} 2)$

21.1 Acarbose $100 \mathrm{mg}$ TID 1

22 Change in diastolic blood 1 pressure $(\mathrm{mmHg})$

22.1 Acarbose $100 \mathrm{mg}$ TID $\quad 1$

23 Change in systolic blood $\quad 1$

pressure $(\mathrm{mmHg})$ 23.1 Acarbose $100 \mathrm{mg}$ TID 1

24 Occurrence of side effects $\quad 1$ (total)

24.1 Acarbose $100 \mathrm{mg}$ TID 1

25 Occurrence of gastro-intestinal 1 side-effects

25.1 Acarbose $100 \mathrm{mg}$ TID $\quad 1$
Mean Difference (IV, Random, 95\% CI)

Mean Difference (IV, Random, 95\% CI)

Mean Difference (IV, Random, 95\% CI)

Mean Difference (IV, Random, 95\% CI)

Mean Difference (IV, Random, 95\% CI)

Mean Difference (IV, Random, 95\% CI)

Mean Difference (IV, Random, 95\% CI)

Mean Difference (IV, Random, 95\% CI)

Mean Difference (IV, Random, 95\% CI)

Mean Difference (IV, Random, 95\% CI)

Mean Difference (IV, Random, 95\% CI)

Mean Difference (IV, Random, 95\% CI)

Mean Difference (IV, Random, 95\% CI)

Mean Difference (IV, Random, 95\% CI)

Mean Difference (IV, Random, 95\% CI)

Mean Difference (IV, Random, 95\% CI)

Mean Difference (IV, Random, 95\% CI)

Odds Ratio (M-H, Random, 95\% CI)

Odds Ratio (M-H, Random, 95\% CI)

Odds Ratio (M-H, Random, 95\% CI)

Odds Ratio (M-H, Random, 95\% CI)
Not estimable

Totals not selected

Not estimable

Totals not selected

Not estimable

Totals not selected

Not estimable

Totals not selected

Not estimable

Totals not selected

Not estimable

Totals not selected

Not estimable

Totals not selected

Not estimable

Totals not selected

Not estimable

Totals not selected

Not estimable

Totals not selected

Not estimable

\section{Comparison 2. Acarbose versus metformin}

\begin{tabular}{|c|c|c|c|c|}
\hline Outcome or subgroup title & $\begin{array}{l}\text { No. of } \\
\text { studies }\end{array}$ & $\begin{array}{c}\text { No. of } \\
\text { participants }\end{array}$ & Statistical method & Effect size \\
\hline $\begin{array}{l}1 \text { Incidence of type } 2 \text { diabetes } \\
\text { mellitus }\end{array}$ & 1 & & Odds Ratio (M-H, Random, 95\% CI) & Totals not selected \\
\hline 1.1 Acarbose $100 \mathrm{mg}$ TID & 1 & & Odds Ratio (M-H, Random, 95\% CI) & Not estimable \\
\hline $\begin{array}{l}2 \text { Change in fasting blood glucose } \\
(\mathrm{mmol} / \mathrm{l})\end{array}$ & 1 & & Mean Difference (IV, Random, 95\% CI) & Totals not selected \\
\hline 2.1 Acarbose $100 \mathrm{mg}$ TID & 1 & & Mean Difference (IV, Random, 95\% CI) & Not estimable \\
\hline $\begin{array}{l}3 \text { Change in post-load blood } \\
\text { glucose }(\mathrm{mmol} / \mathrm{l})\end{array}$ & 1 & & Mean Difference (IV, Random, 95\% CI) & Totals not selected \\
\hline 3.1 Acarbose $100 \mathrm{mg}$ TID & 1 & & Mean Difference (IV, Random, 95\% CI) & Not estimable \\
\hline $\begin{array}{l}4 \text { Change in total cholesterol } \\
\qquad(\mathrm{mmol} / \mathrm{l})\end{array}$ & 1 & & Mean Difference (IV, Random, 95\% CI) & Totals not selected \\
\hline 4.1 Acarbose $100 \mathrm{mg}$ TID & 1 & & Mean Difference (IV, Random, 95\% CI) & Not estimable \\
\hline 5 Change in triglycerides $(\mathrm{mmol} / \mathrm{l})$ & 1 & & Mean Difference (IV, Random, 95\% CI) & Totals not selected \\
\hline
\end{tabular}




\begin{tabular}{|c|c|c|c|}
\hline 5.1 Acarbose $100 \mathrm{mg}$ TID & 1 & Mean Difference (IV, Random, 95\% CI) & Not estimable \\
\hline $\begin{array}{l}6 \text { Change in body mass index } \\
(\mathrm{Kg} / \mathrm{m} 2)\end{array}$ & 1 & Mean Difference (IV, Random, 95\% CI) & Totals not selected \\
\hline 6.1 Acarbose $100 \mathrm{mg}$ TID & 1 & Mean Difference (IV, Random, 95\% CI) & Not estimable \\
\hline $\begin{array}{l}7 \text { Change in diastolic blood } \\
\text { pressure }(\mathrm{mmHg})\end{array}$ & 1 & Mean Difference (IV, Random, 95\% CI) & Totals not selected \\
\hline 7.1 Acarbose $100 \mathrm{mg}$ TID & 1 & Mean Difference (IV, Random, 95\% CI) & Not estimable \\
\hline $\begin{array}{l}8 \text { Change in systolic blood pressure } \\
(\mathrm{mmHg})\end{array}$ & 1 & Mean Difference (IV, Random, 95\% CI) & Totals not selected \\
\hline 8.1 Acarbose $100 \mathrm{mg}$ TID & 1 & Mean Difference (IV, Random, 95\% CI) & Not estimable \\
\hline
\end{tabular}

Comparison 3. Acarbose versus diet and exercise

\begin{tabular}{|c|c|c|c|c|}
\hline Outcome or subgroup title & $\begin{array}{l}\text { No. of } \\
\text { studies }\end{array}$ & $\begin{array}{c}\text { No. of } \\
\text { participants }\end{array}$ & Statistical method & Effect size \\
\hline $\begin{array}{l}1 \text { Incidence of type } 2 \text { diabetes } \\
\text { mellitus }\end{array}$ & 1 & & Odds Ratio (M-H, Random, 95\% CI) & Totals not selected \\
\hline 1.1 Acarbose $100 \mathrm{mg}$ TID & 1 & & Odds Ratio (M-H, Random, 95\% CI) & Not estimable \\
\hline $\begin{array}{l}2 \text { Change in fasting blood glucose } \\
(\mathrm{mmol} / \mathrm{l})\end{array}$ & 1 & & Mean Difference (IV, Random, 95\% CI) & Totals not selected \\
\hline 2.1 Acarbose $100 \mathrm{mg}$ TID & 1 & & Mean Difference (IV, Random, 95\% CI) & Not estimable \\
\hline $\begin{array}{l}3 \text { Change in post-load blood } \\
\text { glucose }(\mathrm{mmol} / \mathrm{l})\end{array}$ & 1 & & Mean Difference (IV, Random, 95\% CI) & Totals not selected \\
\hline 3.1 Acarbose $100 \mathrm{mg}$ TID & 1 & & Mean Difference (IV, Random, 95\% CI) & Not estimable \\
\hline $\begin{array}{l}4 \text { Change in total cholesterol } \\
(\mathrm{mmol} / \mathrm{l})\end{array}$ & 1 & & Mean Difference (IV, Random, 95\% CI) & Totals not selected \\
\hline 4.1 Acarbose $100 \mathrm{mg}$ TID & 1 & & Mean Difference (IV, Random, 95\% CI) & Not estimable \\
\hline 5 Change in triglycerides $(\mathrm{mmol} / \mathrm{l})$ & 1 & & Mean Difference (IV, Random, 95\% CI) & Totals not selected \\
\hline 5.1 Acarbose $100 \mathrm{mg}$ TID & 1 & & Mean Difference (IV, Random, 95\% CI) & Not estimable \\
\hline $\begin{array}{l}6 \text { Change in body mass index } \\
\qquad(\mathrm{Kg} / \mathrm{m} 2)\end{array}$ & 1 & & Mean Difference (IV, Random, 95\% CI) & Totals not selected \\
\hline 6.1 Acarbose $100 \mathrm{mg}$ TID & 1 & & Mean Difference (IV, Random, 95\% CI) & Not estimable \\
\hline $\begin{array}{l}7 \text { Change in diastolic blood } \\
\text { pressure }(\mathrm{mmHg})\end{array}$ & 1 & & Mean Difference (IV, Random, 95\% CI) & Totals not selected \\
\hline 7.1 Acarbose $100 \mathrm{mg}$ TID & 1 & & Mean Difference (IV, Random, 95\% CI) & Not estimable \\
\hline $\begin{array}{l}8 \text { Change in systolic blood pressure } \\
(\mathrm{mmHg})\end{array}$ & 1 & & Mean Difference (IV, Random, 95\% CI) & Totals not selected \\
\hline 8.1 Acarbose $100 \mathrm{mg}$ TID & 1 & & Mean Difference (IV, Random, 95\% CI) & Not estimable \\
\hline
\end{tabular}




\begin{tabular}{|c|c|c|c|c|}
\hline Outcome or subgroup title & $\begin{array}{l}\text { No. of } \\
\text { studies }\end{array}$ & $\begin{array}{c}\text { No. of } \\
\text { participants }\end{array}$ & Statistical method & Effect size \\
\hline $\begin{array}{l}1 \text { Incidence of type } 2 \text { diabetes } \\
\text { mellitus }\end{array}$ & 2 & 140 & Odds Ratio (M-H, Random, 95\% CI) & $0.22[0.08,0.59]$ \\
\hline 1.1 Acarbose $100 \mathrm{mg}$ TID & 2 & 140 & Odds Ratio (M-H, Random, 95\% CI) & $0.22[0.08,0.59]$ \\
\hline $\begin{array}{l}2 \text { Change in fasting blood glucose } \\
(\mathrm{mmol} / \mathrm{l})\end{array}$ & 1 & & Mean Difference (IV, Random, 95\% CI) & Totals not selected \\
\hline 2.1 Acarbose $100 \mathrm{mg}$ TID & 1 & & Mean Difference (IV, Random, 95\% CI) & Not estimable \\
\hline $\begin{array}{l}3 \text { Change in post-load blood } \\
\text { glucose }(\mathrm{mmol} / \mathrm{l})\end{array}$ & 1 & & Mean Difference (IV, Random, 95\% CI) & Totals not selected \\
\hline 3.1 Acarbose $100 \mathrm{mg}$ TID & 1 & & Mean Difference (IV, Random, 95\% CI) & Not estimable \\
\hline $\begin{array}{l}4 \text { Change in total cholesterol } \\
(\mathrm{mmol} / \mathrm{l})\end{array}$ & 1 & & Mean Difference (IV, Random, 95\% CI) & Totals not selected \\
\hline 4.1 Acarbose $100 \mathrm{mg}$ TID & 1 & & Mean Difference (IV, Random, 95\% CI) & Not estimable \\
\hline 5 Change in triglycerides $(\mathrm{mmol} / \mathrm{l})$ & 1 & & Mean Difference (IV, Random, 95\% CI) & Totals not selected \\
\hline 5.1 Acarbose $100 \mathrm{mg}$ TID & 1 & & Mean Difference (IV, Random, 95\% CI) & Not estimable \\
\hline $\begin{array}{l}6 \text { Change in body mass index } \\
(\mathrm{Kg} / \mathrm{m} 2)\end{array}$ & 1 & & Mean Difference (IV, Random, 95\% CI) & Totals not selected \\
\hline 6.1 Acarbose $100 \mathrm{mg}$ TID & 1 & & Mean Difference (IV, Random, 95\% CI) & Not estimable \\
\hline $\begin{array}{l}7 \text { Change in diastolic blood } \\
\text { pressure }(\mathrm{mmHg})\end{array}$ & 1 & & Mean Difference (IV, Random, 95\% CI) & Totals not selected \\
\hline 7.1 Acarbose 100 mg TID & 1 & & Mean Difference (IV, Random, 95\% CI) & Not estimable \\
\hline $\begin{array}{l}8 \text { Change in systolic blood pressure } \\
(\mathrm{mmHg})\end{array}$ & 1 & & Mean Difference (IV, Random, 95\% CI) & Totals not selected \\
\hline 8.1 Acarbose $100 \mathrm{mg}$ TID & 1 & & Mean Difference (IV, Random, 95\% CI) & Not estimable \\
\hline 9 Occurrence of side effects (total) & 1 & & Odds Ratio (M-H, Random, 95\% CI) & Totals not selected \\
\hline 9.1 Acarbose $100 \mathrm{mg}$ TID & 1 & & Odds Ratio (M-H, Random, 95\% CI) & Not estimable \\
\hline $\begin{array}{l}10 \text { Occurrence of gastro-intestinal } \\
\text { side-effects }\end{array}$ & 1 & & Odds Ratio (M-H, Random, 95\% CI) & Totals not selected \\
\hline 10.1 Acarbose $100 \mathrm{mg}$ TID & 1 & & Odds Ratio (M-H, Random, 95\% CI) & Not estimable \\
\hline
\end{tabular}

\section{Analysis I.I. Comparison I Acarbose versus placebo, Outcome I Incidence of type 2 diabetes mellitus.}

Review: Alpha-glucosidase inhibitors for people with impaired glucose tolerance or impaired fasting blood glucose

Comparison: I Acarbose versus placebo

Outcome: I Incidence of type 2 diabetes mellitus

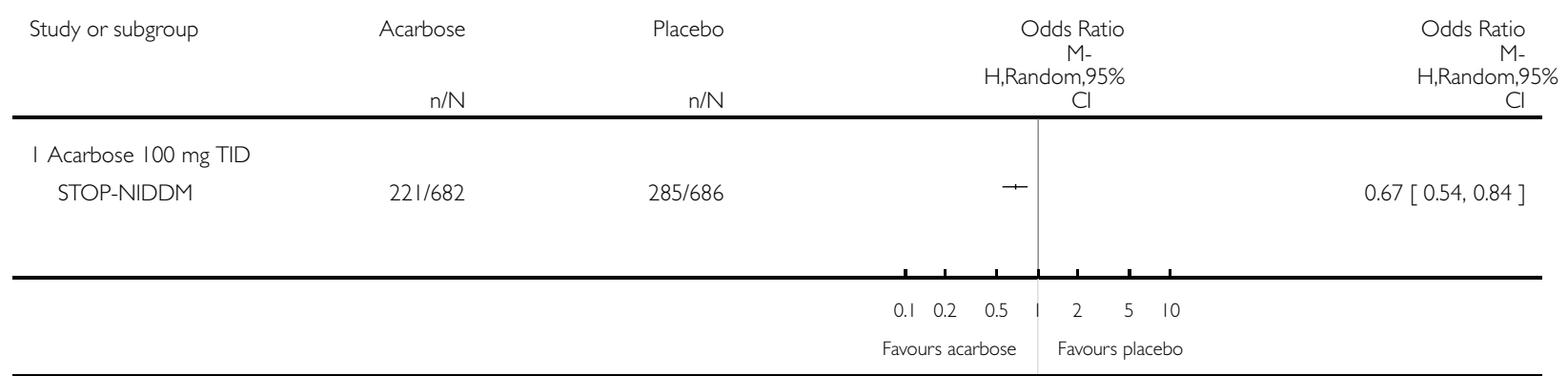


Analysis I.2. Comparison I Acarbose versus placebo, Outcome 2 Occurrence of death (total).

Review: Alpha-glucosidase inhibitors for people with impaired glucose tolerance or impaired fasting blood glucose

Comparison: I Acarbose versus placebo

Outcome: 2 Occurrence of death (total)

\begin{tabular}{|c|c|c|c|c|}
\hline Study or subgroup & $\begin{array}{r}\text { Acarbose } \\
n / N\end{array}$ & $\begin{array}{r}\text { Placebo } \\
n / N\end{array}$ & $\begin{array}{c}\text { Odds Ratio } \\
\text { M- } \\
\text { H,Random, } 95 \% \\
\text { Cl }\end{array}$ & $\begin{array}{c}\text { Odds Ratio } \\
\text { M- } \\
\text { H,Random,95\% } \\
\text { Cl }\end{array}$ \\
\hline \multicolumn{5}{|c|}{ I Acarbose 100 mg TID } \\
\hline STOP-NIDDM & $6 / 7 / 4$ & $3 / 7 \mid 5$ & 1 & $2.01[0.50,8.07]$ \\
\hline
\end{tabular}

Analysis I.3. Comparison I Acarbose versus placebo, Outcome 3 Occurrence of cardiovascular death.

Review: Alpha-glucosidase inhibitors for people with impaired glucose tolerance or impaired fasting blood glucose

Comparison: I Acarbose versus placebo

Outcome: 3 Occurrence of cardiovascular death

\begin{tabular}{|c|c|c|c|c|}
\hline Study or subgroup & $\begin{array}{r}\text { Acarbose } \\
n / N\end{array}$ & $\begin{array}{r}\text { Placebo } \\
\text { n/N }\end{array}$ & $\begin{array}{c}\text { Odds Ratio } \\
\text { M- } \\
\text { H,Random, } 95 \% \\
\text { Cl }\end{array}$ & $\begin{array}{l}\text { Odds Ratio } \\
\text { M- } \\
\text { H,Random,95\% } \\
\text { Cl }\end{array}$ \\
\hline \multicolumn{5}{|c|}{ I Acarbose 100 mg TID } \\
\hline STOP-NIDDM & $3 / 714$ & $2 / 7 / 5$ & 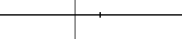 & $1.50[0.25,9.03]$ \\
\hline
\end{tabular}


Analysis I.4. Comparison I Acarbose versus placebo, Outcome 4 Occurrence of cardiovascular disease (any).

Review: Alpha-glucosidase inhibitors for people with impaired glucose tolerance or impaired fasting blood glucose

Comparison: I Acarbose versus placebo

Outcome: 4 Occurrence of cardiovascular disease (any)

\begin{tabular}{|c|c|c|c|c|}
\hline Study or subgroup & $\begin{array}{r}\text { Acarbose } \\
\mathrm{n} / \mathrm{N} \\
\end{array}$ & $\begin{array}{r}\text { Placebo } \\
\text { n/N }\end{array}$ & $\begin{array}{c}\text { Odds Ratio } \\
\text { M- } \\
\text { H,Random,95\% } \\
\mathrm{Cl}\end{array}$ & $\begin{array}{c}\text { Odds Ratio } \\
\text { M- } \\
\text { H,Random,95\% } \\
\text { Cl } \\
\end{array}$ \\
\hline \multicolumn{5}{|c|}{ I Acarbose 100 mg TID } \\
\hline STOP-NIDDM & I5/682 & $32 / 686$ & + & $0.46[0.25,0.86]$ \\
\hline
\end{tabular}

$\begin{array}{lllllll}0.1 & 0.2 & 0.5 & 1 & 2 & 5 & 10\end{array}$

Favours acarbose Favours placebo

Analysis I.5. Comparison I Acarbose versus placebo, Outcome 5 Occurrence of myocardial infarctions.

Review: Alpha-glucosidase inhibitors for people with impaired glucose tolerance or impaired fasting blood glucose

Comparison: I Acarbose versus placebo

Outcome: 5 Occurrence of myocardial infarctions

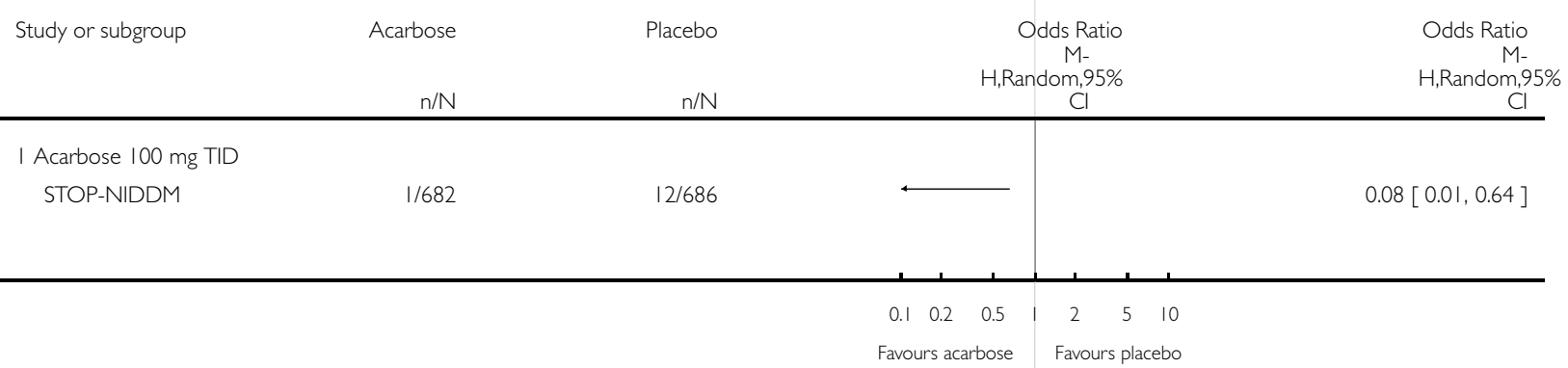


Analysis I.6. Comparison I Acarbose versus placebo, Outcome 6 Occurrence of angina pectoris.

Review: Alpha-glucosidase inhibitors for people with impaired glucose tolerance or impaired fasting blood glucose

Comparison: I Acarbose versus placebo

Outcome: 6 Occurrence of angina pectoris

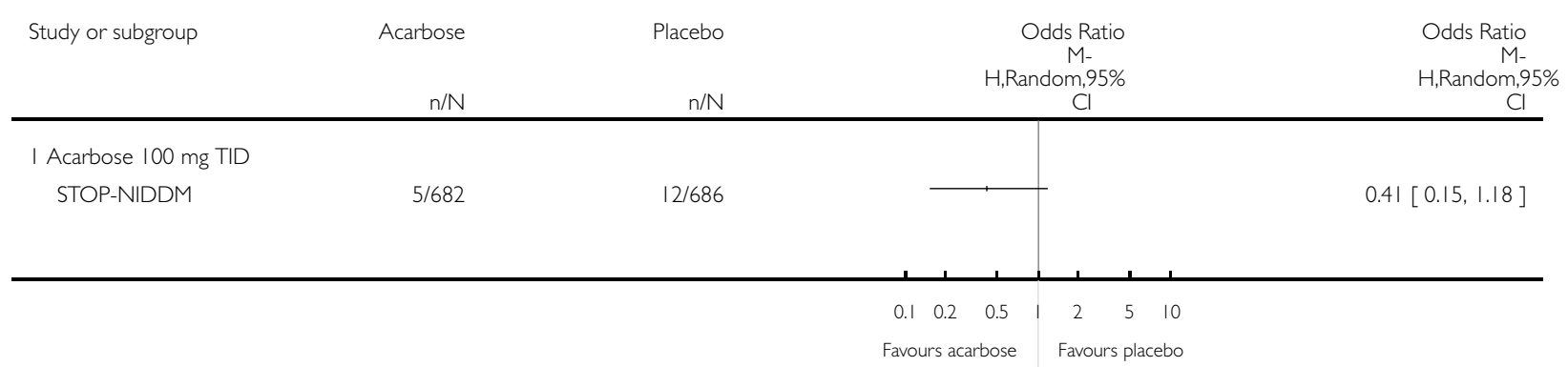

Analysis I.7. Comparison I Acarbose versus placebo, Outcome 7 Occurrence of revascularisation procedures.

Review: Alpha-glucosidase inhibitors for people with impaired glucose tolerance or impaired fasting blood glucose

Comparison: I Acarbose versus placebo

Outcome: 7 Occurrence of revascularisation procedures

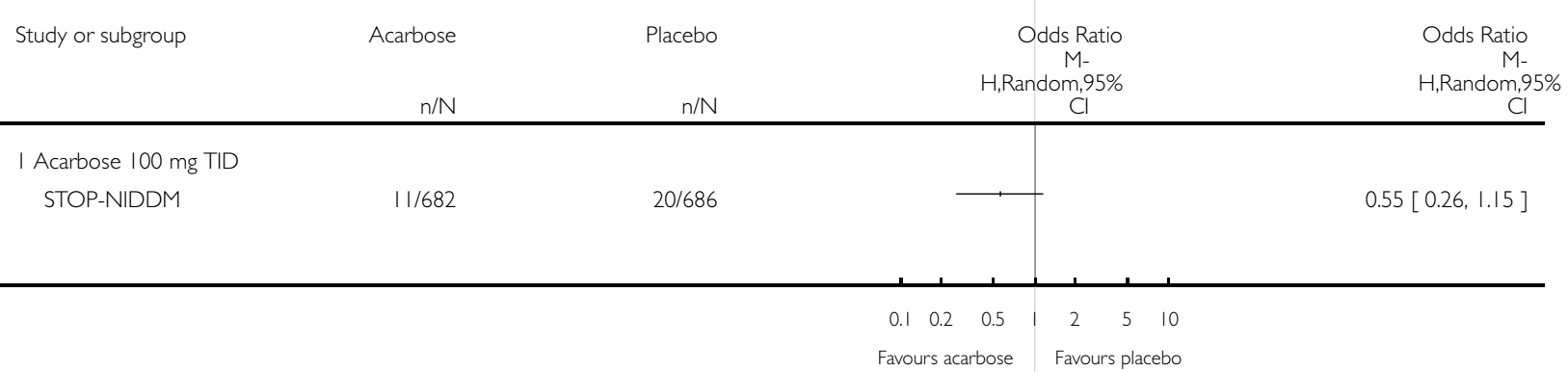


Analysis I.8. Comparison I Acarbose versus placebo, Outcome 8 Occurrence of congestive heart failure.

Review: Alpha-glucosidase inhibitors for people with impaired glucose tolerance or impaired fasting blood glucose

Comparison: I Acarbose versus placebo

Outcome: 8 Occurrence of congestive heart failure

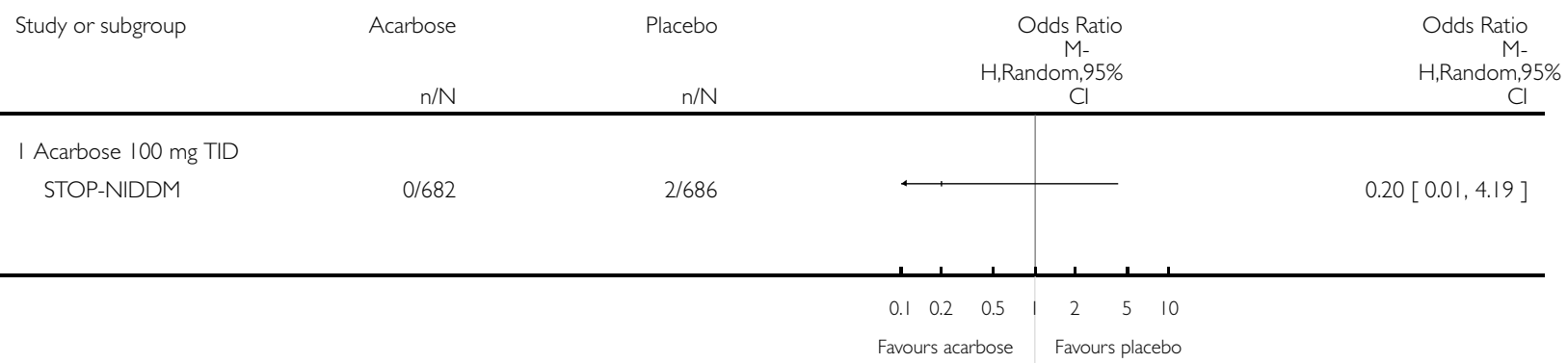

Analysis I.9. Comparison I Acarbose versus placebo, Outcome 9 Occurrence of cerebrovascular events.

Review: Alpha-glucosidase inhibitors for people with impaired glucose tolerance or impaired fasting blood glucose

Comparison: I Acarbose versus placebo

Outcome: 9 Occurrence of cerebrovascular events

\begin{tabular}{|c|c|c|c|c|}
\hline Study or subgroup & $\begin{array}{r}\text { Acarbose } \\
n / N\end{array}$ & $\begin{array}{r}\text { Placebo } \\
n / N\end{array}$ & $\begin{array}{r}\text { Odds Ratio } \\
\text { M- } \\
\text { H,Random,95\% } \\
\mathrm{Cl}\end{array}$ & $\begin{array}{c}\text { Odds Ratio } \\
\text { M- } \\
\text { H,Random,95\% } \\
\text { Cl }\end{array}$ \\
\hline \multicolumn{5}{|c|}{ I Acarbose 100 mg TID } \\
\hline STOP-NIDDM & $2 / 682$ & $4 / 686$ & 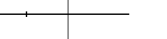 & $0.50[0.09,2.75]$ \\
\hline
\end{tabular}

$\begin{array}{lllllll}0.1 & 0.2 & 0.5 & 1 & 2 & 5 & 10\end{array}$

Favours acarbose Favours placebo 
Analysis I.10. Comparison I Acarbose versus placebo, Outcome 10 Occurrence of peripheral vascular events.

Review: Alpha-glucosidase inhibitors for people with impaired glucose tolerance or impaired fasting blood glucose

Comparison: I Acarbose versus placebo

Outcome: 10 Occurrence of peripheral vascular events

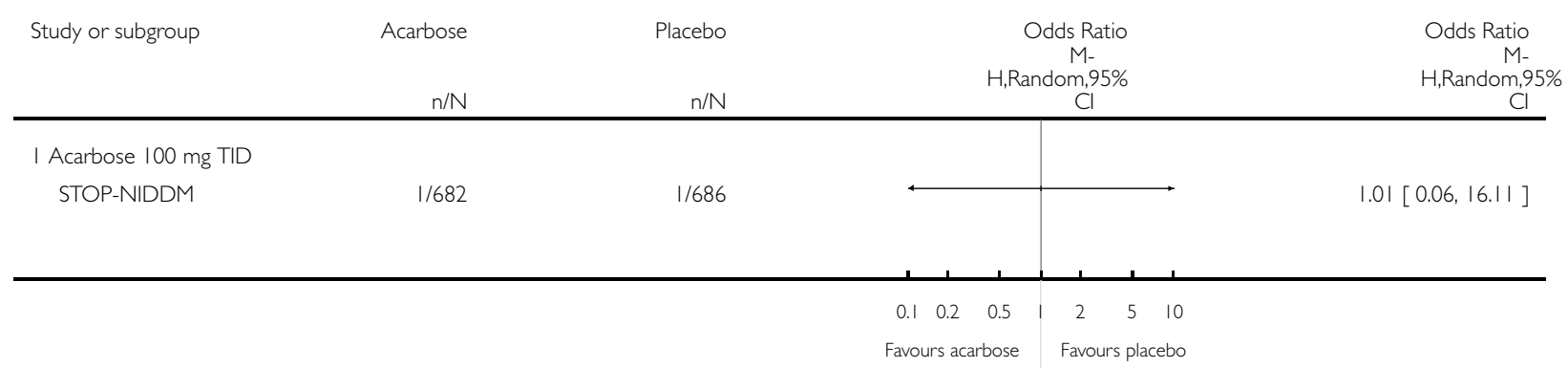

Analysis I.I I. Comparison I Acarbose versus placebo, Outcome I I Change in glycated haemoglobin (\%).

Review: Alpha-glucosidase inhibitors for people with impaired glucose tolerance or impaired fasting blood glucose

Comparison: I Acarbose versus placebo

Outcome: II Change in glycated haemoglobin (\%)

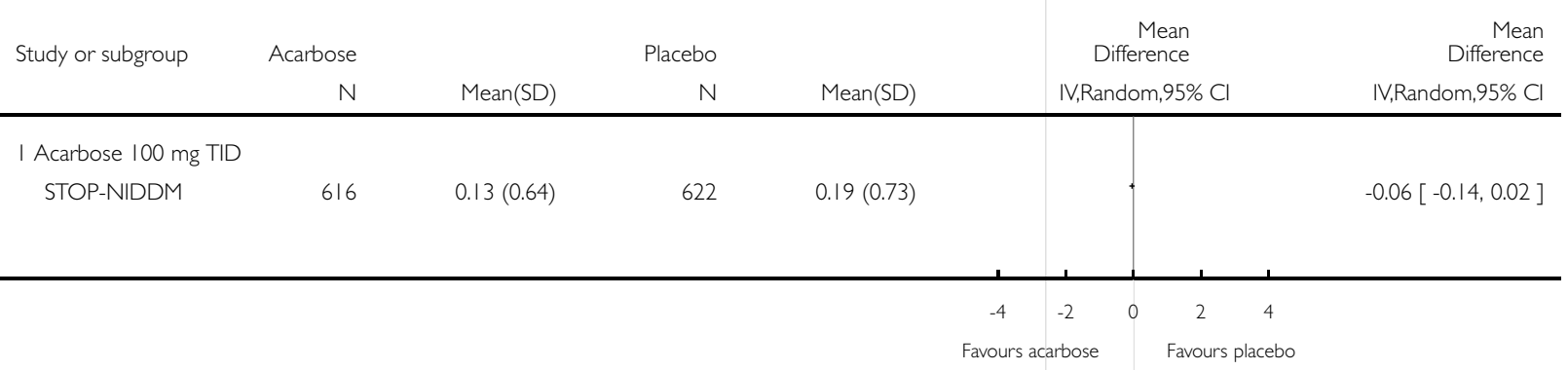


Analysis I.12. Comparison I Acarbose versus placebo, Outcome I 2 Change in fasting blood glucose (mmol/l).

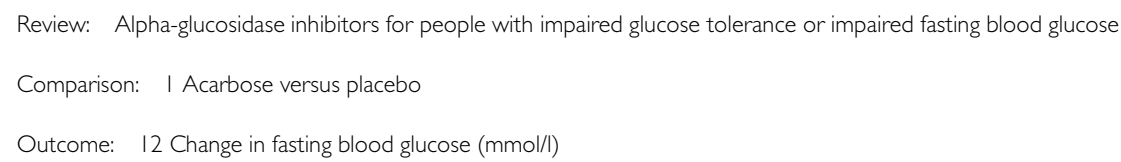

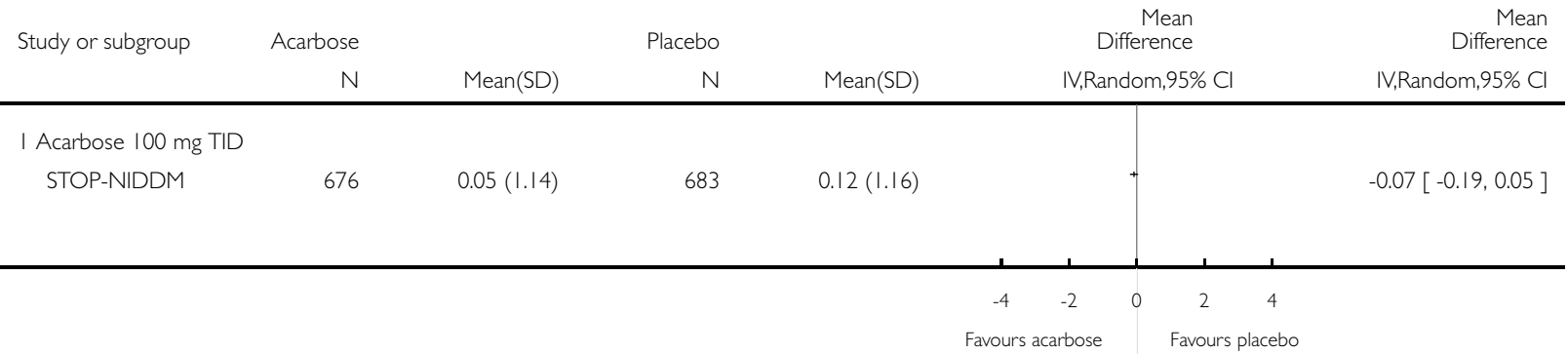

Analysis I.13. Comparison I Acarbose versus placebo, Outcome 13 Change in post-load blood glucose (mmol/l).

Review: Alpha-glucosidase inhibitors for people with impaired glucose tolerance or impaired fasting blood glucose

Comparison: I Acarbose versus placebo

Outcome: 13 Change in post-load blood glucose $(\mathrm{mmol} / \mathrm{l})$

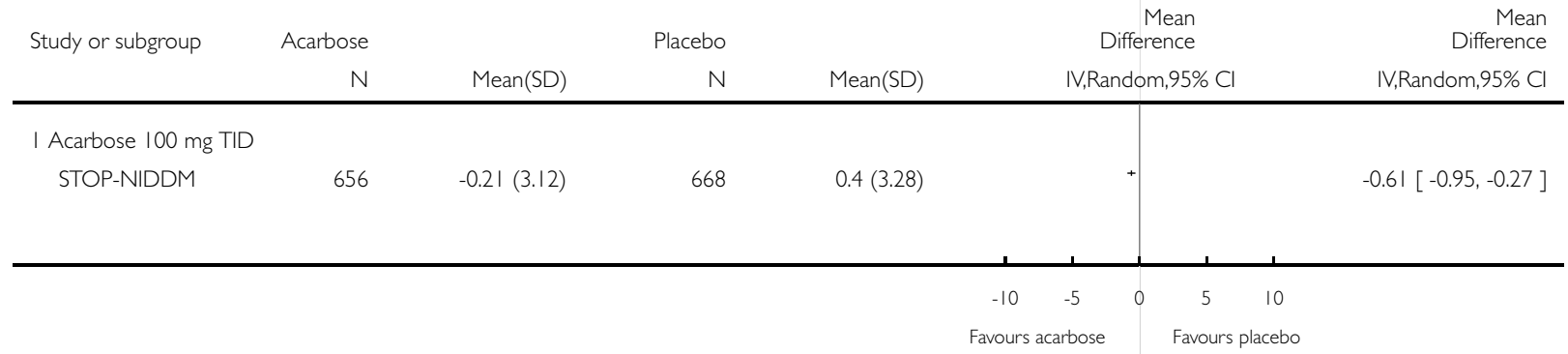


Analysis I.14. Comparison I Acarbose versus placebo, Outcome 14 Change in total cholesterol (mmol/l). Review: Alpha-glucosidase inhibitors for people with impaired glucose tolerance or impaired fasting blood glucose

Comparison: I Acarbose versus placebo

Outcome: 14 Change in total cholesterol (mmol/l)

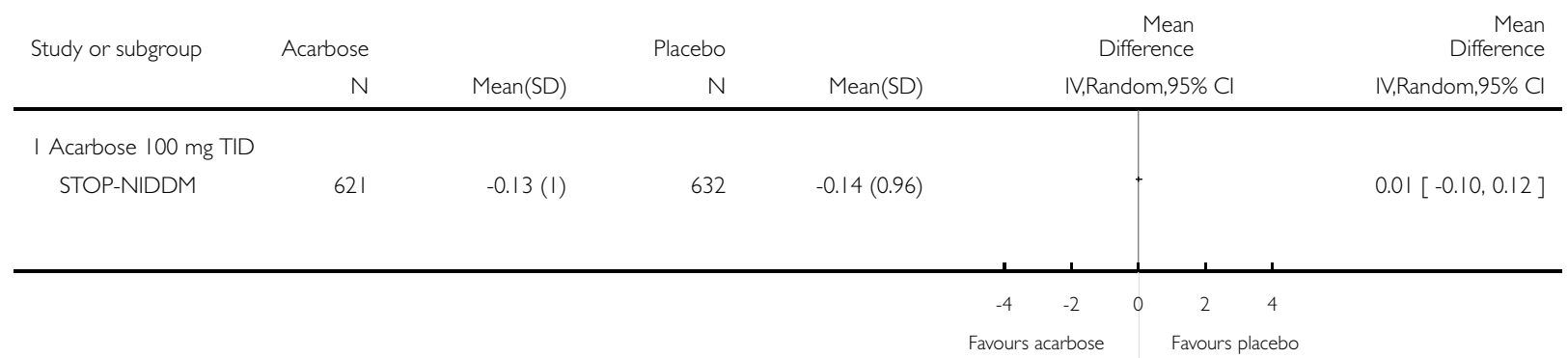

\section{Analysis I.I5. Comparison I Acarbose versus placebo, Outcome I5 Change in HDL-cholesterol (mmol/I).}

Review: Alpha-glucosidase inhibitors for people with impaired glucose tolerance or impaired fasting blood glucose

Comparison: I Acarbose versus placebo

Outcome: 15 Change in HDL-cholesterol (mmol/l)

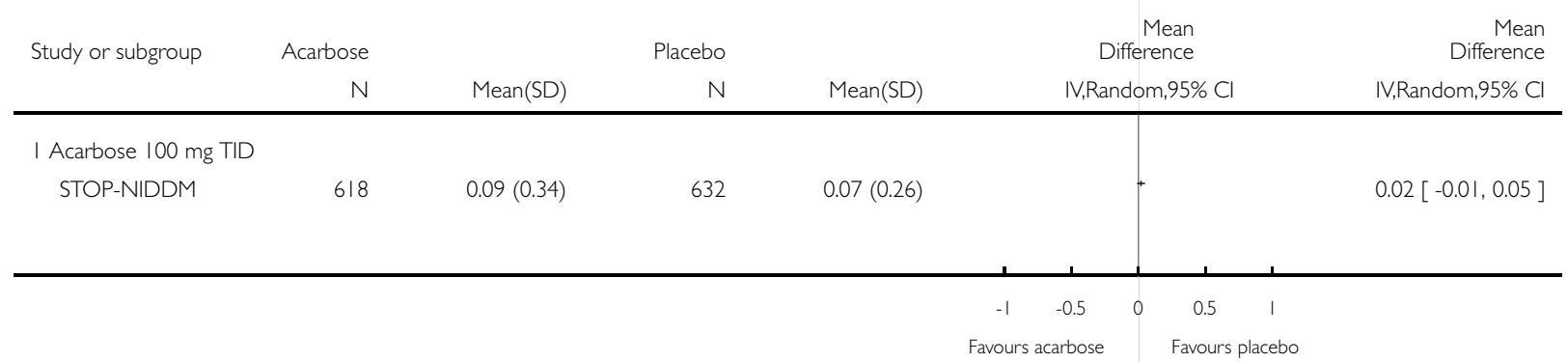


Analysis I.16. Comparison I Acarbose versus placebo, Outcome 16 Change in LDL-cholesterol (mmol/I). Review: Alpha-glucosidase inhibitors for people with impaired glucose tolerance or impaired fasting blood glucose

Comparison: I Acarbose versus placebo

Outcome: 16 Change in LDL-cholesterol (mmol/l)

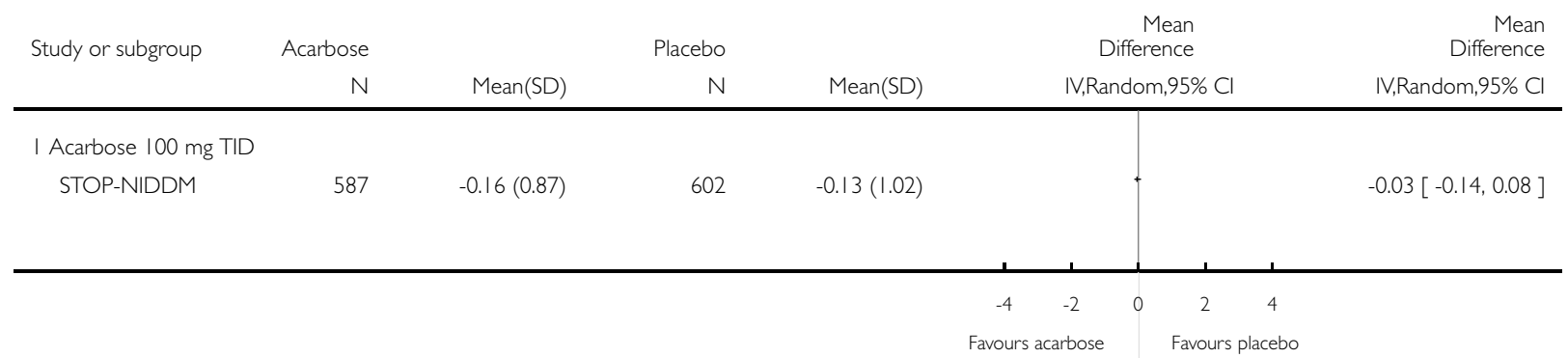

Analysis I.I7. Comparison I Acarbose versus placebo, Outcome 17 Change in triglycerides (mmol/l).

Review: Alpha-glucosidase inhibitors for people with impaired glucose tolerance or impaired fasting blood glucose

Comparison: I Acarbose versus placebo

Outcome: 17 Change in triglycerides $(\mathrm{mmol} / \mathrm{l})$

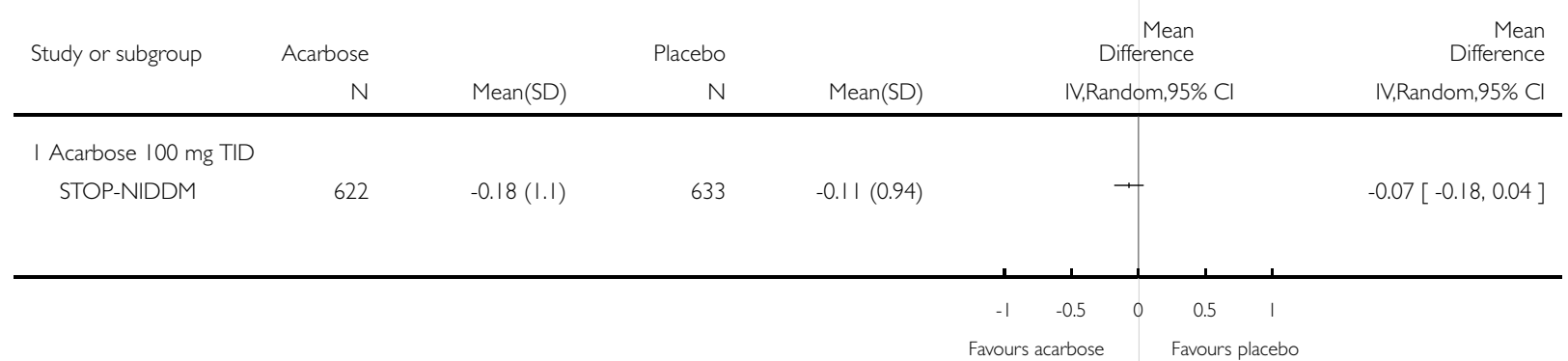


Analysis I.18. Comparison I Acarbose versus placebo, Outcome 18 Change in fasting insulin levels (pmol/I). Review: Alpha-glucosidase inhibitors for people with impaired glucose tolerance or impaired fasting blood glucose

Comparison: I Acarbose versus placebo

Outcome: 18 Change in fasting insulin levels (pmol/l)

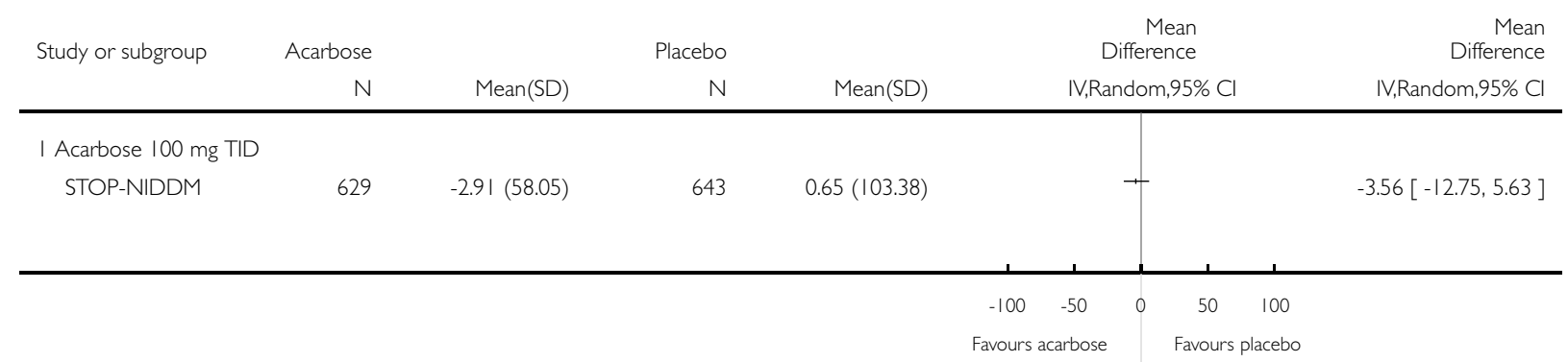

Analysis I.19. Comparison I Acarbose versus placebo, Outcome 19 Change in post-load insulin levels (pmol/l).

Review: Alpha-glucosidase inhibitors for people with impaired glucose tolerance or impaired fasting blood glucose

Comparison: I Acarbose versus placebo

Outcome: 19 Change in post-load insulin levels $(\mathrm{pmol} / \mathrm{l})$

\begin{tabular}{|c|c|c|c|c|c|c|c|c|c|}
\hline \multirow[t]{2}{*}{ Study or subgroup } & \multirow{2}{*}{$\begin{array}{r}\text { Acarbose } \\
N\end{array}$} & \multicolumn{3}{|c|}{ Placebo } & \multicolumn{4}{|c|}{$\begin{array}{r}\text { Mean } \\
\text { Difference }\end{array}$} & \multirow{2}{*}{$\begin{array}{r}\text { Mean } \\
\text { Difference } \\
\text { IV,Random,95\% Cl }\end{array}$} \\
\hline & & Mean(SD) & $\mathrm{N}$ & Mean(SD) & \multicolumn{4}{|c|}{ IV,Random,95\% Cl } & \\
\hline \multicolumn{10}{|c|}{ I Acarbose 100 mg TID } \\
\hline \multirow[t]{2}{*}{ STOP-NIDDM } & 620 & $-52.13(391.43)$ & 634 & $-64.53(403.93)$ & & & + & & $12.40[-31.62,56.42]$ \\
\hline & & & & & -1000 & -500 & 500 & 1000 & \\
\hline
\end{tabular}


Analysis I.20. Comparison I Acarbose versus placebo, Outcome 20 Change in body weight (Kg).

Review: Alpha-glucosidase inhibitors for people with impaired glucose tolerance or impaired fasting blood glucose

Comparison: I Acarbose versus placebo

Outcome: 20 Change in body weight $(\mathrm{Kg})$

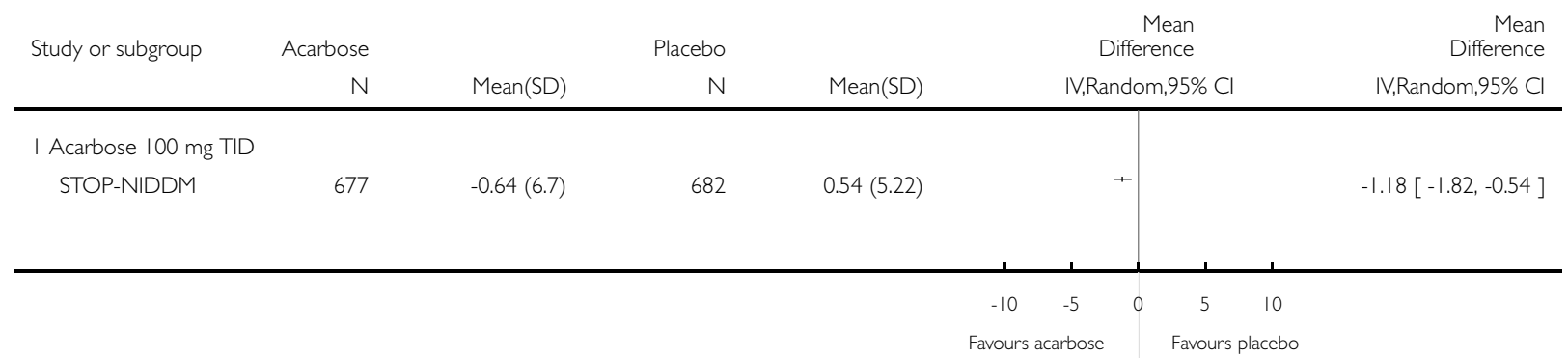

Analysis I.2I. Comparison I Acarbose versus placebo, Outcome $2 \mathrm{I}$ Change in body mass index (Kg/m2).

Review: Alpha-glucosidase inhibitors for people with impaired glucose tolerance or impaired fasting blood glucose

Comparison: I Acarbose versus placebo

Outcome: 21 Change in body mass index $(\mathrm{Kg} / \mathrm{m} 2)$

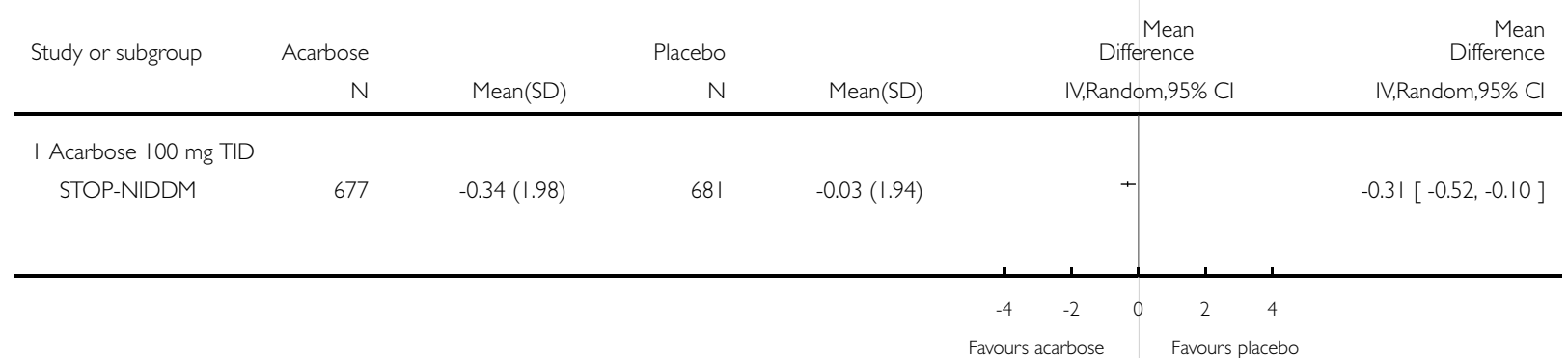


Analysis I.22. Comparison I Acarbose versus placebo, Outcome 22 Change in diastolic blood pressure $(\mathrm{mmHg})$.

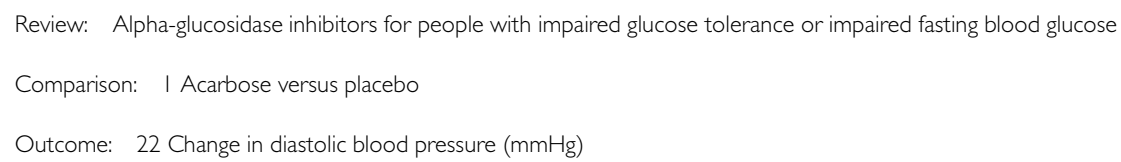

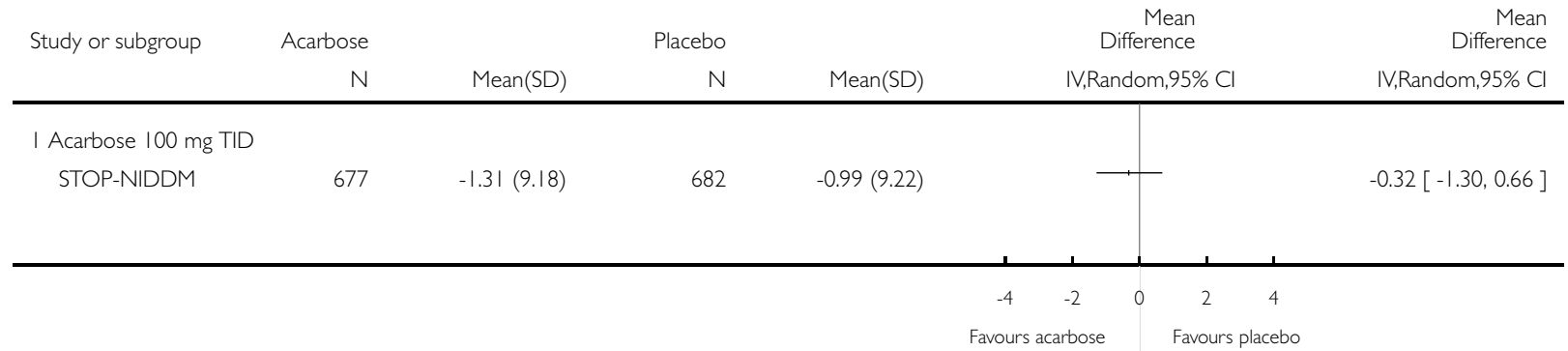

Analysis I.23. Comparison I Acarbose versus placebo, Outcome 23 Change in systolic blood pressure ( $\mathrm{mmHg}$ ).

Review: Alpha-glucosidase inhibitors for people with impaired glucose tolerance or impaired fasting blood glucose

Comparison: I Acarbose versus placebo

Outcome: 23 Change in systolic blood pressure $(\mathrm{mmHg})$

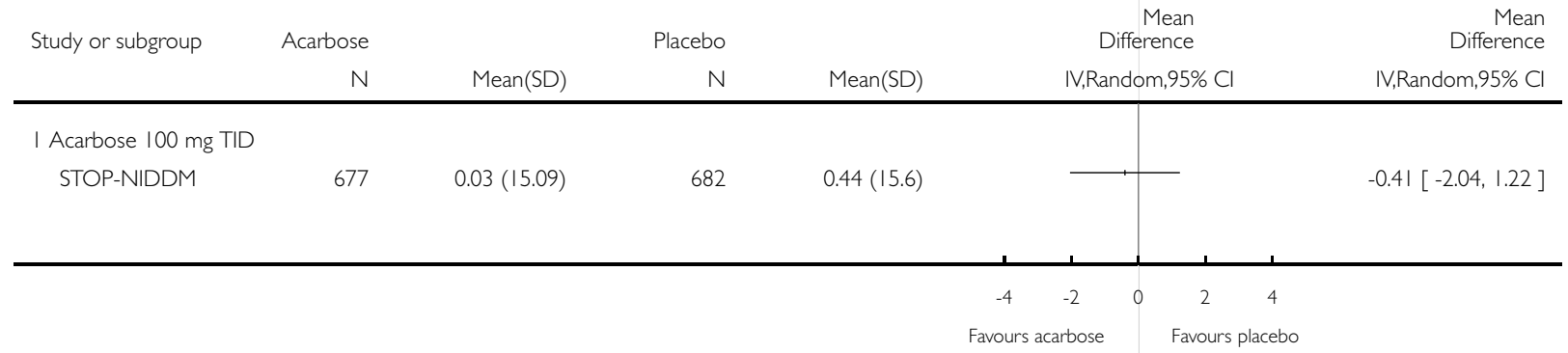


Analysis I.24. Comparison I Acarbose versus placebo, Outcome 24 Occurrence of side effects (total).

Review: Alpha-glucosidase inhibitors for people with impaired glucose tolerance or impaired fasting blood glucose

Comparison: I Acarbose versus placebo

Outcome: 24 Occurrence of side effects (total)

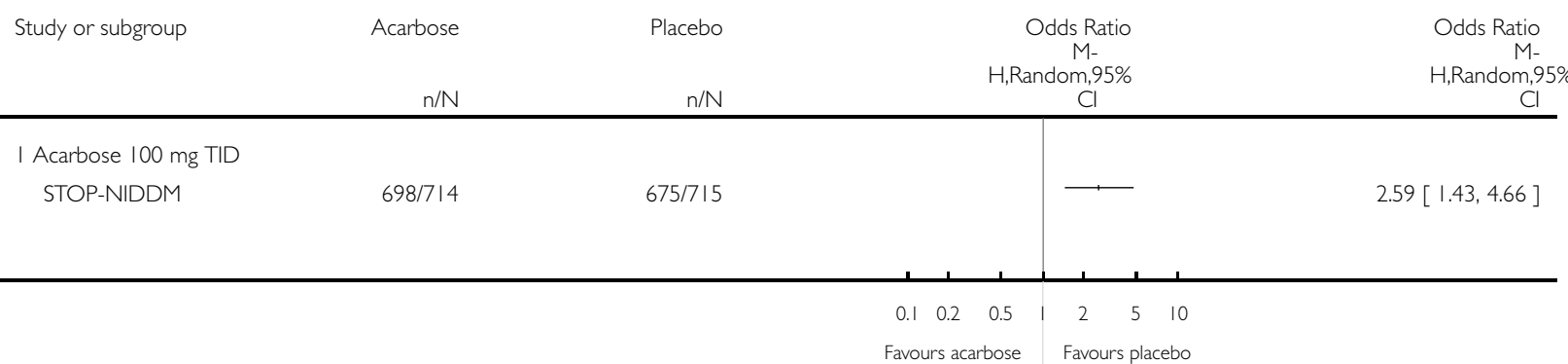

Analysis I.25. Comparison I Acarbose versus placebo, Outcome 25 Occurrence of gastro-intestinal sideeffects.

Review: Alpha-glucosidase inhibitors for people with impaired glucose tolerance or impaired fasting blood glucose

Comparison: I Acarbose versus placebo

Outcome: 25 Occurrence of gastro-intestinal side-effects

\begin{tabular}{|c|c|c|c|c|}
\hline Study or subgroup & Acarbose & $\begin{array}{r}\text { Placebo } \\
\text { n/N }\end{array}$ & $\begin{array}{c}\text { Odds Ratio } \\
\text { M- } \\
\text { H,Random,95\% } \\
\mathrm{Cl}\end{array}$ & $\begin{array}{c}\text { Odds Ratio } \\
\text { M- } \\
\text { H,Random,95\% } \\
\text { Cl }\end{array}$ \\
\hline \multicolumn{5}{|c|}{ I Acarbose 100 mg TID } \\
\hline STOP-NIDDM & $597 / 7 \mid 4$ & $426 / 7 / 5$ & $\leftarrow$ & $3.46[2.70,4.44]$ \\
\hline
\end{tabular}

$\begin{array}{lllllll}0.1 & 0.2 & 0.5 & 1 & 2 & 5 & 10\end{array}$

Favours acarbose Favours placebo 
Analysis 2.I. Comparison 2 Acarbose versus metformin, Outcome I Incidence of type 2 diabetes mellitus. Review: Alpha-glucosidase inhibitors for people with impaired glucose tolerance or impaired fasting blood glucose

Comparison: 2 Acarbose versus metformin

Outcome: I Incidence of type 2 diabetes mellitus

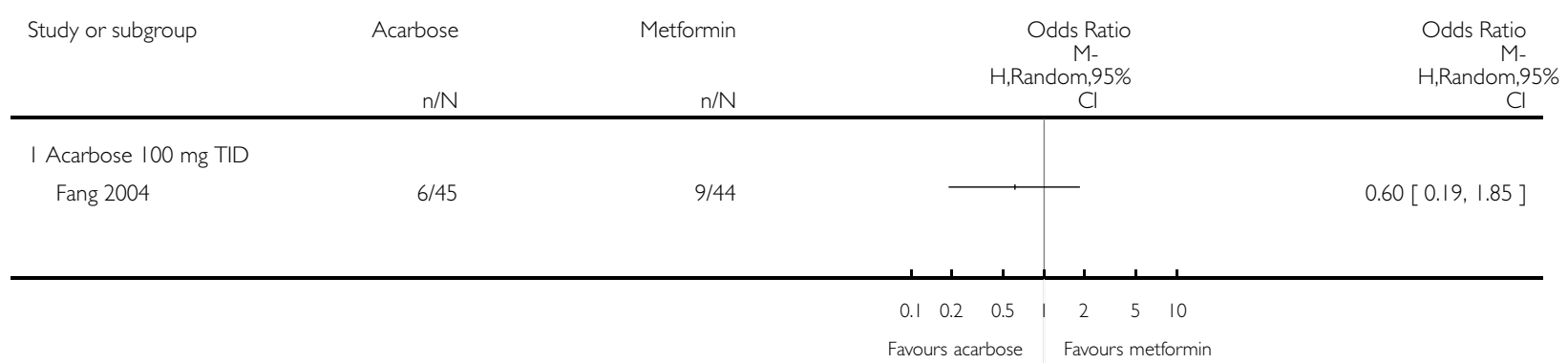

Analysis 2.2. Comparison 2 Acarbose versus metformin, Outcome 2 Change in fasting blood glucose (mmol/l).

Review: Alpha-glucosidase inhibitors for people with impaired glucose tolerance or impaired fasting blood glucose

Comparison: 2 Acarbose versus metformin

Outcome: 2 Change in fasting blood glucose $(\mathrm{mmol} / \mathrm{l})$

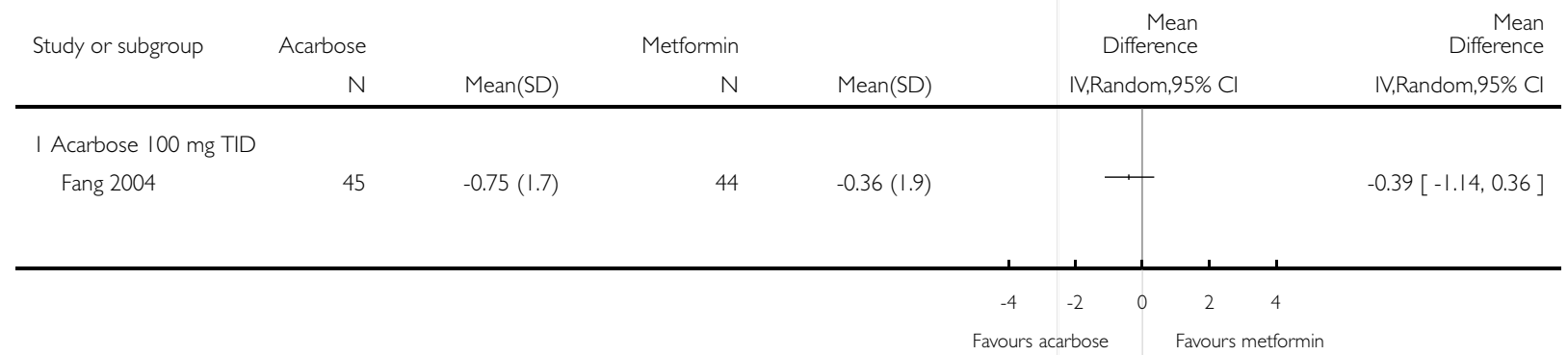


Analysis 2.3. Comparison 2 Acarbose versus metformin, Outcome 3 Change in post-load blood glucose (mmol/l).

Review: Alpha-glucosidase inhibitors for people with impaired glucose tolerance or impaired fasting blood glucose

Comparison: 2 Acarbose versus metformin

Outcome: 3 Change in post-load blood glucose $(\mathrm{mmol} / \mathrm{l})$

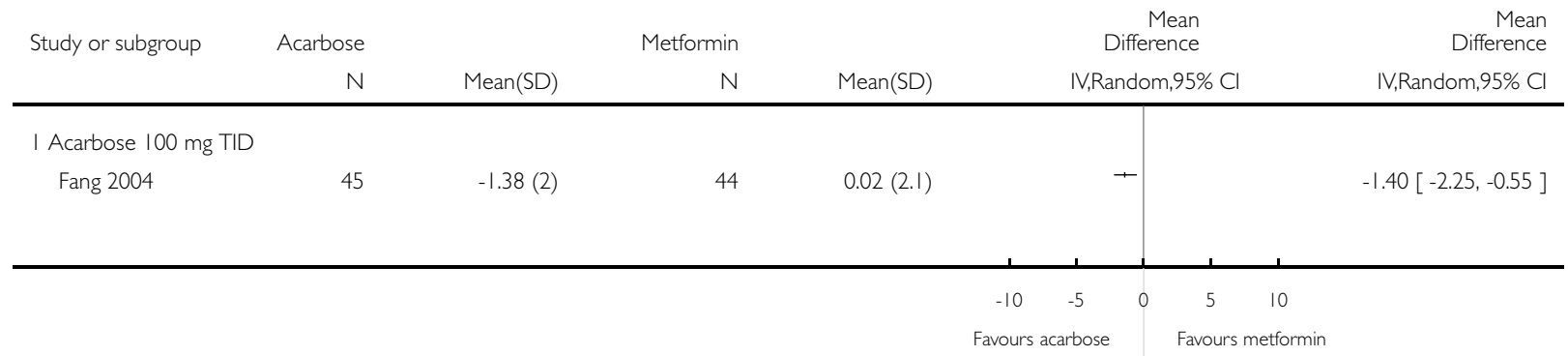

Analysis 2.4. Comparison 2 Acarbose versus metformin, Outcome 4 Change in total cholesterol (mmol/l).

Review: Alpha-glucosidase inhibitors for people with impaired glucose tolerance or impaired fasting blood glucose

Comparison: 2 Acarbose versus metformin

Outcome: 4 Change in total cholesterol $(\mathrm{mmol} / \mathrm{l})$

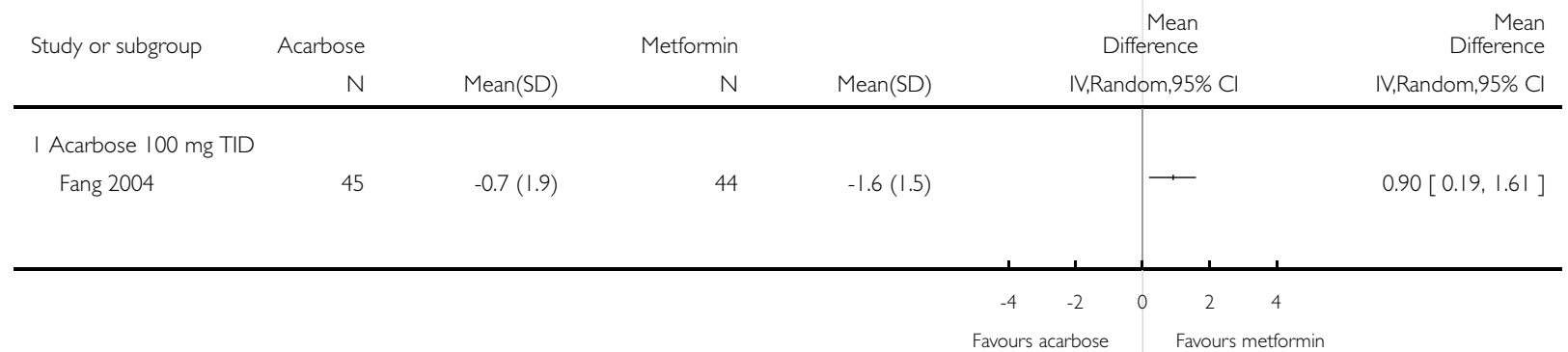


Analysis 2.5. Comparison 2 Acarbose versus metformin, Outcome 5 Change in triglycerides (mmol/l). Review: Alpha-glucosidase inhibitors for people with impaired glucose tolerance or impaired fasting blood glucose

Comparison: 2 Acarbose versus metformin

Outcome: 5 Change in triglycerides $(\mathrm{mmol} / \mathrm{l})$

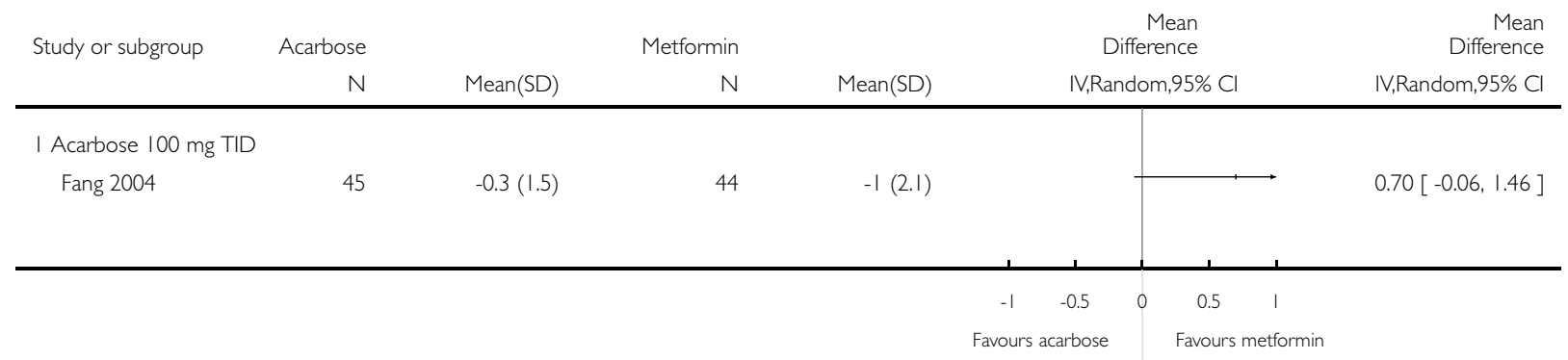

\section{Analysis 2.6. Comparison 2 Acarbose versus metformin, Outcome 6 Change in body mass index $(\mathrm{Kg} / \mathrm{m} 2)$.}

Review: Alpha-glucosidase inhibitors for people with impaired glucose tolerance or impaired fasting blood glucose

Comparison: 2 Acarbose versus metformin

Outcome: 6 Change in body mass index $(\mathrm{Kg} / \mathrm{m} 2)$

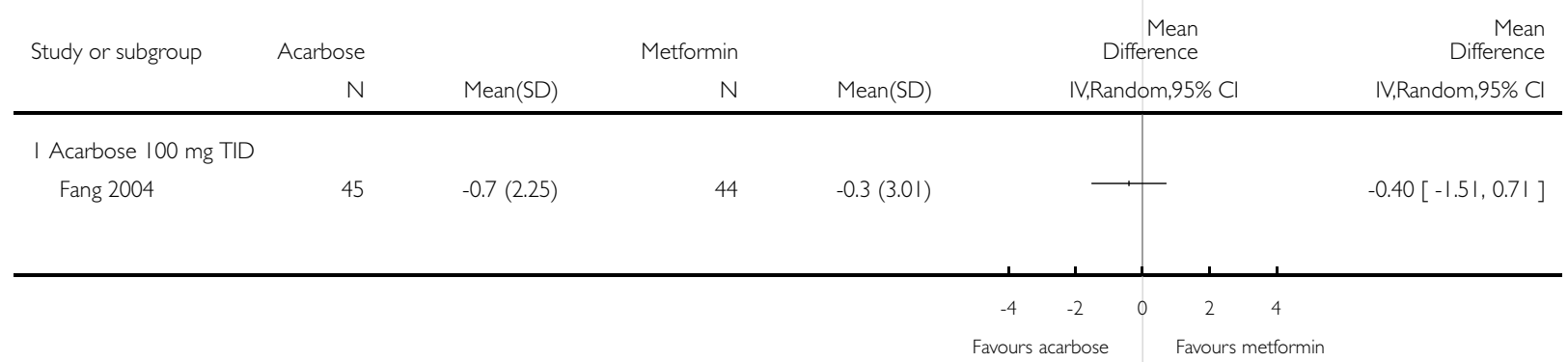


Analysis 2.7. Comparison 2 Acarbose versus metformin, Outcome 7 Change in diastolic blood pressure $(\mathrm{mmHg})$.

Review: Alpha-glucosidase inhibitors for people with impaired glucose tolerance or impaired fasting blood glucose

Comparison: 2 Acarbose versus metformin

Outcome: 7 Change in diastolic blood pressure $(\mathrm{mmHg})$

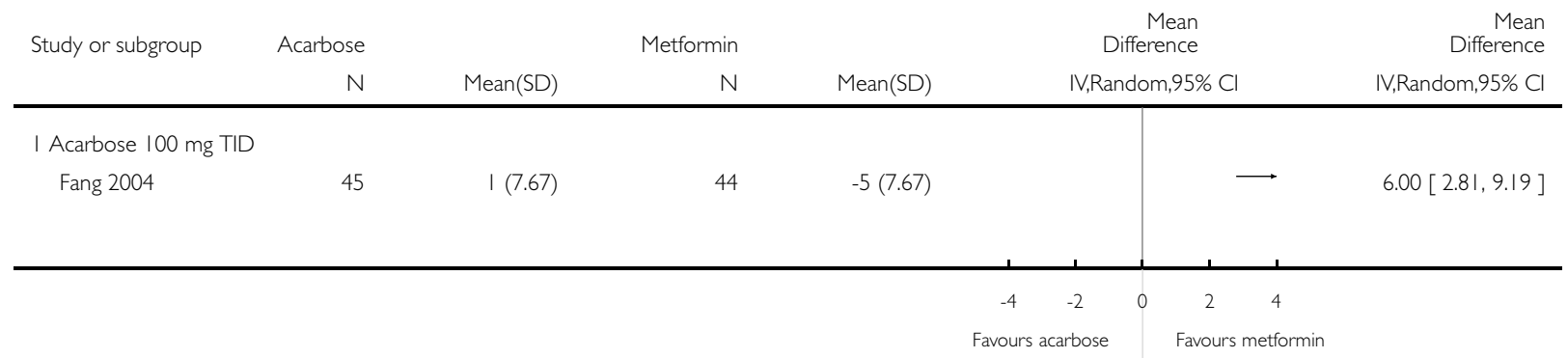

Analysis 2.8. Comparison 2 Acarbose versus metformin, Outcome 8 Change in systolic blood pressure $(\mathrm{mmHg})$.

Review: Alpha-glucosidase inhibitors for people with impaired glucose tolerance or impaired fasting blood glucose

Comparison: 2 Acarbose versus metformin

Outcome: 8 Change in systolic blood pressure $(\mathrm{mmHg})$

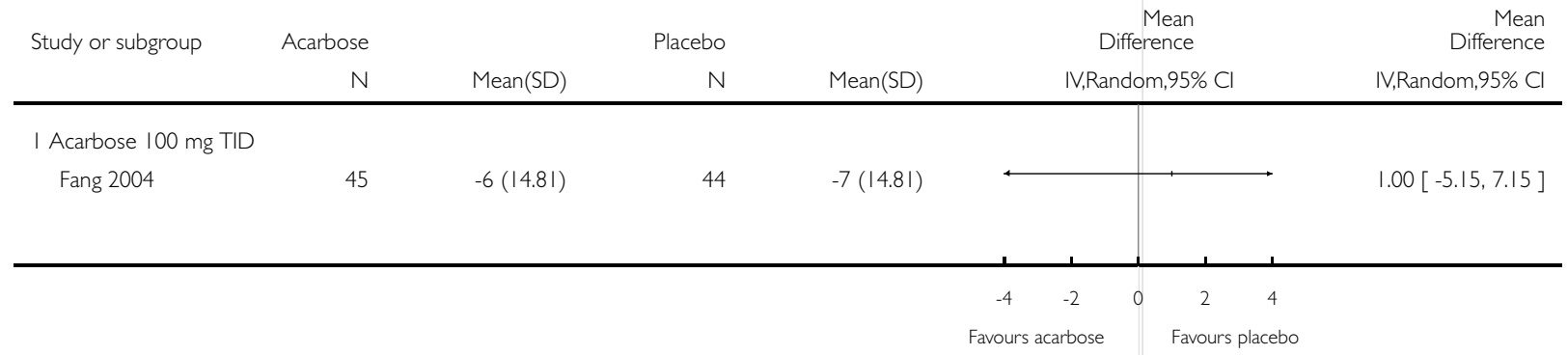




\section{Analysis 3.I. Comparison 3 Acarbose versus diet and exercise, Outcome I Incidence of type 2 diabetes}

mellitus.

Review: Alpha-glucosidase inhibitors for people with impaired glucose tolerance or impaired fasting blood glucose

Comparison: 3 Acarbose versus diet and exercise

Outcome: I Incidence of type 2 diabetes mellitus

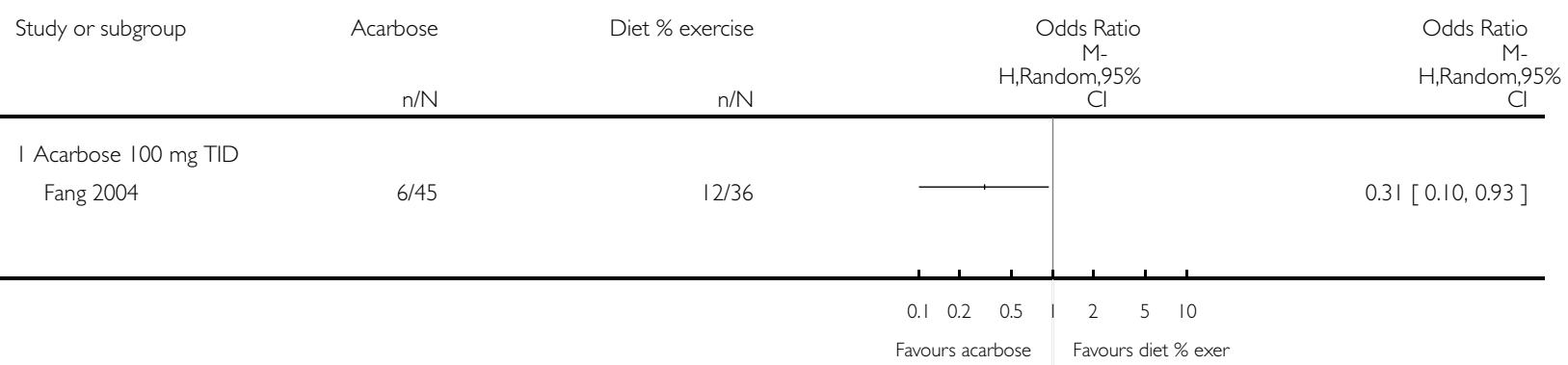

\section{Analysis 3.2. Comparison 3 Acarbose versus diet and exercise, Outcome 2 Change in fasting blood glucose} (mmol/l).

Review: Alpha-glucosidase inhibitors for people with impaired glucose tolerance or impaired fasting blood glucose

Comparison: 3 Acarbose versus diet and exercise

Outcome: 2 Change in fasting blood glucose ( $\mathrm{mmol} / \mathrm{l})$

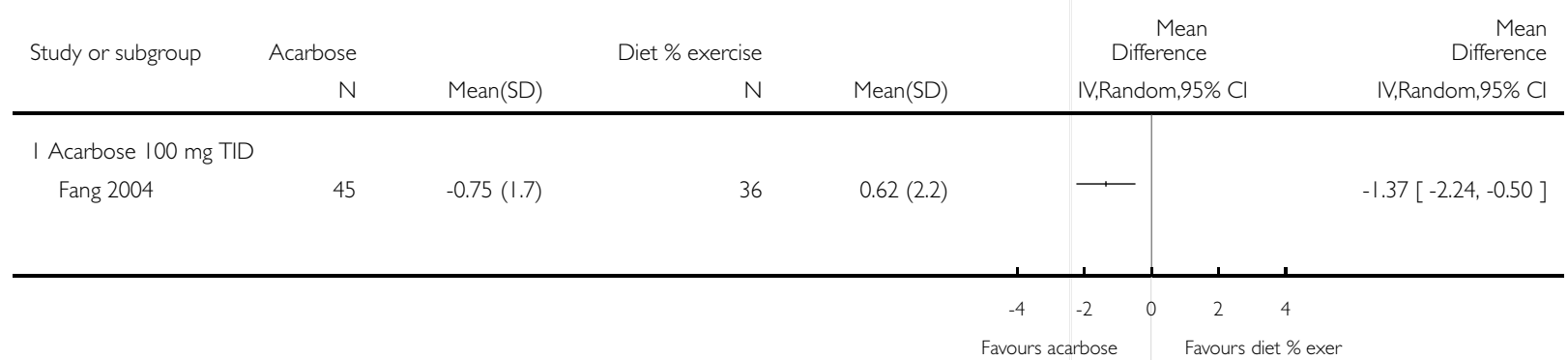


Analysis 3.3. Comparison 3 Acarbose versus diet and exercise, Outcome 3 Change in post-load blood glucose $(\mathrm{mmol} / \mathrm{l})$.

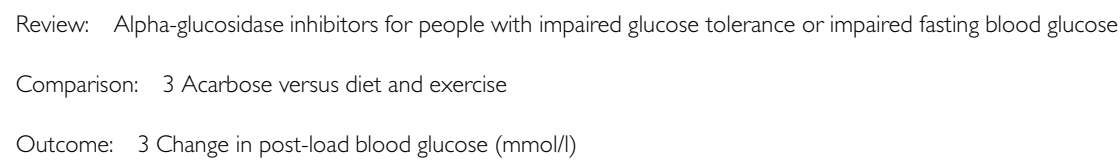

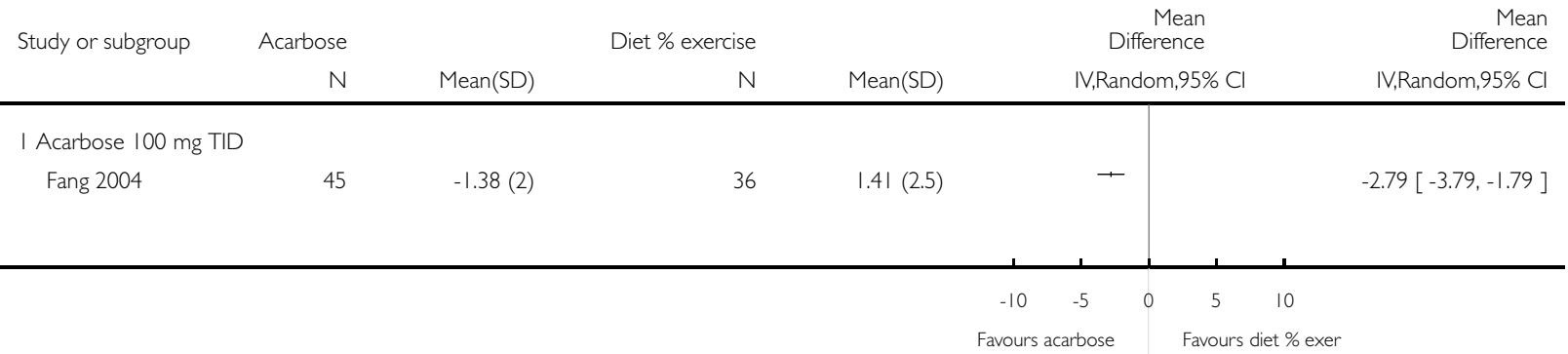

Analysis 3.4. Comparison 3 Acarbose versus diet and exercise, Outcome 4 Change in total cholesterol ( $\mathrm{mmol} / \mathrm{l})$.

Review: Alpha-glucosidase inhibitors for people with impaired glucose tolerance or impaired fasting blood glucose

Comparison: 3 Acarbose versus diet and exercise

Outcome: 4 Change in total cholesterol $(\mathrm{mmol} / \mathrm{l})$

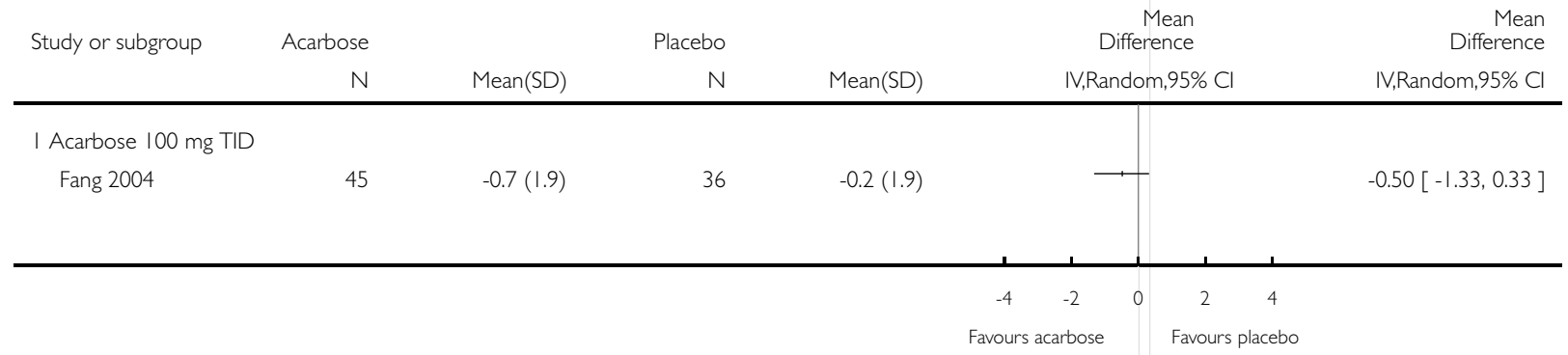


Analysis 3.5. Comparison 3 Acarbose versus diet and exercise, Outcome 5 Change in triglycerides (mmol/l). Review: Alpha-glucosidase inhibitors for people with impaired glucose tolerance or impaired fasting blood glucose

Comparison: 3 Acarbose versus diet and exercise

Outcome: 5 Change in triglycerides $(\mathrm{mmol} / \mathrm{l})$

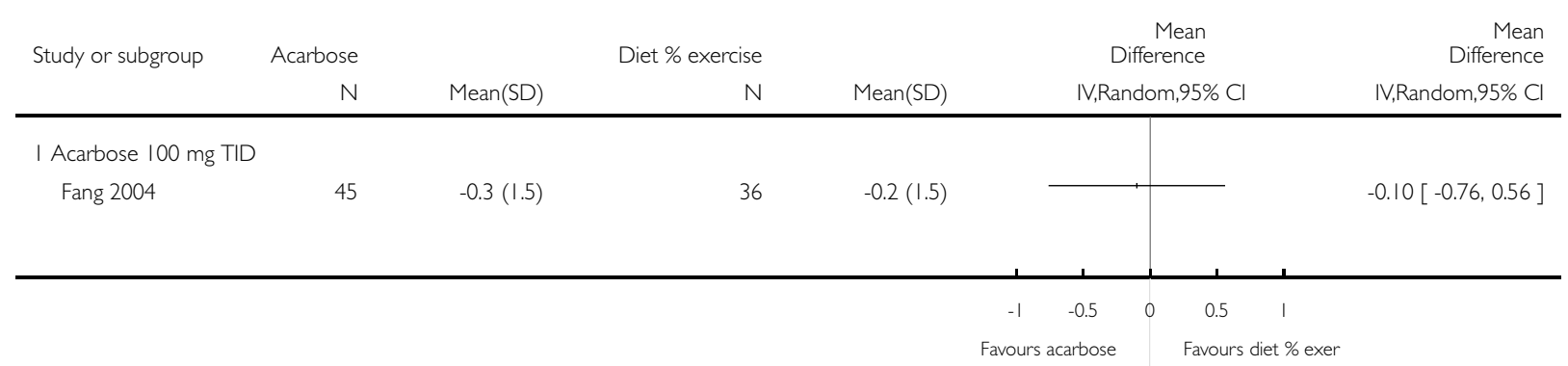

\section{Analysis 3.6. Comparison 3 Acarbose versus diet and exercise, Outcome 6 Change in body mass index} (Kg/m2).

Review: Alpha-glucosidase inhibitors for people with impaired glucose tolerance or impaired fasting blood glucose

Comparison: 3 Acarbose versus diet and exercise

Outcome: 6 Change in body mass index $(\mathrm{Kg} / \mathrm{m} 2)$

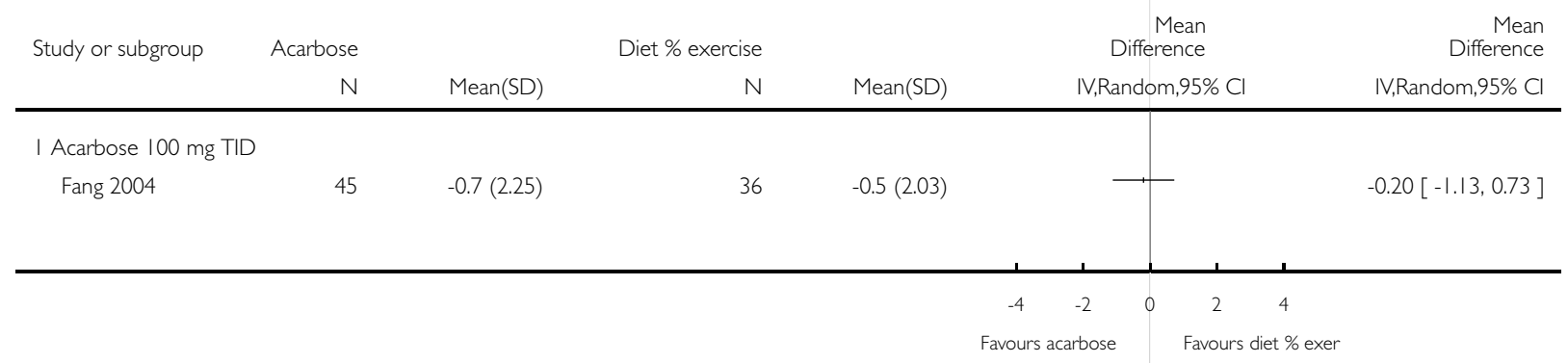


Analysis 3.7. Comparison 3 Acarbose versus diet and exercise, Outcome 7 Change in diastolic blood pressure $(\mathrm{mmHg})$.

Review: Alpha-glucosidase inhibitors for people with impaired glucose tolerance or impaired fasting blood glucose

Comparison: 3 Acarbose versus diet and exercise

Outcome: 7 Change in diastolic blood pressure $(\mathrm{mmHg})$

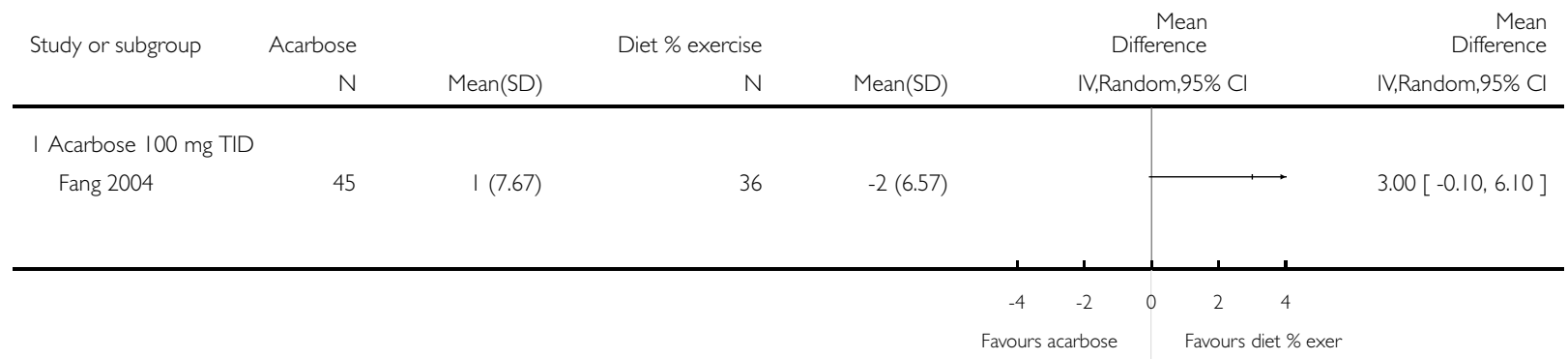

Analysis 3.8. Comparison 3 Acarbose versus diet and exercise, Outcome 8 Change in systolic blood pressure ( $\mathrm{mmHg})$.

Review: Alpha-glucosidase inhibitors for people with impaired glucose tolerance or impaired fasting blood glucose

Comparison: 3 Acarbose versus diet and exercise

Outcome: 8 Change in systolic blood pressure $(\mathrm{mmHg})$

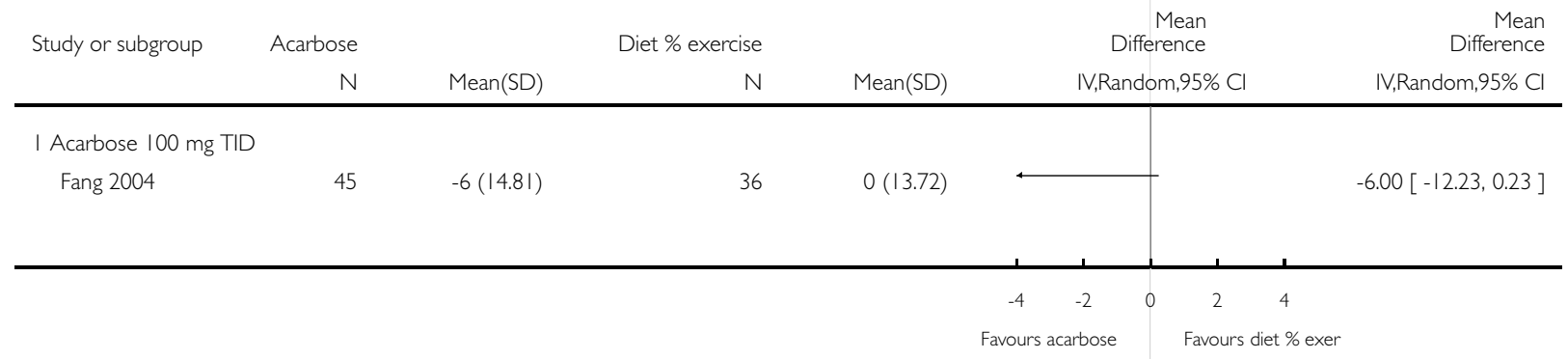




\section{Analysis 4.I. Comparison 4 Acarbose versus no treatment, Outcome I Incidence of type 2 diabetes mellitus.}

Review: Alpha-glucosidase inhibitors for people with impaired glucose tolerance or impaired fasting blood glucose

Comparison: 4 Acarbose versus no treatment

Outcome: I Incidence of type 2 diabetes mellitus

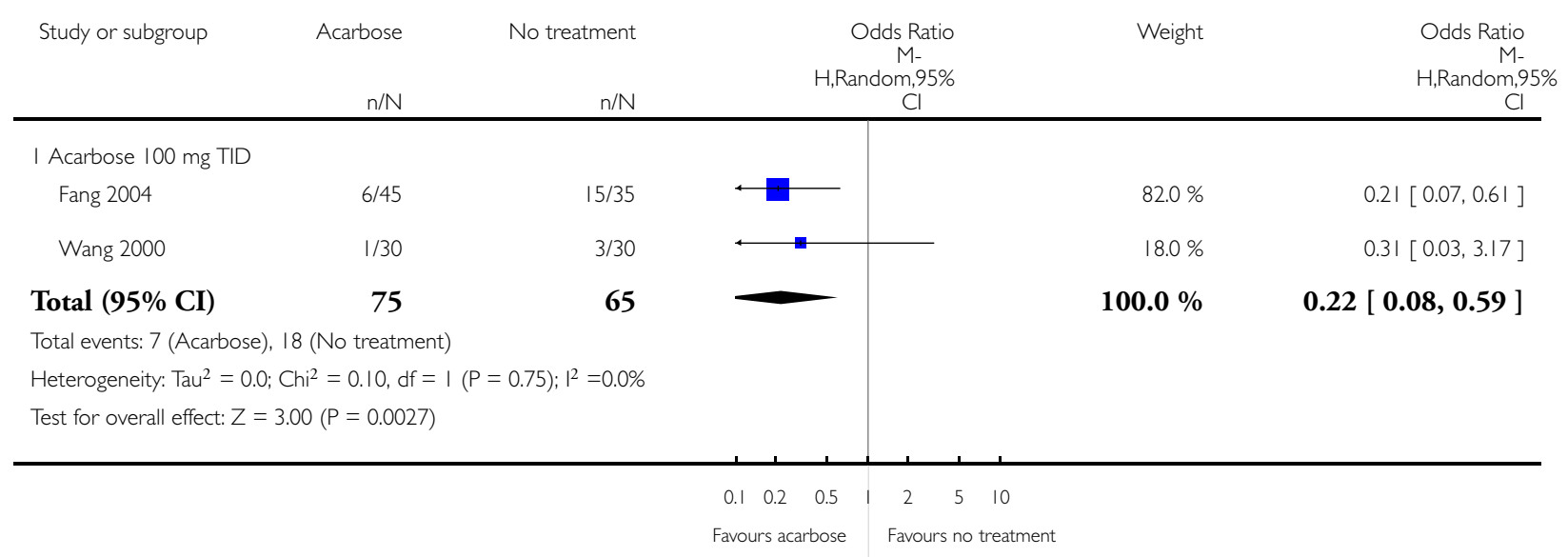

\section{Analysis 4.2. Comparison 4 Acarbose versus no treatment, Outcome 2 Change in fasting blood glucose} (mmol/l).

Review: Alpha-glucosidase inhibitors for people with impaired glucose tolerance or impaired fasting blood glucose

Comparison: 4 Acarbose versus no treatment

Outcome: 2 Change in fasting blood glucose $(\mathrm{mmol} / \mathrm{l})$

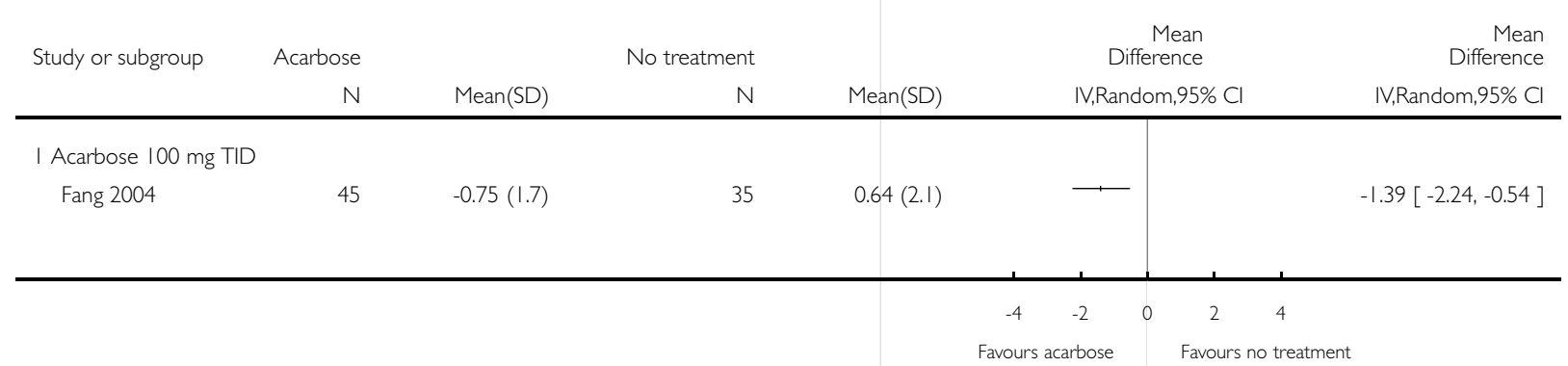


Analysis 4.3. Comparison 4 Acarbose versus no treatment, Outcome 3 Change in post-load blood glucose (mmol/l).

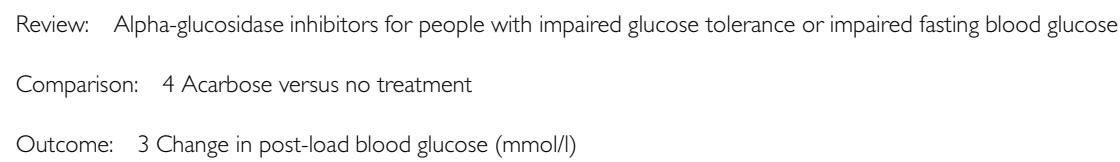

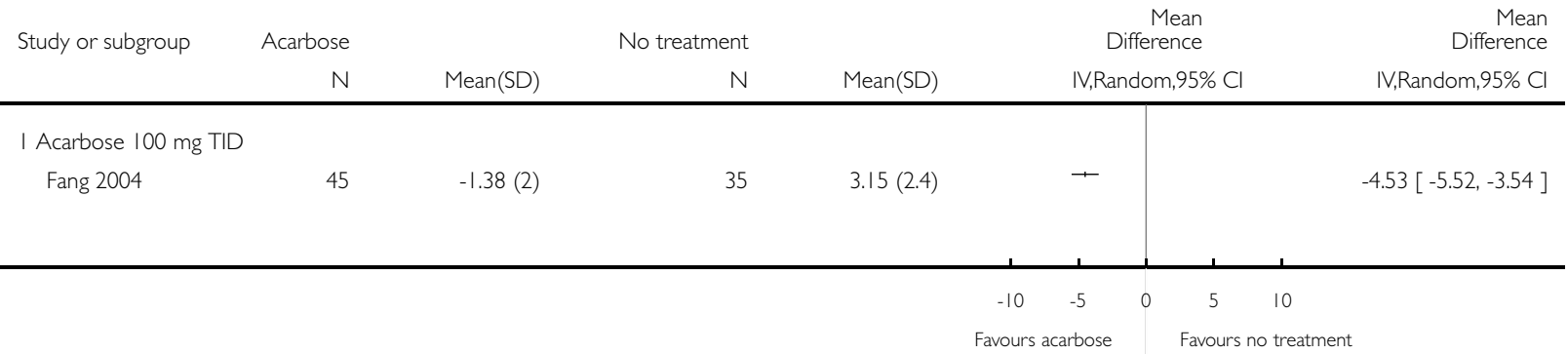

Analysis 4.4. Comparison 4 Acarbose versus no treatment, Outcome 4 Change in total cholesterol (mmol/l).

Review: Alpha-glucosidase inhibitors for people with impaired glucose tolerance or impaired fasting blood glucose

Comparison: 4 Acarbose versus no treatment

Outcome: 4 Change in total cholesterol (mmol/l)

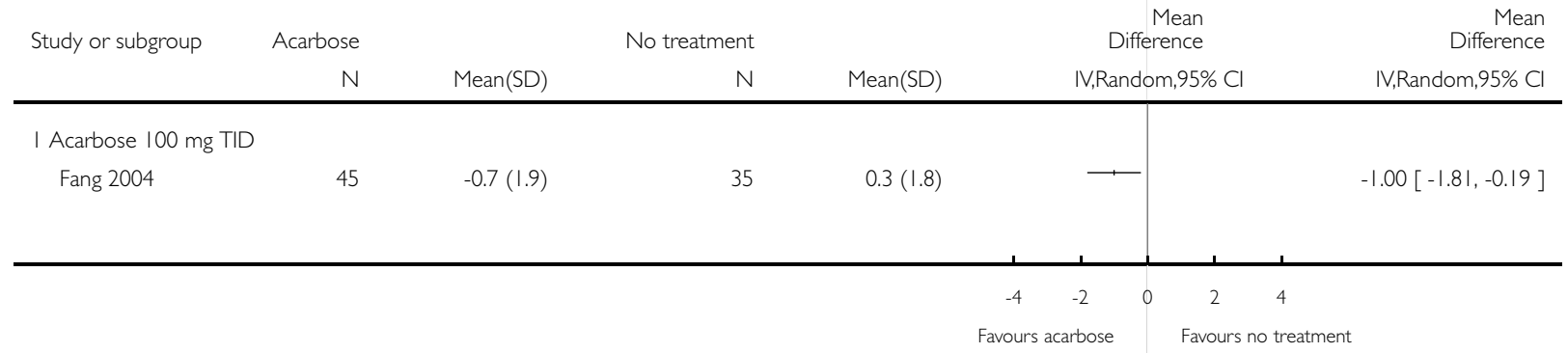


Analysis 4.5. Comparison 4 Acarbose versus no treatment, Outcome 5 Change in triglycerides (mmol/l).

Review: Alpha-glucosidase inhibitors for people with impaired glucose tolerance or impaired fasting blood glucose

Comparison: 4 Acarbose versus no treatment

Outcome: 5 Change in triglycerides $(\mathrm{mmol} / \mathrm{l})$

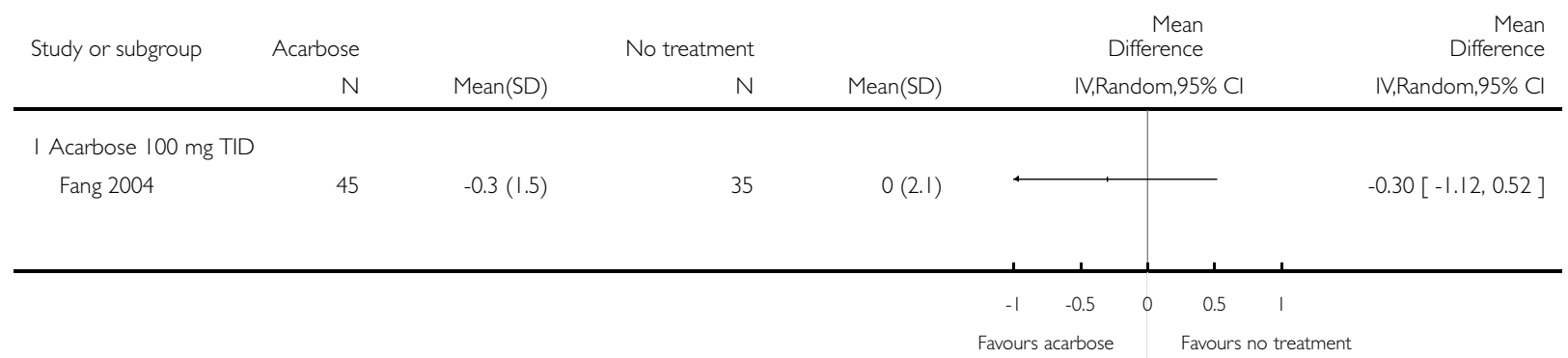

Analysis 4.6. Comparison 4 Acarbose versus no treatment, Outcome 6 Change in body mass index (Kg/m2).

Review: Alpha-glucosidase inhibitors for people with impaired glucose tolerance or impaired fasting blood glucose

Comparison: 4 Acarbose versus no treatment

Outcome: 6 Change in body mass index $(\mathrm{Kg} / \mathrm{m} 2)$

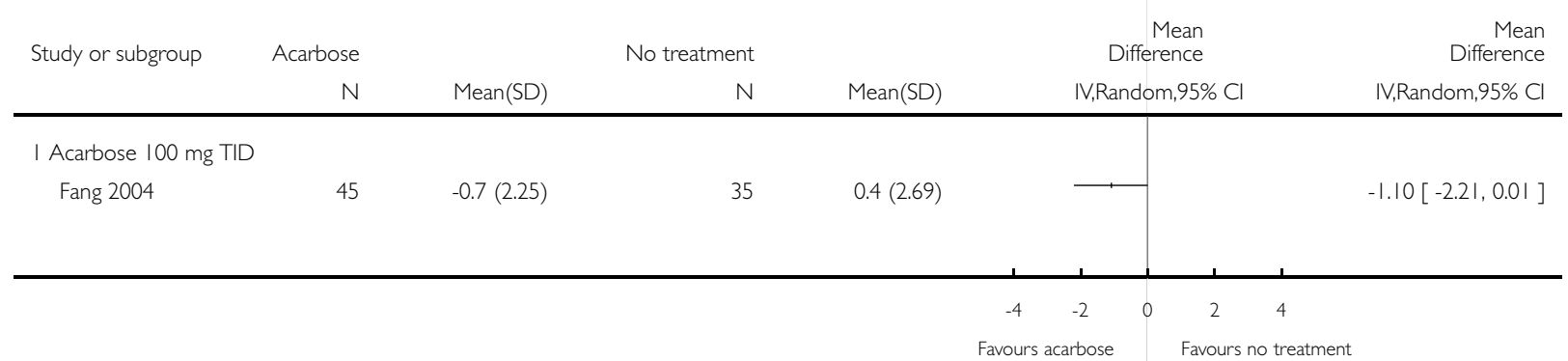


Analysis 4.7. Comparison 4 Acarbose versus no treatment, Outcome 7 Change in diastolic blood pressure $(\mathrm{mmHg})$.

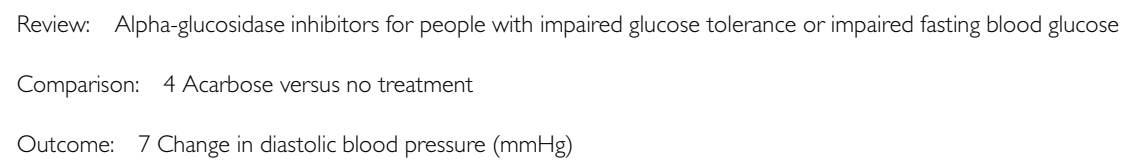

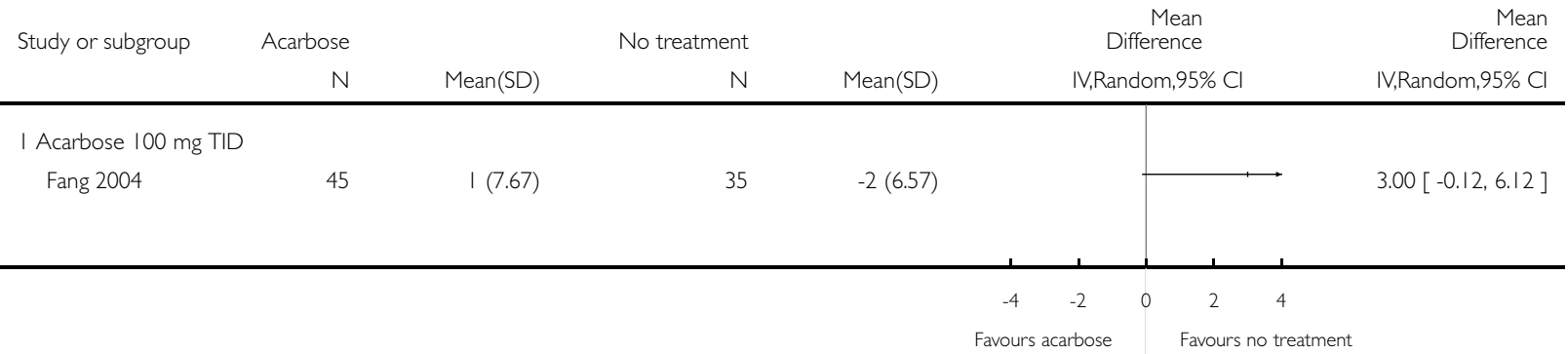

Analysis 4.8. Comparison 4 Acarbose versus no treatment, Outcome 8 Change in systolic blood pressure ( $\mathrm{mmHg})$.

Review: Alpha-glucosidase inhibitors for people with impaired glucose tolerance or impaired fasting blood glucose

Comparison: 4 Acarbose versus no treatment

Outcome: 8 Change in systolic blood pressure $(\mathrm{mmHg})$

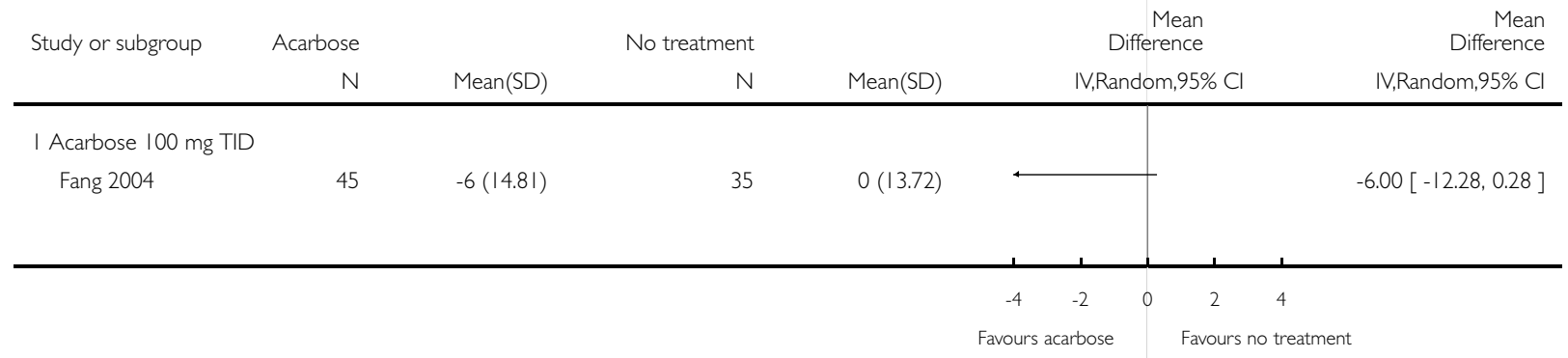


Analysis 4.9. Comparison 4 Acarbose versus no treatment, Outcome 9 Occurrence of side effects (total).

Review: Alpha-glucosidase inhibitors for people with impaired glucose tolerance or impaired fasting blood glucose

Comparison: 4 Acarbose versus no treatment

Outcome: 9 Occurrence of side effects (total)

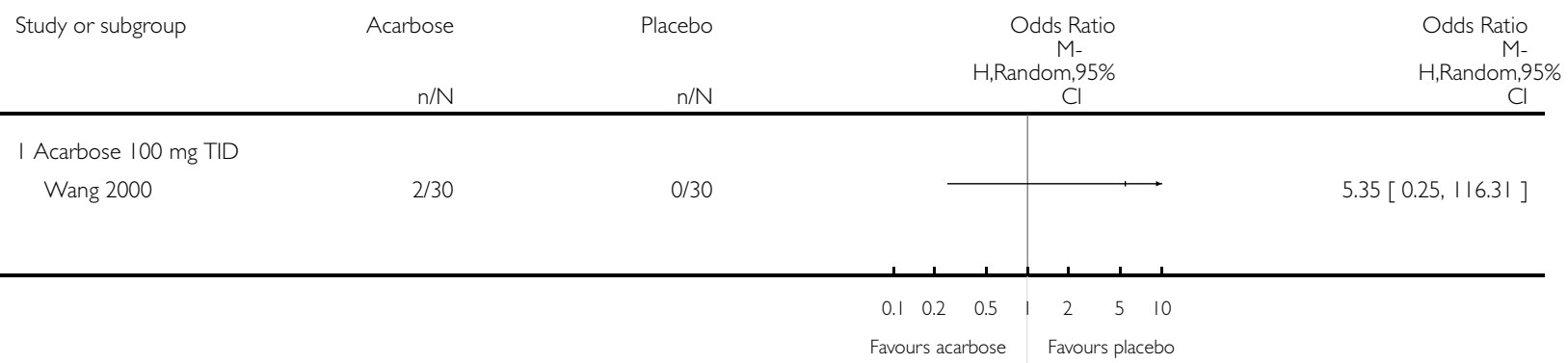

Analysis 4.10. Comparison 4 Acarbose versus no treatment, Outcome 10 Occurrence of gastro-intestinal side-effects.

Review: Alpha-glucosidase inhibitors for people with impaired glucose tolerance or impaired fasting blood glucose

Comparison: 4 Acarbose versus no treatment

Outcome: 10 Occurrence of gastro-intestinal side-effects

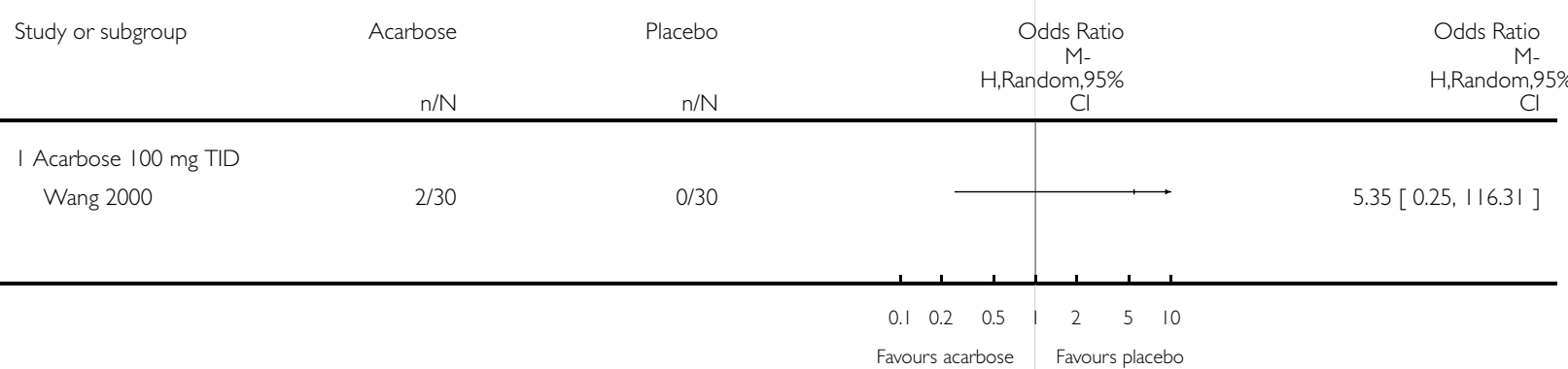


ADDITIONAL TABLES

Table 1. Risk of bias

\begin{tabular}{|c|c|c|c|c|c|c|c|c|c|}
\hline Study & $\begin{array}{l}\text { Randomi- } \\
\text { sation }\end{array}$ & $\begin{array}{l}\text { Allocation } \\
\text { Conceal. }\end{array}$ & $\begin{array}{l}\text { Treatment } \\
\text { Blinding }\end{array}$ & $\begin{array}{l}\text { ITT anal- } \\
\text { ysis }\end{array}$ & $\begin{array}{l}\text { Quantity } \\
\text { drop-out }\end{array}$ & $\begin{array}{l}\text { Selective } \\
\text { drop-out }\end{array}$ & $\begin{array}{l}\text { Blind out- } \\
\text { come- } \\
\text { assess }\end{array}$ & $\begin{array}{l}\text { Analyses } \\
\text { Blinding }\end{array}$ & $\begin{array}{l}\text { Overall } \\
\text { Quality }\end{array}$ \\
\hline & $\begin{array}{l}A=A d- \\
\text { equate; B } \\
=\text { Not ade- } \\
\text { quate / un- } \\
\text { clear }\end{array}$ & $\begin{array}{l}A=\text { Ad- } \\
\text { equate; B } \\
=\text { Not ade- } \\
\text { quate / un- } \\
\text { clear }\end{array}$ & $\begin{array}{l}\text { A = ade- } \\
\text { quate, } B= \\
\text { men- } \\
\text { tioning of } \\
\text { blind- } \\
\text { ing but ex- } \\
\text { act method } \\
\text { unclear, C } \\
=\text { non- } \\
\text { blinded, } \\
\text { inad- } \\
\text { equate or } \\
\text { unknown }\end{array}$ & $\begin{array}{l}A=\text { ade- } \\
\text { quate, B = } \\
\text { ITT inad- } \\
\text { equate, C } \\
=\text { Unclear } \\
\text { or no re- } \\
\text { ported } \\
\text { data on } \\
\text { drop-out / } \\
\text { loss-to- } \\
\text { follow-up }\end{array}$ & $\begin{array}{l}\mathrm{A}<15 \%, \mathrm{~B} \\
>=15 \% \text { or } \\
\text { unknown }\end{array}$ & $\begin{array}{l}A=\text { dif- } \\
\text { ference in } \\
\text { drop- } \\
\text { out rate in } \\
\text { main } \\
\text { groups } \\
<10 \% \text {, B } \\
>=10 \% \text { or } \\
\text { unknown }\end{array}$ & $\begin{array}{l}\mathrm{A}=\text { ade- } \\
\text { quate, } \mathrm{B}= \\
\text { men- } \\
\text { tioning of } \\
\text { blind- } \\
\text { ing but ex- } \\
\text { act method } \\
\text { unclear, C } \\
=\text { non- } \\
\text { blinded, } \\
\text { inad- } \\
\text { equate or } \\
\text { unknown }\end{array}$ & $\begin{array}{l}\mathrm{A}=\text { ade- } \\
\text { quate, } \mathrm{B}= \\
\text { men- } \\
\text { tioning of } \\
\text { blind- } \\
\text { ing but ex- } \\
\text { act method } \\
\text { unclear, C } \\
=\text { non- } \\
\text { blinded, } \\
\text { inad- } \\
\text { equate or } \\
\text { unknown }\end{array}$ & $\begin{array}{l}\mathrm{A}=\text { all } \\
\text { quality cri- } \\
\text { teria met; } \\
\mathrm{B}=\text { one or } \\
\text { more qual- } \\
\text { ity criteria } \\
\text { only par- } \\
\text { tially met; } \\
\mathrm{C}=\text { one or } \\
\text { more qual- } \\
\text { ity criteria } \\
\text { not met }\end{array}$ \\
\hline DAISI & B & B & B & C & B & A & B & B & C \\
\hline EDIT & B & B & B & C & B & B & B & B & C \\
\hline Fang 2004 & A & B & $\mathrm{C}$ & B & A & A & B & B & C \\
\hline $\begin{array}{l}\text { STOP- } \\
\text { NIDDM }\end{array}$ & A & A & A & B & A & A & A & B & A \\
\hline $\begin{array}{l}\text { Wang } \\
2000\end{array}$ & B & B & $\mathrm{C}$ & B & A & A & B & B & C \\
\hline
\end{tabular}

\section{A P PENDICES}

\section{Appendix I. Search strategy}

\section{Electronic searches}

Unless otherwise stated, search terms are free text terms; $\mathrm{MesH}=$ Medical subject heading (Medline medical index term); exp = exploded MeSH; the asterisk $\left(^{*}\right)$ stands for any character(s); tw = text word; $\mathrm{pt}=$ publication type; $\mathrm{sh}=\mathrm{MeSH}$; adj = adjacent.

\#1 Alpha-glucosidase inhibitors (Van de Laar 2005)

"Acarbose" $[\mathrm{MeSH}]$ OR acarbos* [tw] OR bayg5421 OR bay 5421 [tw] OR glucobay [tw] OR precos* [tw] OR prandas* [tw] OR 
akarbos* [tw] OR miglitol [tw] OR glyset [tw] OR diastabol [tw] OR baym1099 [tw] OR bay 1099 [tw] OR voglibos* [tw] OR (basen NOT basen [au]) OR emiglitat* [tw] OR alpha-glucosidase inhibitor [tw] OR glucosidase inhibitor [tw] OR alpha-glucosidase inhibitors [tw] OR glucosidase inhibitors [tw]

\#2 Controlled trials (Robinson 2002)

(Randomized controlled trial [pt] OR controlled clinical trial [pt] OR randomized controlled trials [mh] OR random allocation [mh] OR double-blind method [mh] OR single-blind method [mh] OR clinical trial [pt] OR clinical trials [mh] OR (clinical trial [tw]) OR ((singl*[tw] OR doubl* [tw] OR trebl* [tw] OR tripl* [tw]) AND (mask* [tw] OR blind* [tw])) OR (latin square [tw]) OR placebos [mh] OR placebo* [tw] OR random* [tw] OR research design [mh:noexp] OR comparative study [mh] OR evaluation studies [mh] OR follow-up studies [mh] OR prospective studies [mh] OR cross-over studies [mh] OR control* [tw] OR prospectiv* [tw] OR volunteer* $[\mathrm{tw}])$ NOT (animal [mh] NOT human $[\mathrm{mh}])$

\#3 Impaired Glucose Tolerance or Impaired Fasting Blood Glucose

"Glucose Intolerance" [MeSH] OR "Diabetes Mellitus, Type II/prevention and control”[MeSH] OR "Glucose Tolerance Test”[MeSH] OR "Insulin Resistance/drug effects" [MeSH] OR "Metabolic Syndrome X” [MeSH] OR “impaired fasting glucose” [tw] OR "impaired fasting blood glucose" [tw] OR "impaired fasting bloodglucose" [tw] OR "impaired fasting glycaemia" [tw] OR "impaired fasting glycemia” [tw] OR impaired glucose toleran* [tw] OR impaired glucose stat* [tw] OR impaired glucose-respons* [tw] OR impaired glucose control* [tw] OR IGT [tw] OR glucose intoleran* [tw] OR impaired glucose regul* [tw] OR impaired glucose metab* [tw] OR impaired glucose homeost* [tw] OR reduced glucose metabolism* [tw] OR reduced glucose toleran* [tw] OR glucose intolerant* [tw] OR glucose tolerance test* [tw] OR prediabet* [tw] OR praediabet* [tw] OR "pre diabetes" [tw] OR "prae diabetes" [tw] OR "pre diabetic" [tw] OR "prae diabetic" [tw] OR "pre diabetics" [tw] OR "prae diabetics" [tw] OR metabolic syndr* [tw] OR "syndrome X” [tw] OR borderline diabet* [tw] OR mild diabet* [tw] OR insulin resistan* [tw] OR impaired insulin secret* [tw] OR reduced insulin secret* $[\mathrm{tw}]$

Whole search: \#1 AND \#2 AND \#3

These searches can be cut and pasted into PubMed (http://www.ncbi.nlm.nih.gov/entrez/query.fcgi)

Appendix 2. Outcomes: Acarbose (ACA) versus placebo (PLA)

\begin{tabular}{|c|c|c|c|c|c|c|}
\hline Outcome & $\begin{array}{l}\text { STOP-NIDDM } \\
\text { (ACA) }\end{array}$ & $\begin{array}{l}\text { STOP-NIDDM } \\
\text { (PLA) }\end{array}$ & DAISI (ACA) & DAISI (PLA) & EDIT (ACA) & EDIT (PLA) \\
\hline Mortality $(\mathrm{n} / \mathrm{N})$ & $\begin{array}{l}\text { Total death: 6/ } \\
714 \text {; cardiovas- } \\
\text { cular death: } 3 / \\
714\end{array}$ & $\begin{array}{l}\text { Total death: } 3 / \\
715 \text {; cardiovas- } \\
\text { cular death: } 2 / \\
715\end{array}$ & No Data & No Data & No Data & No Data \\
\hline $\begin{array}{l}\text { Incidence of } \\
\text { Type } 2 \text { Diabetes } \\
\text { Mellitus }(\mathrm{n} / \mathrm{N})\end{array}$ & $221 / 682$ & $285 / 686$ & No Data & No Data & $\begin{array}{l}\text { In those with IGT } \\
\text { at baseline, RR was } \\
\text { reduced with acar- } \\
\text { bose }(\mathrm{RR}=0 . \\
66, \mathrm{P}=0.046) \text { (at } 6 \\
\text { years) }\end{array}$ & No Data \\
\hline
\end{tabular}




\begin{tabular}{|c|c|c|c|c|c|c|}
\hline $\begin{array}{l}\text { Incidence of car- } \\
\text { diovascular mor- } \\
\text { bidity }(n / N)\end{array}$ & $\begin{array}{l}\text { All cardiovascu- } \\
\text { lar event: } \\
15 / 682, \text { myocar- } \\
\text { dial infarction } 1 / \\
682 \text {, angina } 5 / \\
682 \text {, revas- } \\
\text { cularization pro- } \\
\text { cedure } \\
11 / 682 \text {, cardio- } \\
\text { vascular death } 1 / \\
682 \text {, congestive } \\
\text { heart failure } 0 / \\
682, \text { cerebrovas- } \\
\text { cular event or } \\
\text { stroke } 2 / 682, \text { pe- } \\
\text { ripheral vascular } \\
\text { disease } 1 / 682\end{array}$ & $\begin{array}{l}\text { All cardiovascu- } \\
\text { lar event: } 32 / \\
686, \text { myocardial } \\
\text { infarction } \\
12 / 686 \text {, angina } \\
12 / 686 \text {, revascu- } \\
\text { larization proce- } \\
\text { dure } \\
20 / 686 \text {, cardio- } \\
\text { vascular death } 2 / \\
686 \text {, congestive } \\
\text { heart failure } 2 / \\
686, \text { cerebrovas- } \\
\text { cular event or } \\
\text { stroke } 4 / 686 \text {, pe- } \\
\text { ripheral vascular } \\
\text { disease } 1 / 686\end{array}$ & No Data & No Data & No Data & No Data \\
\hline $\begin{array}{l}\text { Glycated haemo- } \\
\text { globin (\%) }\end{array}$ & $\begin{array}{l}\text { Baseline }(\mathrm{n}=641) \\
5.24 \quad( \pm 0.74) \\
\text { Endpoint }(\mathrm{n}= \\
657) 5.38 \quad( \pm 0 . \\
78) \text {, Change }(\mathrm{n}= \\
616) 0.13( \pm 0 . \\
64)\end{array}$ & $\begin{array}{l}\text { Baseline }(\mathrm{n}=640) \\
5.24 \quad \pm \quad 0.78) \\
\text { Endpoint }(\mathrm{n}= \\
667) 5.43( \pm 0 . \\
84) \text {, Change }(\mathrm{n}= \\
622) 0.19( \pm 0 . \\
73)\end{array}$ & No Data & No Data & No Data & No Data \\
\hline $\begin{array}{l}\text { Fasting blood } \\
\text { glucose }(\mathrm{mmol} / \\
\mathrm{L})\end{array}$ & $\begin{array}{l}\text { Baseline }(\mathrm{n}=682) \\
6.23 \quad \pm \quad 0.50) \\
\text {, Endpoint }(\mathrm{n}= \\
676) 6.27( \pm 1 . \\
\text { 17), Change }(\mathrm{n}= \\
676) 0.05( \pm 1 . \\
14)\end{array}$ & $\begin{array}{l}\text { Baseline }(\mathrm{n}=686) \\
6.24 \quad \pm \quad 0.53) \\
\text {, Endpoint }(\mathrm{n}= \\
683) 6.36( \pm 1 . \\
\text { 24), Change }(\mathrm{n}= \\
683) 0.12( \pm 1 . \\
16)\end{array}$ & No Data & No Data & No Data & No Data \\
\hline $\begin{array}{l}\text { Post-load blood } \\
\text { glucose ( } \mathrm{mmol} / \\
\text { L) }\end{array}$ & $\begin{array}{l}\text { Baseline }(\mathrm{n}=682) \\
9.26 \quad \pm \quad \pm .06) \\
\text {, Endpoint }(\mathrm{n}= \\
656) 9.05( \pm 3 . \\
\text { 20), Change }(\mathrm{n}= \\
656)-0.21( \pm 3 . \\
12)\end{array}$ & $\begin{array}{l}\text { Baseline }(\mathrm{n}=686) \\
9.25 \quad \pm 1.01) \\
\text {, Endpoint }(\mathrm{n}= \\
668) 9.64( \pm 3 . \\
\text { 40), Change }(\mathrm{n}= \\
668) 0.40( \pm 3 . \\
28)\end{array}$ & No Data & No Data & $\begin{array}{l}\text { At } 3 \text { years, com- } \\
\text { pared to placebo: - } \\
0.4 \mathrm{mmol} / \mathrm{L}(\mathrm{P}=0 \text {. } \\
0075) \text { [note: half } \\
\text { of these pa- } \\
\text { tients also use met- } \\
\text { formin, due to the } \\
2 \times 2 \text { factorial de- } \\
\text { sign] }\end{array}$ & No Data \\
\hline $\begin{array}{l}\text { Plasma Lipids } \\
(\mathrm{mmol} / \mathrm{L})\end{array}$ & 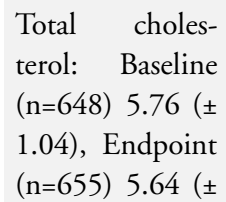 & $\begin{array}{l}\text { Total choles- } \\
\text { terol: } \\
(\mathrm{n}=647) 5.61 \quad( \pm \\
0.99), \text { Endpoint } \\
(\mathrm{n}=669) 5.49( \pm\end{array}$ & No Data & No Data & $\begin{array}{l}\text { At } \\
3 \text { years, compared } \\
\text { to placebo: triglyc- } \\
\text { erides }-0,14 \mathrm{mmol} / \\
\mathrm{L}(\mathrm{P}=0.036) \text { [note: }\end{array}$ & No Data \\
\hline
\end{tabular}




\begin{tabular}{|c|c|c|c|c|c|c|}
\hline & 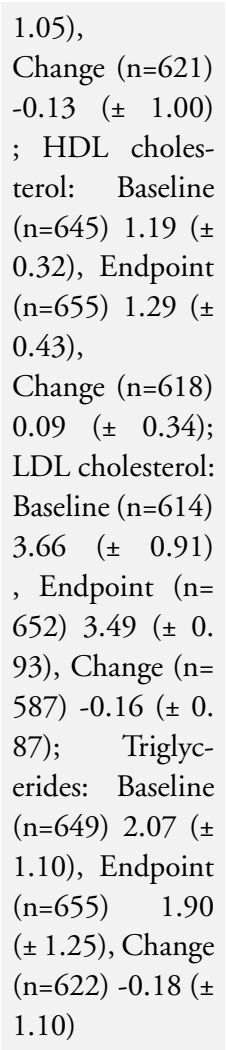 & 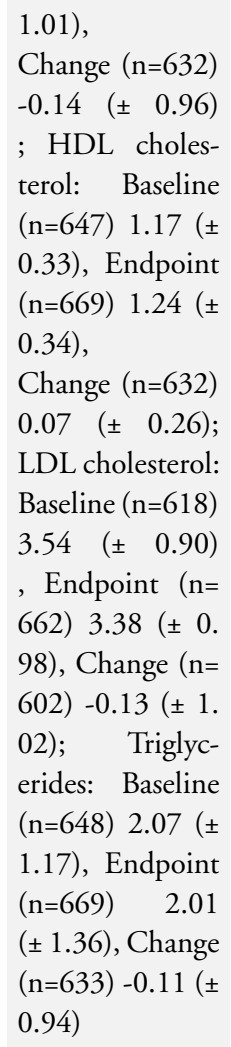 & & & $\begin{array}{l}\text { half of these pa- } \\
\text { tients also use met- } \\
\text { formin, due to the } \\
2 \times 2 \text { factorial de- } \\
\text { sign] Other lipids: } \\
\text { No data }\end{array}$ & \\
\hline $\begin{array}{l}\text { Blood pressure } \\
(\mathrm{mmHg})\end{array}$ & $\begin{array}{l}\text { Diastolic blood } \\
\text { pressure: } \\
\text { Baseline }(\mathrm{n}=681) \\
82.77 \quad( \pm 9.37) \\
\text {, Endpoint }(\mathrm{n}= \\
677) 81.47( \pm 8 . \\
75) \text {, Change }(\mathrm{n}= \\
677) \quad-1.31 \\
( \pm 9.18) \text {; Systolic } \\
\text { blood pressure: } \\
\text { Baseline ( } \mathrm{n}=681) \\
131.43( \pm 16.33) \\
, \text { Endpoint ( }= \\
677) 131.52( \pm \\
15.42) \text { Change } \\
(\mathrm{n}=677) 0.03( \pm \\
15.09)\end{array}$ & $\begin{array}{l}\text { Diastolic blood } \\
\text { pressure: } \\
\text { Baseline }(\mathrm{n}=686) \\
82.02( \pm 9.29) \\
\text {, Endpoint }(\mathrm{n}= \\
682) 81.08( \pm 9 . \\
04) \text {, Change }(\mathrm{n}= \\
682) \quad-0.99 \\
( \pm 9.22) \text {; Systolic } \\
\text { blood pressure: } \\
\text { Baseline }(\mathrm{n}=686) \\
\text { 130.85 }( \pm 16.21) \\
, \text { Endpoint }(\mathrm{n}= \\
682) 131.28 \quad( \pm \\
15.86), \text { Change } \\
(\mathrm{n}=682) 0.44( \pm \\
15.60)\end{array}$ & No Data & No Data & No Data & No Data \\
\hline $\begin{array}{l}\text { Fasting and } \\
\text { post-load insulin } \\
(\mathrm{pmol} / \mathrm{L}) \text { and c- } \\
\text { peptide (nmol/ } \\
\mathrm{L})\end{array}$ & $\begin{array}{l}\text { Fasting insulin: } \\
\text { Baseline }(\mathrm{n}=664) \\
99.93 \quad \pm 58.51) \\
\text {, Endpoint (n= }\end{array}$ & $\begin{array}{l}\text { Fasting insulin: } \\
\text { Baseline }(\mathrm{n}=664) \\
97.35 \quad \pm 52.39) \\
\text {, Endpoint }(\mathrm{n}=\end{array}$ & No Data & No Data & No Data & No Data \\
\hline
\end{tabular}




\begin{tabular}{|c|c|c|c|c|c|c|}
\hline & $\begin{array}{l}646) \\
95.64( \pm 62.35), \\
\text { Change }(\mathrm{n}=629) \\
-2.91 \quad \pm 58.05) ; \\
\text { Post-load } \\
\text { insulin: Baseline } \\
(\mathrm{n}=658) 606.37 \\
( \pm 437.46), \text { End- } \\
\text { point ( } \mathrm{n}=642) \\
548.95 \quad( \pm 451 . \\
19), \text { Change }(\mathrm{n}= \\
620)-52.13 \quad( \pm \\
391.43)\end{array}$ & $\begin{array}{l}664) \quad 97 . \\
23( \pm 100.89), \\
\text { Change }(\mathrm{n}=643) \\
0.65( \pm 103.38) ; \\
\text { Post-load } \\
\text { insulin: Baseline } \\
(\mathrm{n}=657) 597.99 \\
( \pm 414.38), \text { End- } \\
\text { point (n=661) } \\
535.12 \quad( \pm 436 . \\
74), \text { Change }(\mathrm{n}= \\
634)-64.53 \quad( \pm \\
403.93)\end{array}$ & & & & \\
\hline $\begin{array}{l}\text { Body } \\
\text { weight (Kg) / } \\
\text { Body Mass Index } \\
(\mathrm{Kg} / \mathrm{m} 2)\end{array}$ & 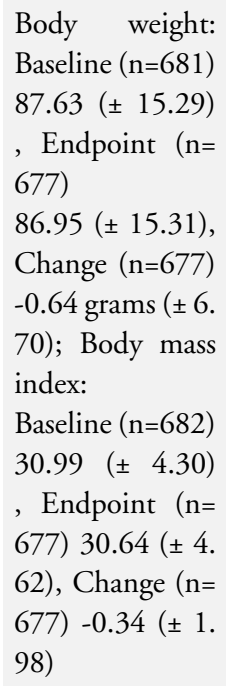 & $\begin{array}{l}\text { Body weight: } \\
\text { Baseline }(\mathrm{n}=686) \\
87.01 \quad( \pm 14.14) \\
\text {, Endpoint }(\mathrm{n}= \\
682) \\
87.57( \pm 15.23) \text {, } \\
\text { Change }(\mathrm{n}=682) \\
0.54 \text { grams }( \pm 5 . \\
22) \text {; Body mass } \\
\text { index: } \\
\text { Baseline }(\mathrm{n}=685) \\
30.87( \pm 4.17) \\
\text { Endpoint }(\mathrm{n}= \\
681) 30.82( \pm 4 . \\
70) \text {, Change }(\mathrm{n}= \\
681)-0.03( \pm 1 . \\
94)\end{array}$ & No Data & No Data & No Data & No Data \\
\hline $\begin{array}{l}\text { Adverse events } \\
(\mathrm{AE})(\mathrm{n} / \mathrm{N})\end{array}$ & $\begin{array}{l}\text { All AEs: 698/ } \\
\text { 714; Gastro-in- } \\
\text { testinal AEs: } \\
\text { 597/714 }\end{array}$ & $\begin{array}{l}\text { All AEs: 675/ } \\
\text { 715; Gastro-in- } \\
\text { testinal AEs: } \\
426 / 715\end{array}$ & No Data & No Data & No Data & No Data \\
\hline $\begin{array}{l}\text { Costs / Compli- } \\
\text { ance }\end{array}$ & No Data & No Data & No Data & No Data & No Data & No Data \\
\hline
\end{tabular}


Appendix 3. Adjustment for high discontinuation rate in acarbose arm of STOP-NIDDM study

\begin{tabular}{llll}
\hline Outcome & Without correction & With correction \\
\hline Incidence of type 2 diabetes & Effect size (OR) $0.67(0.54$ to 0.84$)$ & Effect size (OR) $0.78(0.63$ to 0.97) \\
\hline Incidence of any cardiovascular disease & Effect size (OR) $0.46(0.25$ to 0.86$)$ & Effect size (OR) $0.52(0.29$ to 0.95) \\
\hline Incidence of myocardial infarctions & Effect size (OR) $0.08(0.01$ to 0.64$)$ & Effect size (OR) $0.08(0.01$ to 0.64) \\
\hline Incidence of angina pectoris & Effect size (OR) $0.41(0.15$ to 1.18$)$ & Effect size (OR) $0.50(0.19$ to 1.34$)$ \\
\hline Incidence of revascularization procedures & Effect size (OR) $0.55(0.26$ to 1.15$)$ & Effect size (OR) $0.60(0.29$ to 1.23$)$ \\
\hline Incidence of congestive heart failure & Effect size (OR) $0.20(0.01$ to 4.19$)$ & Effect size (OR) $0.20(0.01$ to 4.19) \\
\hline Incidence of cerebrovascular events & Effect size (OR) $0.50(0.09$ to 2.75$)$ & Effect size (OR) $0.50(0.09$ to 2.75) \\
\hline Incidence of peripheral vascular events & Effect size (OR) $1.01(0.06$ to 16.11$)$ & Effect size (OR) $1.01(0.06$ to 16.11)
\end{tabular}

Appendix 4. Outcomes: Acarbose (ACA) versus metformin (MET)

\begin{tabular}{|c|c|c|c|c|}
\hline Outcome & EDIT (ACA) & EDIT (MET) & Fang 2004 (ACA) & Fang 2004 (MET) \\
\hline Mortality $(\mathrm{n} / \mathrm{N})$ & No Data & No Data & No Data & No Data \\
\hline $\begin{array}{l}\text { Incidence of Type } 2 \text { Di- } \\
\text { abetes Mellitus }(n / N)\end{array}$ & No Data & No Data & $6 / 45$ & $9 / 44$ \\
\hline $\begin{array}{l}\text { Incidence of cardiovas- } \\
\text { cular morbidity }(n / N)\end{array}$ & No Data & No Data & No Data & No Data \\
\hline $\begin{array}{l}\text { Glycated haemoglobin } \\
(\%)\end{array}$ & No Data & No Data & No Data & No Data \\
\hline $\begin{array}{l}\text { Fasting blood glucose } \\
(\mathrm{mmol} / \mathrm{L})\end{array}$ & No Data & No Data & $\begin{array}{l}\text { Baseline }(n=50) 6.45( \pm 1.9), \text { End- } \\
\text { point }(n=45) 5.7( \pm 0.7) \text {, Change } \\
(n=45)-0.75( \pm 1.7)\end{array}$ & $\begin{array}{l}\text { Baseline }(n=48) 6.26( \pm 2.1) \text {, End- } \\
\text { point }(n=44) 5.9( \pm 0.7) \text {, Change } \\
(n=44)-0.36( \pm 1.9)\end{array}$ \\
\hline $\begin{array}{l}\text { Post-load blood glucose } \\
(\mathrm{mmol} / \mathrm{L})\end{array}$ & No Data & No Data & $\begin{array}{l}\text { Baseline }(n=50) 8.38( \pm 1.9), \text { End- } \\
\text { point }(n=45) 7.0( \pm 1.8), \text { Change } \\
(n=45)-1.38( \pm 2.0\end{array}$ & $\begin{array}{l}\text { Baseline }(n=48) 7.48( \pm 1.9) \text {, End- } \\
\text { point }(n=44) 7.5( \pm 1.9) \text {, Change } \\
(n=44) 0.02( \pm 2.1)\end{array}$ \\
\hline Plasma Lipids (mmol/L) & No Data & No Data & $\begin{array}{l}\text { Total cholesterol: Baseline }(n=50) \\
6.3( \pm 1.8) \text {, Endpoint }(n=45) 5.6 \\
( \pm 1.7) \text {, Change }(n=45)-0.7( \pm 1.9)\end{array}$ & $\begin{array}{l}\text { Total cholesterol: Baseline }(n=48) \\
6.5( \pm 1.5) \text {, Endpoint }(n=44) 4.9 \\
( \pm 1.2) \text {, Change }(n=44)-1.6( \pm 1.5)\end{array}$ \\
\hline
\end{tabular}




\begin{tabular}{|c|c|c|c|c|}
\hline & & & $\begin{array}{l}\text {; Triglycerides: Baseline }(n=50) 1.9 \\
( \pm 1.4) \text {, Endpoint }(n=45) 1.6( \pm 1 \\
\text { 4), Change }(n=45)-0.3( \pm 1.5)\end{array}$ & $\begin{array}{l}\text {; Triglycerides: Baseline }(n=48) 2.5 \\
( \pm 2.2) \text {, Endpoint }(n=44) 1.5( \pm 0 \text {. } \\
\text { 5), Change }(n=44)-1.0( \pm 2.1)\end{array}$ \\
\hline Blood pressure $(\mathrm{mmHg})$ & No Data & No Data & $\begin{array}{l}\text { Diastolic blood pressure: Baseline } \\
(\mathrm{n}=50) 82( \pm 7), \text { Endpoint }(\mathrm{n}=45) \\
83( \pm 7) \text {, Change }(\mathrm{n}=45) 1( \pm 7.67) \\
\text {; Systolic blood pressure: Baseline } \\
(\mathrm{n}=50) 130( \pm 14) \text {, Endpoint }(\mathrm{n}= \\
\text { 45) } 124( \pm 13), \text { Change }(\mathrm{n}=45)-6 \\
( \pm 14.81)\end{array}$ & $\begin{array}{l}\text { Diastolic blood pressure: Baseline } \\
(\mathrm{n}=48) 85( \pm 7), \text { Endpoint }(\mathrm{n}=44) \\
80( \pm 7) \text {, Change }(\mathrm{n}=44)-5( \pm 7.67) \\
\text {; Systolic blood pressure: Baseline } \\
(\mathrm{n}=48) 132( \pm 14), \text { Endpoint }(\mathrm{n}= \\
44) 125( \pm 13), \text { Change }(\mathrm{n}=44)-7 \\
( \pm 14.81)\end{array}$ \\
\hline $\begin{array}{l}\text { Fasting and post-load in- } \\
\text { sulin }(\mathrm{pmol} / \mathrm{L}) \text { and c- } \\
\text { peptide }(\mathrm{nmol} / \mathrm{L})\end{array}$ & No Data & No Data & No Data & No Data \\
\hline $\begin{array}{l}\text { Body weight }(\mathrm{Kg}) / \text { Body } \\
\text { Mass Index }(\mathrm{Kg} / \mathrm{m} 2)\end{array}$ & No Data & No Data & $\begin{array}{l}\text { Body mass index: Baseline }(n=50) \\
24.9( \pm 2.1) \text {, Endpoint }(n=45) 24 \text {. } \\
2( \pm 2.0) \text {, Change }(n=45)-0.7( \pm 2 \text {. } \\
25)\end{array}$ & $\begin{array}{l}\text { Body mass index: Baseline }(n=48) \\
25.2( \pm 2.8) \text {, Endpoint }(n=44) 24 \text {. } \\
9( \pm 2.7) \text {, Change }(n=44)-0.3( \pm 3 . \\
01)\end{array}$ \\
\hline $\begin{array}{l}\text { Adverse events (AE) (n/ } \\
N)\end{array}$ & No Data & No Data & No Data & No Data \\
\hline Costs / Compliance & No Data & No Data & No Data & No Data \\
\hline
\end{tabular}

\section{Appendix 5. Outcomes: Acarbose (ACA) versus diet and exercise (DIE)}

\begin{tabular}{|c|c|c|}
\hline Outcome & Fang 2004 (ACA) & Fang 2004 (DIE) \\
\hline Mortality $(\mathrm{n} / \mathrm{N})$ & No Data & No Data \\
\hline $\begin{array}{l}\text { Incidence of Type } 2 \text { Diabetes Mellitus (n/ } \\
\text { N) }\end{array}$ & $6 / 45$ & $12 / 36$ \\
\hline $\begin{array}{l}\text { Incidence of cardiovascular morbidity ( } \mathrm{n} / \\
\mathrm{N} \text { ) }\end{array}$ & No Data & No Data \\
\hline Glycated haemoglobin (\%) & No Data & No Data \\
\hline Fasting blood glucose (mmol/L) & $\begin{array}{l}\text { Baseline }(\mathrm{n}=50) 6.45( \pm 1.9) \text {, Endpoint }(\mathrm{n}= \\
\text { 45) } 5.7( \pm 0.7) \text {, Change }(\mathrm{n}=45)-0.75( \pm 1 \text {. } \\
\text { 7) }\end{array}$ & $\begin{array}{l}\text { Baseline }(n=40) 5.58( \pm 2.4) \text {, Endpoint }(n= \\
\text { 36) } 6.2( \pm 0.6) \text {, Change }(n=36) 0.62( \pm 2 . \\
\text { 2) }\end{array}$ \\
\hline
\end{tabular}


(Continued)

\begin{tabular}{|c|c|c|}
\hline Post-load blood glucose (mmol/L) & $\begin{array}{l}\text { Baseline }(\mathrm{n}=50) 8.38( \pm 1.9) \text {, Endpoint }(\mathrm{n}= \\
\text { 45) } 7.0( \pm 1.8) \text {, Change }(\mathrm{n}=45)-1.38( \pm 2 \text {. } \\
0\end{array}$ & $\begin{array}{l}\text { Baseline }(\mathrm{n}=40) 6.99( \pm 2.1) \text {, Endpoint }(\mathrm{n}= \\
\text { 36) } 8.4( \pm 2.4) \text {, Change }(\mathrm{n}=36) 1.41( \pm 2 . \\
\text { 5) }\end{array}$ \\
\hline Plasma Lipids (mmol/L) & $\begin{array}{l}\text { Total cholesterol: Baseline }(\mathrm{n}=50) 6.3( \pm 1 \text {. } \\
\text { 8), Endpoint }(\mathrm{n}=45) 5.6( \pm 1.7) \text {, Change } \\
(\mathrm{n}=45)-0.7( \pm 1.9) \text {; Triglycerides: Baseline } \\
(\mathrm{n}=50) 1.9( \pm 1.4) \text {, Endpoint }(\mathrm{n}=45) 1.6( \pm \\
1.4) \text {, Change }(\mathrm{n}=45)-0.3( \pm 1.5)\end{array}$ & $\begin{array}{l}\text { Total cholesterol: Baseline }(\mathrm{n}=40) 6.0( \pm 1 . \\
6), \text { Endpoint }(\mathrm{n}=36) 5.8( \pm 1.8) \text {, Change } \\
(\mathrm{n}=36)-0.2( \pm 1.9) \text {; Triglycerides: Baseline } \\
(\mathrm{n}=40) 1.9( \pm 1.3) \text {, Endpoint }(\mathrm{n}=36) 1.7( \pm \\
1.5) \text {, Change }(\mathrm{n}=36)-0.2( \pm 1.5)\end{array}$ \\
\hline Blood pressure $(\mathrm{mmHg})$ & $\begin{array}{l}\text { Diastolic blood pressure: Baseline }(\mathrm{n}=50) \\
82( \pm 7) \text {, Endpoint }(\mathrm{n}=45) 83( \pm 7) \text {, Change } \\
(\mathrm{n}=45) 1( \pm 7.67) \text {; Systolic blood pressure: } \\
\text { Baseline }(\mathrm{n}=50) 130( \pm 14) \text {, Endpoint }(\mathrm{n}= \\
\text { 45) } 124( \pm 13) \text {, Change }(\mathrm{n}=45)-6( \pm 14 . \\
81)\end{array}$ & $\begin{array}{l}\text { Diastolic blood pressure: Baseline }(n=40) \\
86( \pm 6) \text {, Endpoint }(n=36) 84( \pm 6) \text {, Change } \\
(n=36)-2( \pm 6.57) \text {; Systolic blood pressure: } \\
\text { Baseline }(n=40) 126( \pm 13) \text {, Endpoint }(n= \\
\text { 36) } 126( \pm 12) \text {, Change }(n=36) 0( \pm 13.72)\end{array}$ \\
\hline $\begin{array}{l}\text { Fasting and post-load insulin }(\mathrm{pmol} / \mathrm{L}) \text { and } \\
\text { c-peptide }(\mathrm{nmol} / \mathrm{L})\end{array}$ & No Data & No Data \\
\hline $\begin{array}{l}\text { Body weight }(\mathrm{Kg}) / \text { Body Mass Index }(\mathrm{Kg} / \\
\mathrm{m} 2)\end{array}$ & $\begin{array}{l}\text { Body mass index: Baseline }(n=50) 24.9 \\
( \pm 2.1) \text {, Endpoint }(n=45) 24.2 \quad( \pm 2.0) \\
\text { Change }(n=45)-0.7( \pm 2.25)\end{array}$ & $\begin{array}{l}\text { Body mass index: Baseline }(\mathrm{n}=40) 25.3 \\
( \pm 1.9) \text {, Endpoint }(\mathrm{n}=36) 24.8( \pm 1.8), \\
\text { Change }(\mathrm{n}=36)-0.5( \pm 2.03)\end{array}$ \\
\hline Adverse events (AE) $(\mathrm{n} / \mathrm{N})$ & No Data & No Data \\
\hline Costs / Compliance & No Data & No Data \\
\hline
\end{tabular}

Appendix 6. Outcomes: Acarbose (ACA) versus no treatment (NO)

\begin{tabular}{|c|c|c|c|c|}
\hline Outcome & Fang 2004 (ACA) & Fang 2004 (NO) & Wang 2000 (ACA) & Wang 2000 (NO) \\
\hline Mortality (n/N) & No Data & No Data & No Data & No Data \\
\hline $\begin{array}{l}\text { Incidence of Type } 2 \text { Di- } \\
\text { abetes Mellitus }(n / N)\end{array}$ & $6 / 45$ & $15 / 35$ & $\begin{array}{l}\text { Type } 2 \text { diabetes: } 1 / 30 \text {, } \\
\text { persisting IGT: } 20 / 30 \text {, } \\
\text { normal glucose toler- } \\
\text { ance: } 9 / 30\end{array}$ & $\begin{array}{l}\text { Type } 2 \text { diabetes: } 3 / 30 \text {, } \\
\text { persisting IGT: } 25 / 30 \text {, } \\
\text { normal glucose toler- } \\
\text { ance: } 2 / 30\end{array}$ \\
\hline $\begin{array}{l}\text { Incidence of cardiovas- } \\
\text { cular morbidity }(\mathrm{n} / \mathrm{N})\end{array}$ & No Data & No Data & No Data & No Data \\
\hline $\begin{array}{l}\text { Glycated haemoglobin } \\
(\%)\end{array}$ & No Data & No Data & No Data & No Data \\
\hline
\end{tabular}


(Continued)

\begin{tabular}{|c|c|c|c|c|}
\hline $\begin{array}{l}\text { Fasting blood glucose } \\
(\mathrm{mmol} / \mathrm{L})\end{array}$ & $\begin{array}{l}\text { Baseline }(\mathrm{n}=50) 6.45( \pm \\
1.9), \text { Endpoint }(\mathrm{n}=45) 5 . \\
7( \pm 0.7), \text { Change }(\mathrm{n}=45) \\
-0.75( \pm 1.7)\end{array}$ & $\begin{array}{l}\text { Baseline }(\mathrm{n}=40) 5.66( \pm \\
2.3), \text { Endpoint }(\mathrm{n}=35) 6 . \\
3( \pm 1.2) \text {, Change }(\mathrm{n}=35) \\
0.64( \pm 2.1)\end{array}$ & No Data & No Data \\
\hline $\begin{array}{l}\text { Post-load blood glucose } \\
(\mathrm{mmol} / \mathrm{L})\end{array}$ & $\begin{array}{l}\text { Baseline }(\mathrm{n}=50) 8.38( \pm \\
1.9) \text {, Endpoint }(\mathrm{n}=45) 7 . \\
0( \pm 1.8), \text { Change }(\mathrm{n}=45) \\
-1.38( \pm 2.0\end{array}$ & $\begin{array}{l}\text { Baseline }(\mathrm{n}=40) 6.35( \pm \\
\text { 2.2), Endpoint } 9.5( \pm 2 . \\
\text { 2), Change }(\mathrm{n}=35) 3.15 \\
( \pm 2.4)\end{array}$ & No Data & No Data \\
\hline Plasma Lipids (mmol/L) & $\begin{array}{l}\text { Total cholesterol: Base- } \\
\text { line }(\mathrm{n}=50) 6.3( \pm 1.8) \text {, } \\
\text { Endpoint }(\mathrm{n}=45) 5.6( \pm \\
1.7) \text {, Change }(\mathrm{n}=45)-0 . \\
7( \pm 1.9) \text {; Triglycerides: } \\
\text { Baseline }(\mathrm{n}=50) 1.9( \pm 1 \text {. } \\
4) \text {, Endpoint }(\mathrm{n}=45) 1.6 \\
( \pm 1.4) \text {, Change }(\mathrm{n}=45)- \\
0.3( \pm 1.5)\end{array}$ & $\begin{array}{l}\text { Total cholesterol: Base- } \\
\text { line }(\mathrm{n}=40) 5.7( \pm 1.7) \text {, } \\
\text { Endpoint }(\mathrm{n}=35) 6.0( \pm \\
\text { 1.6), Change }(\mathrm{n}=35) 0 . \\
3( \pm 1.8) ; \text { Triglycerides: } \\
\text { Baseline }(\mathrm{n}=40) 1.9( \pm 1 . \\
\text { 3), Endpoint }(\mathrm{n}=35) 1.9 \\
( \pm 1.3), \text { Change }(\mathrm{n}=35) \\
0.0( \pm 2.1)\end{array}$ & No Data & No Data \\
\hline Blood pressure $(\mathrm{mmHg})$ & $\begin{array}{l}\text { Diastolic blood pressure: } \\
\text { Baseline }(\mathrm{n}=50) \quad 82 \quad( \pm \\
7) \text {, Endpoint }(\mathrm{n}=45) 83 \\
( \pm 7) \text {, Change }(\mathrm{n}=45) 1 \\
( \pm 7.67) \text {; Systolic blood } \\
\text { pressure: Baseline ( } \mathrm{n}= \\
\text { 50) 130 ( } \pm 14) \text {, End- } \\
\text { point }(\mathrm{n}=45) 124( \pm 13) \text {, } \\
\text { Change }(\mathrm{n}=45)-6( \pm 14 . \\
81)\end{array}$ & $\begin{array}{l}\text { Diastolic blood pressure: } \\
\text { Baseline }(\mathrm{n}=40) \quad 84 \quad( \pm \\
6) \text {, Endpoint }(\mathrm{n}=35) 82 \\
( \pm 6) \text {, Change }(\mathrm{n}=35)-2 \\
( \pm 6.57) \text {; Systolic blood } \\
\text { pressure: Baseline ( } \mathrm{n}= \\
40) 128 \quad( \pm 13), \text { End- } \\
\text { point }(\mathrm{n}=35) 128( \pm 12) \text {, } \\
\text { Change }(\mathrm{n}=35) 0( \pm 13 . \\
72)\end{array}$ & No Data & No Data \\
\hline $\begin{array}{l}\text { Fasting and post-load in- } \\
\text { sulin }(\mathrm{pmol} / \mathrm{L}) \text { and } \mathrm{c}- \\
\text { peptide }(\mathrm{nmol} / \mathrm{L})\end{array}$ & No Data & No Data & No Data & No Data \\
\hline $\begin{array}{l}\text { Body weight }(\mathrm{Kg}) / \text { Body } \\
\text { Mass Index }(\mathrm{Kg} / \mathrm{m} 2)\end{array}$ & $\begin{array}{l}\text { Body mass index: Base- } \\
\text { line }(n=50) 24.9( \pm 2.1) \\
\text {, Endpoint }(n=45) 24.2 \\
( \pm 2.0) \text {, Change }(n=45)- \\
0.7( \pm 2.25)\end{array}$ & $\begin{array}{l}\text { Body mass index: Base- } \\
\text { line }(\mathrm{n}=40) 24.8( \pm 2.5) \text {, } \\
\text { Endpoint }(\mathrm{n}=35) 25.2( \pm \\
2.4) \text {, Change }(\mathrm{n}=35) 0.4 \\
( \pm 2.69)\end{array}$ & No Data & No Data \\
\hline $\begin{array}{l}\text { Adverse events (AE) (n/ } \\
N)\end{array}$ & No Data & No Data & $2 / 30$ & $0 / 30$ \\
\hline Costs / Compliance & No Data & No Data & No Data & No Data \\
\hline
\end{tabular}


WHAT'S NEW

Last assessed as up-to-date: 27 February 2006.

\begin{tabular}{l|l|l}
\hline Date & Event & Description \\
\hline 30 October 2008 & Amended & Converted to new review format. \\
\hline
\end{tabular}

\section{H I S T O R Y}

Protocol first published: Issue 4, 2004

Review first published: Issue 4, 2006

\section{CONTRIBUTIONS OFAUTHORS}

FLORIS VAN DE LAAR: Protocol development, searching for trials, abstract assessment for eligibility, quality assessment of trials, data extraction, data entry, data analysis, review development.

PETER LUCASSEN: Protocol development, abstract assessment for eligibility, quality assessment of trials, data extraction, data analysis, review development.

WIM DE GRAUW: Protocol development, data analysis, review development.

REINIER AKKERMANS: (double) data entry, data analysis, review development.

ELOY VAN DE LISDONK: Quality assessment of trials (referee), data analysis, review development.

\section{DECLARATIONS OF INTEREST}

None known.

\section{SOURCES OF SUPPORT}

\section{Internal sources}

- Radboud University Nijmegen Medical Centre, Netherlands. 


\section{External sources}

- No sources of support supplied

\section{INDEX TERMS}

\section{Medical Subject Headings (MeSH)}

Acarbose [therapeutic use]; Blood Glucose [*drug effects]; Diabetes Mellitus, Type 2 [prevention \& control]; Enzyme Inhibitors [ ${ }^{*}$ therapeutic use]; Fasting [ ${ }^{*}$ blood]; Glucose Intolerance [* drug therapy]; Metformin [therapeutic use]; Prediabetic State [drug therapy]; Randomized Controlled Trials as Topic; alpha-Glucosidases [*antagonists \& inhibitors]

\section{MeSH check words}

Humans 